Linköping Studies in Science and Technology

Dissertations No. 2131

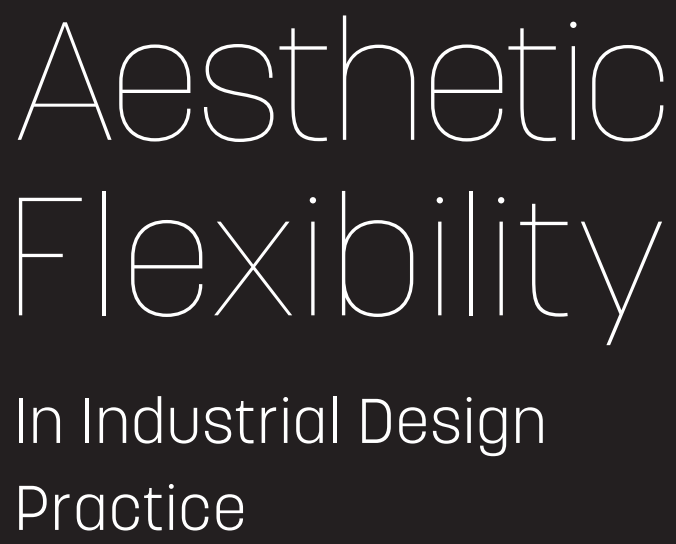

o, 



\section{Aesthetic Flexibility \\ In Industrial Design Practice}

\section{Torbjörn Andersson}

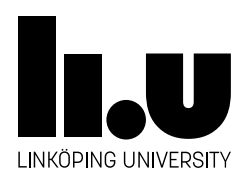

Division of Product Realisation

Department of Management and Engineering Linköping University, SE-581 83 Linköping, Sweden

Linköping 2021 
$(\mathrm{cc})$ EY-NG This work is licensed under a Creative Commons AttributionNonCommercial 4.0 International License.

https://creativecommons.org/licenses/by-nc/4.0/

Copyright (C) Torbjörn Andersson, 2021

Aesthetic Flexibility - In Industrial Design Practice

ISBN 978-91-7929-681-0

ISSN 0345-7524

Distributed by:

Division of Product Realisation

Department of Management and Engineering

Linköping University

SE-581 83 Linköping, Sweden

Printed in Sweden by LiU-Tryck, Linköping 2021 
North by Northwegt. Alfred Hitchcock, 1959

SCENE: In the dining car of the Twentieth Century Iimited en route to Chlcago. The 9py, Eve Kendall has tipped the steward I1ve dollars to seat advertising executive Mr. Thornhill at her dining table.

Roger Thornhtll (Cary Grant):

Tell me, what do you do besldes lure men into thelr doom on the Iwentieth Century Iimited?

Eve Kendall (Eva Marle Saint):

I'm an indugtrial deglgner... 



\section{ABSTRACT}

Competition among companies that produce complex or large product portfolios has created a need to use modularity strategies not only to flexibly manage technical complexity in a cost-effective manner but also to produce visually appealing products. This research aims to understand how the visual appearance of products is affected by modular product development strategies and creates coherent product brands. Thus, this study examines the intersection of strategic design (e.g., industrial design), product portfolio management, product brand management, and decision making in design. Specifically, this study aims to understand how such strategies constrain and generate possibilities when the industrial design process concerns itself with visual appearance.

The main research approach has been qualitative multi-case methodology (Miles et al, 2014; Eisenhardt, 1989) and design theory building (Chakrabarti and Blessing, 2016) that collects data through interviews, experimentation, and theoretical studies based on findings in the literature. Sixteen face-to-face interviews were conducted with design vice presidents, senior designers, and senior design engineers at five Swedish manufacturers from the automotive, medtech, consumer goods, commercial vehicles, and materials handling industries.

This approach has resulted in the description of three theoretical models and a design method, product gist, for investigating prototypicality in a product category. Aesthetic flexibility reflects the requirement that under certain circumstances an industrial designer has to plan for future (as yet unknown) changes in a design.

Each of the three theoretical models has a different focus: one model describes three ways manufacturing companies organise a strategic in-house design function; one model describes how design decisions are made on a general level through an intuitive and knowledge-based judgment process; 
and one model describes the strategies a manager needs to consider when developing an existing product portfolio and how the strategies influence industrial design practice.

Understanding visual flexibility serves as a starting point for further investigations of how development strategies affect visual product design. This understanding provides industrial designers insight into how they can develop product systems that share design components across product lines to promote brand identity. The findings of this work illustrate and explain a complex and multi-facetted design phenomenon that many designers manage more or less intuitively today; therefore, this study advances the understanding of the field for academics, teachers, and professional designers.

Keywords: industrial design, product development, product modularity, product branding, and dual decision-making. 


\section{POPULÄRVETENSKAPLIG SAMMANFATTNING}

Konkurrensen mellan företag som producerar komplexa produkter och har stora produktportföljer ökar ständigt, detta har skapat ett behov av att använda modulära designprinciper när deras produktutvecklare tar fram nya produkter. Några av de främsta skälen för att använda modulära design strategier är för att företagen skall kunna uppnå kostnadseffektiva och tidsbesparande effekter vilket gör dom mer konkurrenskraftiga. För att uppnå maximal effekt av denna strategi väljer många företag att skapa denna modulära flexibilitet i både de tekniska och estetiska designlösningarna.

Målet med denna forskning är att bättre förstå hur estetiska designstrategier, som är ämnade att skapa visuellt sammanhållna produktvarumärken, påverkas av de tekniska modulstrategierna. Med fokus på att förstå hur modulära strategier skapar motstånd men även möjligheter för utvecklingen av estetisk design.

Denna avhandling rör sig främst mellan fyra forskningsfält, strategisk design (eller industridesign), modulär produktutveckling, organisation och styrning av produktportföljer samt beslutsfattande inom industridesign. Forskningen har byggt på både empirisk och teoretisk grund. Empirisk data har samlats in genom multipla fallstudier genomförda som intervjustudier och videoinspelningar gjorda under en designworkshop. Den empiriska dataanalysen har gjorts med främst kvalitativa metoder som beskrivna av Miles et al. (2014) och Eisenhardt (1989). Sammanlagt genomfördes 16 intervjuer med designchefer, seniora designers och seniora designingenjörer. Intervjuerna genomfördes på fem svenska produktproducerandeföretag där varje företag hade en egen designorganisation inhouse och som verkade inom en egen marknad, dessa var: Automotive, MedTech, Consumer goods, Commercial Vehicles and Material handling.

Forskningen har resulterat $\mathrm{i}$ en beskrivning av ett strategiskt produktutvecklingsfenomen inom industridesign, en ny analysmetod vid namn Product Gist och tre nya teoretiska modeller. Fenomenet döptes till 
Aesthetic Flexibility och beskriver de omständigheter som skapar behov hos industridesigners att planera in möjligheter för framtida designförändringar under pågående designutvecklingsarbete. Product Gist är en analysmetod där användaren kan objektivt undersöka vad som utgör visuell prototypikalitet i en bestämd produktkategori. De tre teoretiska modellerna beskriver: (1) tre olika sätt som produktproducerande företag kan organisera en designfunktion, (2) vad som påverkar beslutsfattande inom industridesign och slutligen (3) en modell som beskriver vilka designstrategier en produktplanerare kan använda sig av när en existerande produktportfölj expanderas eller omdanas samt hur det påverkar formgivningen av ett företags produkter.

Att förstå och applicera estetisk flexibilitet utgör en grundpelare för industridesigners och designingenjörer som vill utveckla produkter och produktportföljer med större möjlighet att minska det totala antalet designkomponenter men ändå bibehålla visuella identiteter i olika produkter.

Resultaten av denna forskning belyser och förklarar hur industridesigners mer eller mindre intuitiva designprocesser har påverkats och adapterats för att kunna hantera de mer komplexa och mångfasetterade designproblem som uppstår i företag med stora produktportföljer. Insikterna och resultaten från dessa studier bygger på existerande akademisk kunskap samt hjälper lärare och professionella designers att bättre förstå mer avancerade aspekter av industridesign. 


\section{ACKNOWLEDGEMENT}

The journey of pursuing a doctorate is a transformative experience that for the most time is a long and lonesome expedition; luckily, many people have supported me along the way who I would like to express my gratitude to for making this thesis possible.

During this doctoral process, I have had two main supervisors as I followed the Swedish doctoral tradition of pursuing a licentiate thesis before finishing the doctoral thesis. Professor Johan Ölvander was my main supervisor until the end of my licentiate, succeeded by design Professor Renee Wever, who I chose to be my main supervisor for the remaining time of my doctoral activity. They have both have been of great support and given me invaluable advice and guidance, including providing advice on my drafts and articles, during this endeavour.

My co-supervisor Professor Anders Warell has been a great discussion partner regarding product form, Rune Monö's models and design research, proofreading drafts, and advice on how to structure the licentiate thesis. My co-supervisor Stefan Holmlid has provided advice regarding design research and on my first papers.

I am also very grateful to all of participants in my studies and workshop for lending their time and knowledge of the industrial design practice. Without your thoughts and insights this thesis would not have turned out as well as it did. Special thanks goes to Magnus Andersson Olivera, Head of Design at Toyota Material Handling, who influenced a lot of my initial thoughts on industrial design practice in a large company. The thesis would also look very meagre and findings would be difficult to explain without the product photographs kindly lent to me by these companies: Makita, Husqvarna, AtlasCopco, Sony, Volvo Cars, and Scania. 
I would like to thank all my old and new colleagues at the division of Product Realization (former Machine Design) and the department of Management and Engineering for supporting me while researching and writing this thesis but most of all for creating a fun and inspiring working environment. A special thanks goes to the O.G. design crew, David Beuger, David Eklöf, Mats Nåbo, and Vanja Pavlasevic, who have been with me since I started my position as a teacher and doctoral candidate at the division and it's newer members Martijn van Den Bosch, Chu Wanjun, Rene Wever, and Nazli Öskan. I would also like to thank all Ph.D. students I've met over the years who I've discussed science, personal matters, and shared a lot of laughs with.

Finally, I would like to thank friends and family, my mom Birgit, my dad Per-Gunnar, and my brothers Erik, Magnus, and Lars and their families for encouragement along the way.

And last, but not least, my fiancé Elin Rungstad for being my main supporter and giving me a lot of love and understanding throughout the challenging times that are inevitable during a doctoral study.

\author{
Torbjörn Andersson \\ Linköping, February 2021
}

This research has been funded by Linköping University and carried out at the division of Product realization (former Machine Design) at the Department of Management and Engineering (IEI). 


\section{APPENDED PUBLICATIONS}

Overall, this research can be considered an extension my licentiate thesis, which was published in 2016 by Linköping University Press and titled Aesthetic Flexibility - Modularity of Visual Form in Product Portfolio and Branded Products. Specifically, the appended papers and the introductory chapters of the licentiate thesis are the basis of this doctoral compilation thesis; they are referred to as Papers I-VI and licentiate in the following text, illustrations, and table. The papers were appended as published, only with minor corrections in spelling and grammar.

In the Swedish academic system, the structure of a licentiate thesis is similar to the structure of a PhD thesis, including a minor defence process with an opponent and an examiner. Licentiate thesis is commonly conducted halfway through a $\mathrm{PhD}$ process and aims at summarizing theory, narrowing scope, and providing a set of initial answers to research questions. Thus, it should be noted that findings and texts from the licentiate thesis are included as an interpretation or in its original phrasing. 


\section{PAPER I}

Andersson T., Warell A., Holmlid S. (2013) Product gist: An approach to identifying from characteristics of the current product sign, 10th European Academy of Design Conference - Crafting the Future, Gothenburg, 17-19 April, 2013

\section{PAPER II}

Andersson T., (2014) Workshop in the influence of "Carry over" details on strategic formgiving. 13th NORDCODE seminar \& Workshop, Gothenburg, 10-12 September 2014

\section{PAPER III}

Andersson T., Warell A. (2015) Aesthetic flexibility in the management of visual product branding, 6th International Conference on Applied Human Factors and Ergonomics and the Affiliated Conferences (AHFE 2015), Las Vegas, Nevada, 26-30 July.

\section{PAPER IV}

Andersson T., Wever R., Warell A., Ölvander J., (2021) The product Portfolio Development model - Design strategies for evolving portfolios, International Journal of Product Development - Accepted on conditions of minor changes.

\section{PAPER V}

Andersson T., Wever R., and Ölvander J., (2021) Strategically managing design flexibility, 23rd , International Conference on Engineering Design, Gothenburg, Sweden, 16-20 August. - Submitted

\section{PAPER VI}

Andersson T. (2021) Design judgment processes in mature Swedish manufacturing companies, Journal of Design Research - Accepted 
The author has been the main contributor to all of the published papers, but co-author contributions have primary been during the planning and writing phase (Table 1). The dots in the table indicate the content of the articles and circles around the dots indicate that the co-authors contributed to the development of the phase.

Table 1. Show the distribution of work between the main author and co-authors in each included paper.

\begin{tabular}{|c|c|c|c|c|c|c|c|c|}
\hline & 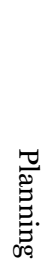 & . & 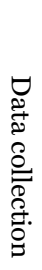 & 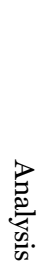 & 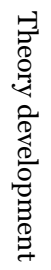 & 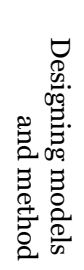 & 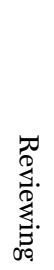 & 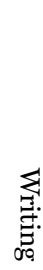 \\
\hline Paper I & $\bullet$ & (-) & $\bullet$ & • & & • & (2) & • \\
\hline Paper II & $\bullet$ & $\bullet$ & $\bullet$ & $\bullet$ & & $\bullet$ & $\bullet$ & $\bullet$ \\
\hline Paper III & • & (-) & $\bullet$ & • & - & $\bullet$ & ( ) & $\bullet$ \\
\hline Paper IV & () & (-) & $\bullet$ & $\bullet$ & $\bullet$ & • & ( ) & $\bullet$ \\
\hline Paper V & ( ) & (-) & $\bullet$ & - & & & () & $\bullet$ \\
\hline Paper VI & $\bullet$ & $\bullet$ & - & - & - & - & $\bullet$ & - \\
\hline
\end{tabular}




\section{ADDITIONAL PUBLICATIONS}

Additional publications that were published during the course of the research that are not included or discussed in this licentiate thesis.

Berglund M., Andersson T., Hedbrant J., Pavlasevic V., and Stålhand J., 2015.Understanding the user beyond 'common sense' - Teaching Product Ergonomics to design engineering students. Proceedings 19th Triennial Congress of IEA, Melbourne 9-14, August 2015.

Berglund M., Pavlasevic V., Andersson T., Hedbrant J., and Stålhand J., 2014. Theme-based assessment of education in design and product development. In: 1Oth International CDIO Conference at Universitat Politécnica de Catalunya, Barcelona June 15-19, 2014.

Andersson T., Warell A., Holmlid S., Ölvander J., 2011. Desirability in the development of In-Car Infotainment Systems, In: 13th IFIP TC13 Conference on Human-Computer Interaction. Lisbon, Portugal September 5-9, 2011. 


\section{TABLE OF CONTENTS}

O1 INTRODUCTION

1.1 Purpose and aim of the reserach ............................... 4

1.2 Reserach scope .......................................... 4

1.2 .1 Reseach questions. ...................................... 5

1.3 Outline of the thesis ......................................... 6

O2 RESEARCH METHODOLOGY

2.1 Hermeneutic reserach rationale ............................... 9

O3 GENERAL RESEARCH PROCESS

3.1 Theoretical reserach ......................................... 12

3.11 Literature reviews . ....................................... 12

3.12 Development of theoretical models ......................... 13

3.2 Empirical reserach.......................................... 14

3.2 .1 Data collection........................................... 15

3.2.2 Data condensation ........................................ 19

3.2.3 Data display ............................................. 19

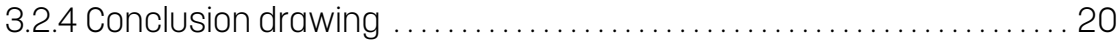

3.3 Persp. 1 - Aesthetic flexibility in Industrial Design .................. 22

3.4 Persp. 2 - Development of an Industrial Design P. P. model ........... 23

3.5 Persp. 3 - Investigation of Design decisions in strategic design ..... 24

04 THEORY 28

4.1 Branded product portfolio ................................. 29

4.2 Strategic design thinking in branded product portfolio ............. 29

4.3 Design components ........................................ 32

4.4 Product modularisation and its impact on industrial design ......... 33

4.5 Product architecture ...................................... 35

4.5.1 Modular product design architecture ........................ 36

4.5 .2 Integral product architecture ................................ 37

4.5.3 Branded product architecture . .............................. 37

4.6 Product Platforms ....................................... 40

4.7 The dev. of strategic I.D. functions in manufacturing companies .... 42

4.8 Decision making theory - The dual design decision process........ 43

4.8 .1 Design judgment. .................................... 45

4.8.2 Multidimentional design decision. .........................47 
4.9 Three Persp. correlation to the theory ....................... 48

05 FINDINGS 49

5.1 Persp. 1 - The influence of prod. mod. and branding on ID practice. ... 49

5.11 Method development - Product gist .......................... 50

5.1.2 Case study A - Aesthetic flexibility: a design strategy to cope with

modular-platform brands................................. 52

5.1.3 Carry-over Workshop - Evaluating an aspect of aesthetic flexibility 54

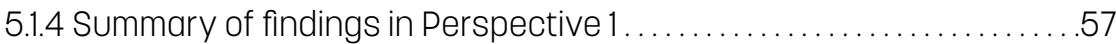

5.2 Persp. 2 - Industrial Design product portfolio development .......... 58

5.2 .1 Industrial design product portfolio management strategies........ 58

5.2.2 The evolution of the IDPPM model. ......................... 60

5.2 .3 Final version of the IDPPM model...........................62

5.2.4 Validation of the seven industrial design strategies and findings of the impact on industrial design practice....................62 62

5.2 .5 Summary of findings in Perspective $2 \ldots \ldots \ldots \ldots \ldots \ldots \ldots \ldots \ldots . \ldots \ldots$

5.3 Persp. 3 - Design judgment in manufacturing companies.............79

5.3.1 Part 1 - Design functions organised to facilitate design decisions . . . 79

5.3.2 Part 2 - Dual design decisions in major and single strategic design teams........................................... 84

5.3 .3 Summary of findings in Perspective $3 \ldots \ldots \ldots \ldots \ldots \ldots \ldots \ldots$

O6 DISCUSSION 89

6.1 The influence of prod. mod. in the dev. of aesthetic flexibility......... 90

6.2 The IDPPM model - strategic product portfoliomanagement from

a design perspective................................... 93

6.3 Decision making in the industrial design practice................ 99

6.4 Reflection on the conducted design reserach.................... 102

6.5 Validity of reserach results. ................................... 105

0.6 Limitations ............................................. 107

07.CONCLUSIONS AND FUTUREWORKS 109

7.1 Future works ........................................... 111 


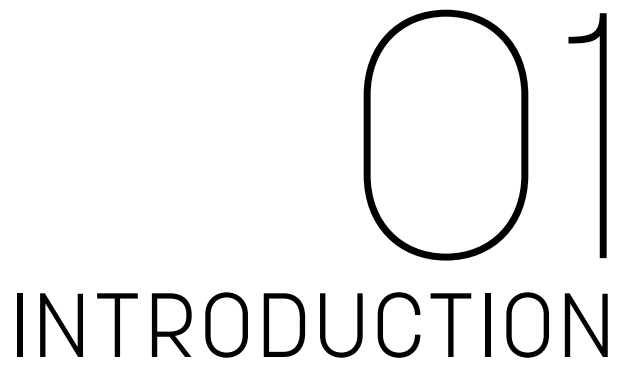

Manufacturers have employed artists, architects, and craftsmen for millennia to develop products and create a competitive edge through the apparency of artifacts. With the rise of industrialization and the development of new methods for mass production, a new aesthetic profession emerged, industrial design.

These new methods evolved from the early phases of the industrialization through today's advanced methods of mass customization and mass optimization. A major step in the development of mass production was the development of the American system of standardization in the mid 19th century, including the production of machine-tooled parts that made it possible to churn out products at a rapid pace (Hounshell, 1984; Heskett 1991). The standardization and precision of machine-tooled parts had the added benefit of interchangeability within the same type of product, a much soughtafter function of the American armed forces (Hounshell, 1984; Heskett 1991).

The increase of wealth in society and the speed in which new products entered the market created a shortage of skilled artists, craftsmen, and draftsmen who could supply the new factories with quality and producible designs. Art schools with industrial design curricula started to emerge in the mid 19th century to cater to the needs of merging aesthetic, utilitarian, and producibility demands in these new industries (Art journal 1840; Heskett 1991, pp. 10-11). In the early days, the design focus of mass production were mainly directed at ceramics, patterns (textile and wallpapers), and household goods. With the increase of technology, the early industrial designers were tasked to be part of technological development. The design icon Raymond Loewy described this evolution as a shift from art industries to industrial design, where the later to a greater extent catered to the demands originating 
from corporate structures and technology (Loewy 1951; 2002). This focus is still at the core of the modern industrial design practice ${ }^{1}$ even though it has expanded over the decades to encompass strategic management, innovation marketing, branding, user experience, service design, etc. (Heskett, 1991; Coates, 2003; Buxton, 2007; Hertenstein et al., 2013; Ulrich et al., 2020 pp. 216-223; Micheli et al., 2018).

Today, industrial design is an important part of the development of competitive products. This importance becomes apparent in competitive markets where everything that can provide a positive experience toward a company is central for management. Competitive companies have established strong brand equity that needs to be managed. To meet this demand, manufacturing companies develop in-house design functions for competitive product segments where the portfolio and complexity of the products create a need for continuous changes and update. In addition, many manufacturing companies focus on creating mass customizable product platforms. These platforms are organized into product families where standard parts and modules are interchangeable, easy to redesign, and create derivate products (Ulrich, 1995; Ulrich et al., 2020, pp.193-197). The need for modularity, product platforms, and brand development have influenced how industrial designers think about strategic design. Industrial designers working under these conditions have adopted a flexible approach in their design thinking by creating designs that are easy to expand into new markets and easy to update. Industrial designers must consider not only present and future design opportunities but also how to implement a visual design strategy across a portfolio containing several product families. By sharing designed parts across a product portfolio (i.e., lateral thinking), economy of scales come into play (Ulrich et al., 2020) that promote a company's positive brand value through repetition and transfer of

\footnotetext{
${ }^{1}$ The concept of practice has been described from several perspectives; the most prevalent ones are anthropological, philosophical, and organisational. I adhere to the organisational perspective and adopt Corradi et al.'s (2010) three dimensions of practice:

1. the set of interconnected activities that, if socially recognized as a way of ordering, stabilize collective action and common orientation;

2. the sense-making process that supports the accountability of a shared way of doing things and which allows the continuous negotiation (ethical and aesthetic) of the meaning of a practice by its practitioners;

3. and the social effects generated by a practice in connection with other social practices, a dimension of the reproduction of practice that addresses what doing the practice does.
} 
design elements associated with the company across all its products (Keller et al., 2012; Kapferer, 2014). The flexibility and lateral thinking have not only influenced the individual industrial designer but also to the design team, or design function to be more aligned with organisation literature (De Wit and Meyer, 2010).

A design function's internal development processes is a mix of intuitive and rational decisions supported by inputs originating from their own investigations and other company functions. That is, the industrial design's innovation and development processes are by nature open-ended, human centred, reliant on intuitive and aesthetic decisions, and primarily future oriented (Cross, 2006; Buxton, 2007; Lawson and Dorst, 2009; Blaszczyk and Wubs, 2018). This approach challenges traditional decision-making processes found in engineering product development literature. The traditional approach, described as a rational process, relies on scientific principles, logical processes, and preferably predictable outcomes (Fielden, 1963; Ulrich et al., 2020 pp. 154-5). The difference in decision styles creates a need for the company's functions to be negotiated and to allow for compromises if a development project is to progress. Giannini et al. (2006) conclude that designers change what they communicate depending on whether they are discussing styling with marketing or functionality with engineering. With the engineers, designers' communicative style is more fact based, including metrics; with the marketeers, designers' communicative style is more affective, relying on emotional descriptions of products and concepts. This difference indicates that designers have to make different types of compromises depending on what company function (and with whom) they are addressing. 


\subsection{Purpose and aim of the research}

The general purpose of this research is to increase existing knowledge of how industrial designers work with aesthetic demands created by mass-produced modular products that are part of a branded product portfolio. Specifically, this research investigates how this dual demand influences professional industrial designers' decision-making and work processes.

Inspired by the discussion that industrial designers and design functions are gaining more strategic roles in companies (Tovey, 1997; Giannini et al., 2006; Buxton, 2007; Johansson and Holm-Svengren, 2008; Verganti, 2009; Stompff and Smulder, 2013; Micheli et al. 2018), I have chosen to more fully investigate these two factors more thoroughly than has been done in previous design research literature. Brand management and product modularity literature mainly states that there is a need to use industrial design to achieve differentiation, but this literature does not describe how this should be done or how it can be managed as part of developing a product portfolio (Keller et al., 2012; Kapferer, 2014; Ulrich et al., 2020). Design research on how a single product's design features influence a brand concludes that a single product design can influence a product portfolio (Warell, 2006; Karjalainen \& Snelders, 2010; Ranscombe et al., 2012), but so far there is no generic model that describes what industrial design development strategies exist and how they influence the evolution of an existing product portfolio.

\subsection{Research scope}

This research explores how industrial designers work with complex product and product portfolios by focusing on mature manufacturing companies with an in-house design organisation as this strategy enhances the chance of finding respondents experienced in strategic design (Giannini et al., 2006; Johansson and Holm-Svengren, 2008; Person et al., 2016; Micheli et al. 2018). This approach also makes it possible to gain insights into their practice, decisionmaking process, and the organisation of in-house design functions. The manufacturing companies participating in the research design, market, and produce their products under their own brands. Respondents participating in the research were employed by the company and judged as experts or experienced by their peers (Schön, 1987). This arrangement increased the 
chance to gain both tacit and explicit expert knowledge from the respondents, increasing the chance for new and unexpected findings.

\subsubsection{Research questions}

To understand some of the premises for industrial designer's practice and decision-making in these conditions, this research explores the strategic design projects and how design teams were organised as complexity, massproduction, and brand coherence influence a designer's work process and practice. Hence the following research questions were formulated (findings and insights from the first research question inspired the second and third research questions):

RQ1: How does the strategic thinking of industrial designers influence the development of products in large product portfolios?

RQ2: How does industrial design in a manufacturing company foster strategic decision-making when participating in the management of a company's existing product portfolio?

RQ3: How do intuitive design decisions and rational compromises in industrial design practice influence decision-making in strategic design? 


\subsection{Outline of the thesis}

The thesis is structured as follows.

\section{Chapter 1 - Introduction}

The first chapter introduces the background to and purpose of the research. Research aims as well as research questions are presented.

\section{Chapter 2 - Research methodology}

The second chapter describes what research epistemology and scientific methods were used to explore and answer the research questions.

\section{Chapter 3 - Research Process}

Chapter three describes what research process were used to explore and answer the research questions.

\section{Chapter 4 - Theoretical framework}

In chapter four the theoretical foundation to frame the research scope, contribution and discussion.

\section{Chapter 5 - Findings}

In chapter five, results from the studies are presented and further elaborated through the focal lens of three Perspectives.

\section{Chapter 6 - Discussion}

Chapter six discuss the results from studies are discussed with the support of the theoretical framework in chapter four and the research methods are scrutinised and discussed.

\section{Chapter 7 - Conclusions and future work}

Finally, in chapter seven the research questions are answered, and directions for new research endeavours are presented. 


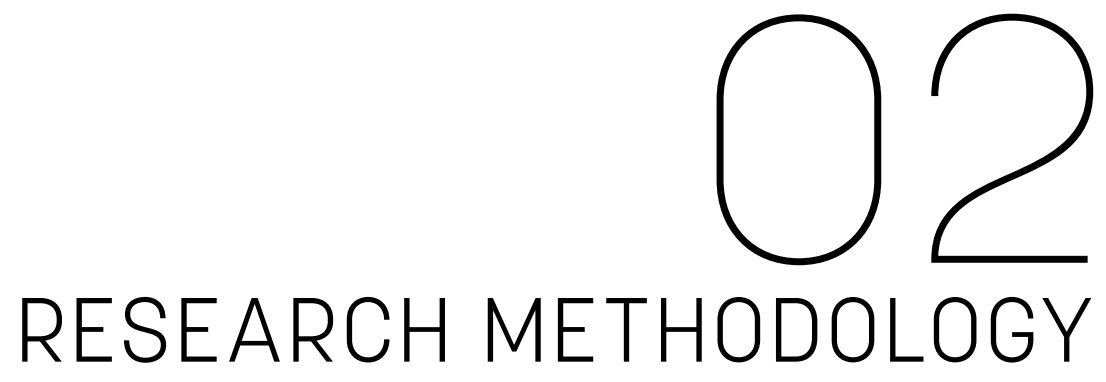

This research explores how advancements in manufacturing, branding, and product development have influenced industrial design activities, work processes, and decision process. That is, all findings and results focus on the industrial designer's perspective and how other company functions, such as research and development (R\&D), engineering, marketing, and manufacturing, view the designer's influence on the development of products. Therefore, the general methodological approach is design research.

Design research has at least two roots: one originating from the field of technology (Chakrabarti and Blessing, 2016; Pahl et al., 2007) and one originating from art and design (Rodgers and Yee, 2018). Both explore practice, but recognise that scientific reasoning, with its demand on generalisation and deductive inference, is an impractical approach that in the end may create meagre results. According to the researchers, a traditional scientific approach would be too costly, time consuming, and cumbersome to effectively scrutinise collected data. Whereas technology driven by design research mostly excludes uncertainties such as subjective and aesthetic aspects of a design, art and design embrace these aspects. In this thesis, the methodological and epistemological focus lies in the later, so the meaning of design research will incorporate subjective and aesthetic aspects of design.

According to Glanville (Rodgers and Yee, 2018, p13-14) and Boyd Davis and Gristwood (2016), Bruce Archer and Tomas Maldonado and Horst Rittel are pioneers in the development of modern western design research. In 1972-73, Archer was promoted to research professor at Royal College of Art (RCA) in London and developed a Department of Design Research (Boyd Davis \& Gristwood, 2016). His research focused on understanding the design process 
to create a theoretical understanding of practical design experience. The next leap in design research theory was made by Sir Christopher Frayling (1993); in his paper "Research in Art and Design", Frayling proposed a third way of conducting design research where the researcher is both the focus and part of the research. Inspired by Herbert Read's (1934;1966, p. 196) ideas about art being taught through practice, Frayling concludes that that research in the field should be conducted for design, into design, and through design. Wolfgang Jonas (Rodgers and Yee, 2018, p. 30-31), adapting a cybernetic approach to Frayling's concept of design research, proposes a fourth dimension - research as design. His conclusions are presented below:

Research For design: The researcher, from an observatory position, investigates what underlying cognitive/semiotic/communicative/learning processes influence design. The aim is to use scientific methods to understand and improve the general practice of design.

Research About (into) design: The researcher, from an observatory position, tries to understand and generate knowledge about the design system. The methods are of inquisitive nature aimed at understanding how designers practice their craft within a system. Prominent research fields include anthropology, philosophy, history, and physiology.

Research Though design: The researcher, embedded in a design system, actively participates in a design process. The aim is to transfer practical knowledge and innovations to a wider audience by providing different perspectives such as Practice-Led Research (also known as Practice-Based Research), Project-Grounded Research, and Research through Design (Chow, 2010).

Research As design: The researcher uses design to explore new ways of doing and thinking about design (Micheli et al., 2019) to develop the field of design and produce new knowledge.

This research focuses on research about design. Research for and as design have also been used in parts of the conducted studies. Chapter 3 provides a more in-depth description. 


\subsection{Hermeneutic research rationale}

Epistemologically, the author has adopted a hermeneutic approach (cf. Alvesson and Sköldberg, 2017, pp. 139-141). At its core, hermeneutics can be described as 'the meaning of a part can only be understood if it is related to the whole' and where deductive knowledge production does not exclude intuitive processes (Alvesson and Skjöldberg, 2017). That is, because knowledge cannot solely be achieved through reasoning and rational analysis, the role of the researcher cannot be excluded from the research process as the researcher's search for comprehension is influenced by pre-understandings of the subject matter, which ultimately influences the creation of new understandings (Alvesson and Sköldberg, 2017, p. 134).

Therefore, I recognise that I have a pre-understanding of the research scope, both applied and academic knowledge. My applied knowledge originates from working as a design consultant for several years, and my academic knowledge originates from my bachelor's and master's degree studies in industrial design at the Academy of Art and Design in Gothenburg, Sweden (HDK-Valand, 2020). 



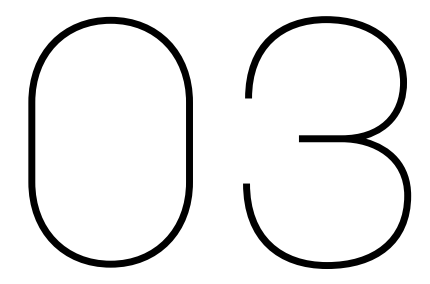

\section{GENERAL RESEARCH}

This design research process used three of the four design methodological categories to explore the research scope and answer the three research questions. Each research question was explored through a series of studies and investigations. As the studies and investigations were not aimed at one specific research question, three perspectives were used to focus on the collected data, which are described in more detail in each of the three perspectives. All three perspectives were explored using the design research methodology About designers' practices, because understanding what influences current work processes requires investigations be conducted with professionals in the field.

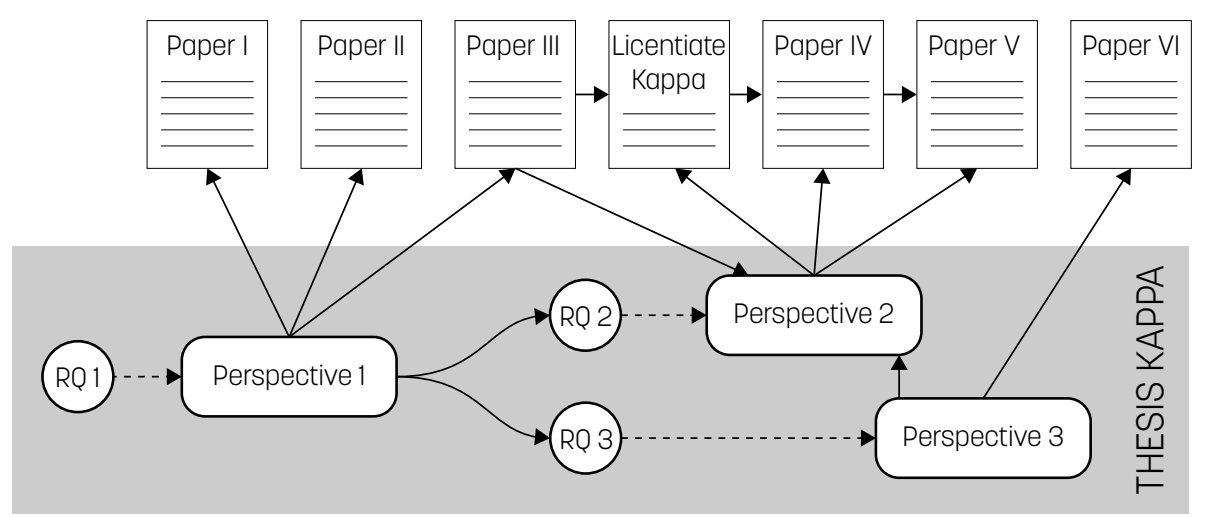

Figure 1. Illustration of the overall scheme of the conducted research process and how findings in perspective one influenced research question two and three. The model depicts how the seven published papers links to the three perspectives. 
Research For design has been used primarily in Perspective 1 and Perspective 2 to explore professional industrial designers' cognitive processes when making design decisions. Lastly, I used my own design knowledge to explore aspects of the individual industrial designers' practice, creating a new design method in Perspective 1. Theoretical and empirical research methods were used during the investigation of the three perspectives (Figure 1). The contents of the three perspectives are further elaborated in 3.3-3.5.

\subsection{Theoretical research}

The theoretical research was conducted in two ways. First, it explored and drew conclusions from existing literature and literature reviews and each of the three perspectives (Figure 6). Second, the theoretical findings from the literature reviews in Perspective 2 and Perspective 3 were used to develop theoretical models. These models were developed through a visual hermeneutic process where the author's preunderstanding of industrial design practice was part of the development process. The theoretical model developed within Perspective 2 and Perspective 3 was empirically evaluated through interviews with professionals.

\subsubsection{Literature reviews}

During the course of this research literature, reviews were conducted in two ways: the first as general exploration of the field of design, branding, and product development and the second as structured literature reviews where the research scope framed the reviews. The structured literature reviews followed snowballing guidelines as described by Wohlin (2014). According to Wohlin, snowballing is preferred when searching a wide body of literature across a broad research area as it builds on the same principles as systematic literature reviews (SLR) and systematic mapping studies (Kitchenham \& Chartes, 2007), but with a different approach. Rather than starting with a wide database search, the focus lies in creating a starting set and using this as a reference list to find additional literature. According to Wohlin (2014) and Badampudi et al. (2015), the snowballing strategy quickly finds relevant 
literature and reveals literature not available via database searches.

To create a starting set, researchers from different research fields - e.g., industrial design, design engineering, and brand management - were contacted. Specifically, these researchers were asked to recommend prominent research within their field, especially prominent books, articles, and other researchers. Reference lists from the recommended literature and principal researchers were used to conduct backward snowballing (Wohlin, 2014) to find more relevant articles. Simultaneously, searches in Google Scholar and UniSearch, which contains more than 115 different academic databases such as Scopus, ScienceDirect, and Web of Science, were conducted to expand and corroborate the found and recommended literature. The database searches placed no restriction on publication dates but restricted the searches to peerreviewed articles, journals, and books.

\subsubsection{Development of theoretical models}

Hallberg (2020, pp. $76 \neg 80)$ identifies two primary ways a theory can be created: by an adapting an existing theory or by creating new theories. Evolving an existing theoretical model is made by creating new contributions, increasing the realism or opposing it, and developing a new model. The general process of developing theories constitutes examining data (empirical and theoretical) and developing hypothesises that are eventually tested and validated. The validation can be done empirically through tests or non-empirically by examining the underlying logic and plausibility (ibid.). When describing how new theories are developed, Hallberg (2020) takes on a Popperian stance, concluding that no systematic processes exist for how new theories emerge: '[A] new theory is believed to appear from the inherent creativity of talented people and more or less wild guesses' (translation from Swedish, Hallberg, 2020, p. 76).

According to Vermaas (Chakrabarti \& Blessing, 2014, pp. 49, 54, 59), a model is an abstract representation that aims to capture a phenomenon or theory. The abstraction can be either low or High; that is, the purpose of the model either depicts reality as close as possible (low) or extrapolates reality to form general descriptions (high).

In this research, theoretical models have been advanced by evolving existing theoretical models and by exploring data from literature reviews and case studies. Pen and paper, Power Point presentations, and Adobe Creative Cloud 
(2D-visualisation software) presentations were used to evolve the proposed models and visually experiment with conclusions drawn from the theoretical findings.

In Perspective 2, the model was evolved from a theoretical model proposed by Monö (1997) in combination with literature reviews from the fields of product portfolio management, brand management, and industrial design. The level of abstraction is high in the three-dimensional visualisations due to the aspiration to create a general theoretical model that illuminates the industrial practice of designers. As stated, the final proposition of the model was empirically evaluated (see Perspective 2 and Paper V).

The theoretical models in Perspective 3 were developed by analysing the theory found in the literature and from the empirical case studies. The proposed theoretical models are "high" abstractions of how design functions are organised and how members (focusing on industrial design practitioners) of these functions make design decisions and judgments. For more information, see Paper VI.

\subsection{Empirical research}

Empirical research has been conducted for all perspectives (Figure 1). Perspective 1 and Perspective 3 were used to investigate RQ 1 and RQ 3, and Perspective 2 was used to validate the proposed theoretical model. The research approach was qualitative due to the exploratory nature of investigating about (into) design, how the data are collected, and in the way conclusions are drawn (Miles et al., 2014; Yin, 2014; Baxter \& Jack, 2008). The main qualitative methodology is single and multi-case study research (Yin, 2014; Eisenhardt, 1989). Most data were gathered from interviews with professionals and design students and through a design workshop in Perspective 1. Miles et al.'s (2014) model of a qualitative data process (Figure 2) was used as a framework to collect and analyse information in the multi-case studies consisting of four phases: data collection, data condensation, data display, and conclusion drawing/verifying (Figure 2). How the different methods and tools are used are described in each of the three perspectives. 


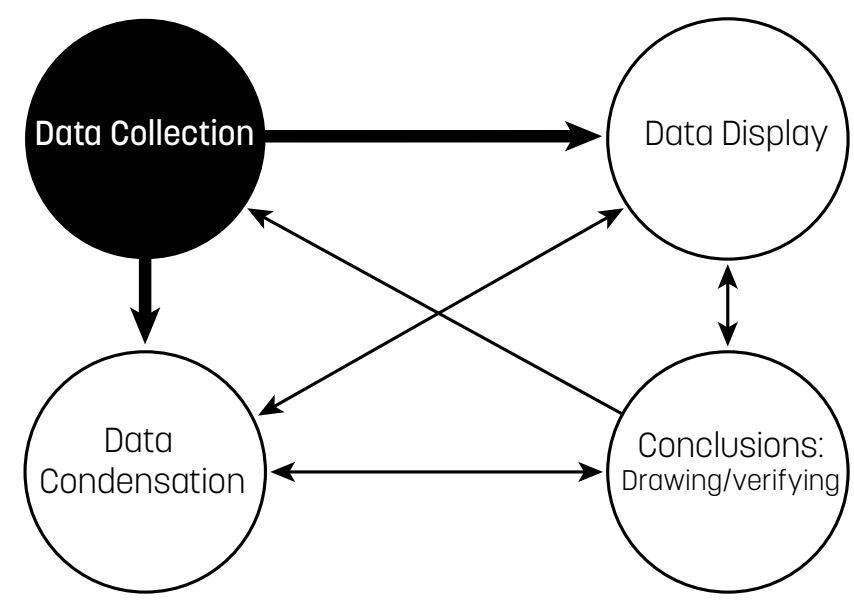

Figure 2. Miles and Huberman's (2014, p14) model for qualitative data processing.

\subsubsection{Data collection}

Data collection involves gathering information using different methods and from mainly human sources. Two case studies and one design workshop were conducted. The case studies are named Case A and Case B, where the collected data from A is first used in Perspective 1. Data collection method used in Case A was reused in Case B, making it possible to combine the data from Case A and B. The combined data sets were analysed in Perspective 2 and used to evaluate the theoretical results in Perspective 3, validating the answer to RQ3.

The design workshop, carried out in Perspective 1, builds on a finding made in Case A and uses qualitative data gathering methods such as interviews, videorecording, photographs of workshop results, and a design diary (Barapour et al., 2012).

Dane and Pratt (2009), in their review paper 'Conceptualizing and measuring intuition: A review of recent trends', overview methods designed for empirically capturing intuitive decisions. They conclude that retrospective reports are the most practical approach when doing field research (i.e., interviews with professionals). This view is in-line with what Yin (2006) describes as the premise for case study or qualitative research: the necessity to answer exploratory "why" and "how" questions and capture contextual 
phenomena. More rigorous data samples can be obtained through multi-case studies (Eisenhardt, 1989).

\section{Case companies}

Determining the focus and boundaries of whom should be included or excluded in a case study are important for achieving a good result (Miles et al., 2014, pp. 28-30) or a 'good case study' as described by Yin (2014, p. 201). Miles et al. (2014, p. 29) presents eleven ways a case may be defined; in this research, the following six criteria were used to frame the selection of interviewees (Table 2): role (VP, chief, manager, senior), small group (in-house design function), organisation (manufacturing companies), episodes (industrial design practice), process (how a product is designed), and nation (Sweden).

Two strategies were used to find suitable case companies to investigate in Case A and Case B. In Case A, the researchers' own knowledge of Swedish manufacturing companies with a design function were used and the chief designer of company E in Table 2 was contacted. The second strategy for Case B was more elaborate - i.e., a review of Swedish design companies was conducted to find suitable companies to include. The review was done by compiling the researcher's existing knowledge of manufacturing companies with in-house design teams and searching data from the Swedish Industrial Design Foundation (SVID) and Form Design Centre (FDC) in Malmö. To supplement the review, an internet search and the business directory Eniro. se were used to find additional companies and cross compare them with the compiled list.

Of the Chief Design Officers, Design VPs, and Heads of Design from several manufacturing companies who were contacted, four agreed to participate (Case study B). The design of Case A's and Case B's interview process and semi-structured questionnaire were first developed in Case A then reused in Case B. By doing this, the interview process was tested and evaluated, and the collected data from the Case A was included in the qualitative analysis conducted in Perspective 2 and Perspective 3.

The selected companies had strategic design functions with decision processes in place, which also included several non-designers. The contacted persons recommended senior team members within the design organisation or closely related to design who could be approached to be interviewed. In total, 16 face-to-face interviews were conducted. 
Table 2. Details of the case organisations, interviewees and types of design organisations found in Figure 27 and figure 28.

\begin{tabular}{|c|c|c|c|c|}
\hline case & Sector & Employees & Design team type & Interviewees \\
\hline A & Automotive & $\begin{array}{l}50,000- \\
100,000\end{array}$ & $\begin{array}{l}\text { Major Strategic } \\
\text { Design team }\end{array}$ & $\begin{array}{l}\text { VP design director, } \\
\text { senior design engineer. }\end{array}$ \\
\hline B & MedTech & $1000-10,000$ & $\begin{array}{l}\text { Single Strategic } \\
\text { Design team }\end{array}$ & $\begin{array}{l}\text { Chief designer, } \\
\text { senior designer. }\end{array}$ \\
\hline $\mathrm{C}$ & Consumer goods & $\begin{array}{l}50,000- \\
100,000\end{array}$ & $\begin{array}{l}\text { Major Strategic } \\
\text { Design team }\end{array}$ & $\begin{array}{l}\text { Global design director } \\
\text { (interviewed twice), } \\
\text { senior design manager, } \\
\text { two design managers, } \\
\text { portfolio manager. }\end{array}$ \\
\hline $\mathrm{D}$ & Comercial vehicles & $\begin{array}{l}10,000- \\
50,000\end{array}$ & $\begin{array}{l}\text { Major Strategic } \\
\text { Design team }\end{array}$ & $\begin{array}{l}\text { Chief designer, design } \\
\text { manager exterior, senior } \\
\text { ergonomics manager, } \\
\text { design engineer manager. }\end{array}$ \\
\hline $\mathrm{E}$ & Material handling & $1000-10,000$ & $\begin{array}{l}\text { Single Strategic } \\
\text { Design team }\end{array}$ & $\begin{array}{l}\text { Chief designer, senior } \\
\text { engineer, surface designer. }\end{array}$ \\
\hline
\end{tabular}

\section{Interview process}

In this research, the interview process was aided by photographs of the company's products, and markers and sheets of paper were provided to the interviewees so they could write comments and illustrate concepts. Before the interviews, prominent company products were recommended by the contacted design chiefs or selected by the researcher. Photographs of the chosen products were printed that showed the products from different angles. The photographs were used to prompt the respondents to illustrate and communicate their thoughts with regard to prominent design features and their design rationale. In addition, the respondents were given sheets of A3 paper and markers and asked to map a typical design process, identifying how the design team was organised within the company. The researcher used a semi-structured interview approach with a focus on the organisation of the design function within the company, a typical design process, and how design decisions were made.

The interview guide is found in Appendix A. The interviews were audiorecorded and lasted between 60 and 90 minutes. In line with recommendations for interview studies, supplementary fieldnotes were taken during the interviews (Miles et al., 2014). Finally, the interviews were transcribed and later analysed and coded as described in section 3.2.5. 


\section{Design Workshop}

To evaluate a strategic design aspect found in Case A, a workshop was designed and organised at Konstfack, the Swedish University of Arts, Crafts, and Design (Konstfack, 2020). In total, 13 people participated in the workshop: seven industrial design students, four PhD students in design, and two lecturers in design. Martin and Hanning's (2012) design workshop methodology framed for the process. The overarching theme was constructed to simulate a design task where the participant had to reuse a designed part (called carry-over by the respondents in Case $\mathrm{A}$ ) in a redesign process.

The workshop consisted of two phases, with a coffee break in-between. In the first phase, the participants were tasked to redesign an electric toothbrush constructed of at least three distinct modules: the head, body, and the charging station. The second step was to reuse (i.e., carry-over) one of the parts in a redesign task. The workshop was documented using digital recordings, photography, and fieldnotes (Figure 3). The participants' physical and digital design results from the workshop were also gathered and used in the analysis. For more information, see Paper II.

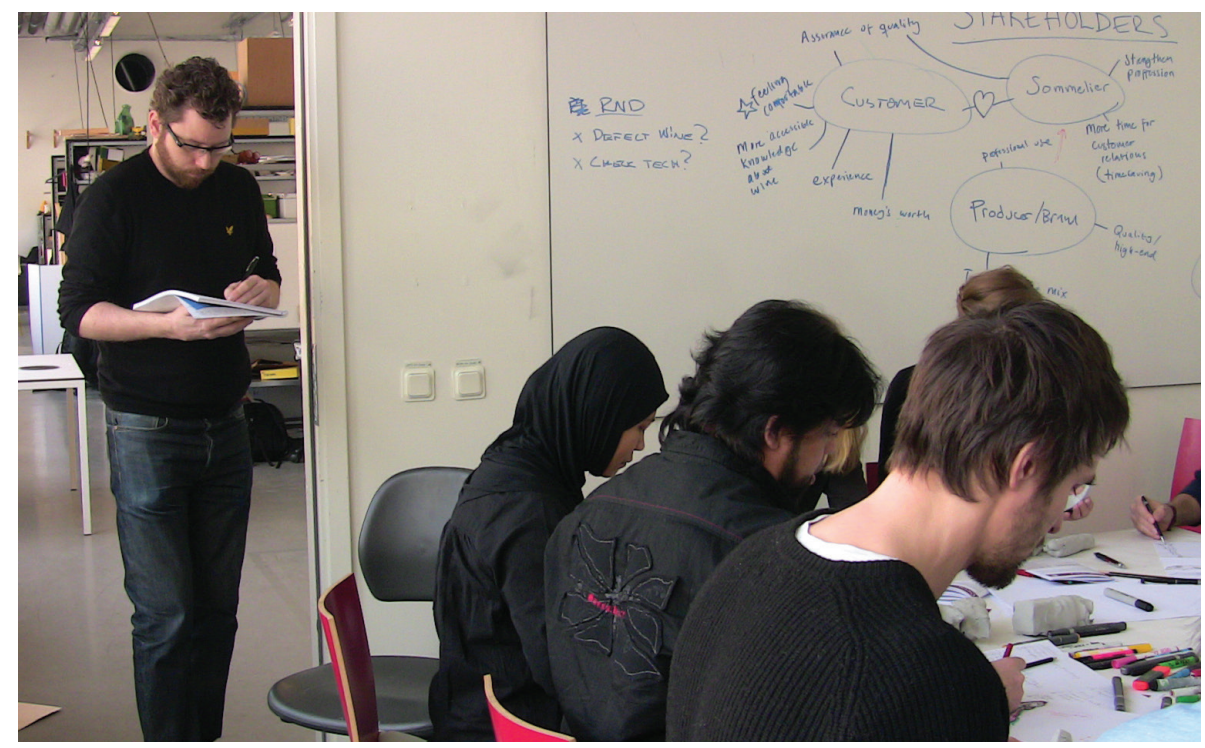

Figure 3. The photograph, taken in 2014, shows the author, far left, taking fieldnotes during the workshop in a conference room adjacent to the second-grade industrial design students' study room at Konstfack (Stockholm, Sreeden). 


\subsubsection{Data condensation}

Data condensation is part of the analysis process accomplished by selecting, simplifying, and abstracting the collected data from the case studies and the workshop. The audio-recorded material from Case A and B were transcribed. The data analysis in the case studies and design workshop used qualitative methods, originating from grounded theory (Glaser and Strauss, 1967), as described by Miles et al. (2014) and influenced by Micheli et al.'s (2018) data organisation. In a grounded theory approach, the collected data drive the development of codes, and meta-analyses are derived from the coding results.

The data condensation process used in processing the multi-case study material consisted of several coding steps. First, a sorting of the text was undertaken focusing on finding representative traces of and quotations about design decision processes. Second, an initial coding session was performed on the results from the sorting. These were then clustered into correlating groups and a second or meta coding was performed. The final results from the coding sessions were then used to explore the research questions in the three Perspectives (see Figure 3 and Paper VI).

Data gathered from the design workshop were first sorted according to two criteria: if the participants followed the instructions and redesigned only one of the modules of the electric toothbrush in phase two or made a totally new redesign of the entire product or used what the module calls 'carry over' and if the results of the two group workshops together with the gathered data from two groups were analysed and condensed into two themes (see 5.1.3 and Paper II).

\subsubsection{Data display}

Data display is the process of organising and assembling collected data. In all of the studies conducted in the three Perspectives, sketching ideas with pen and paper and Microsoft computer software were used to display and organise the data into tables, PowerPoint presentations, models, and text documents (see Figure 4). Displaying the condensed data in the case studies was mainly done in Microsoft Excel, which was used to sort and organise case companies, codes, themes, and quotations. In addition, as with lists inspired by Micheli et al. (2018), displaying the primary and secondary codes was done with 
representative quotations. The secondary codes were thematised, and a visual model was created to explain findings in Perspective 3.

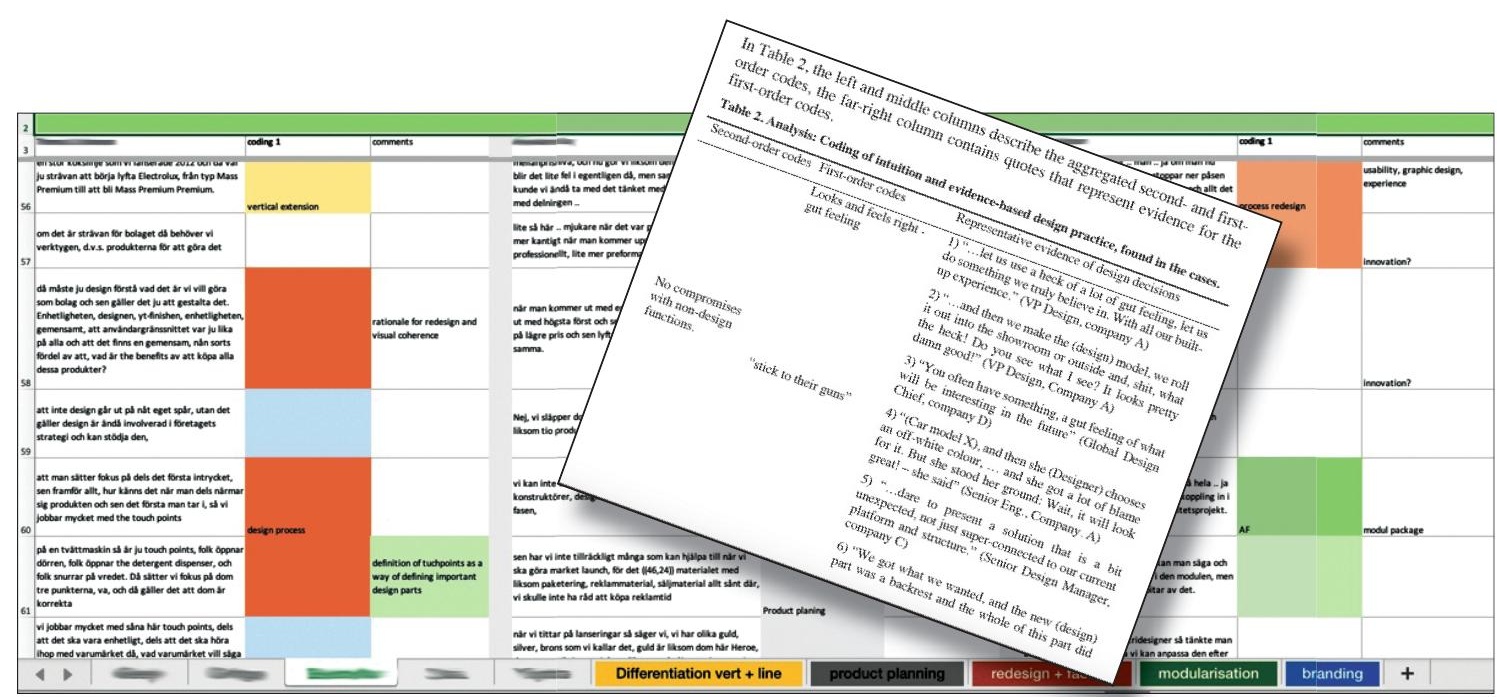

Figure 4. The data display processes are illustrated with relevant quotations from each respondent, text coded and colour coded into themes, which were entered into a Microsoft Excel file. The themes were then investigated to explore commonalities and differences between the respondents and the case companies. Lastly, the findings were organised in separate tables (see Appendix in Paper VI).

\subsubsection{Conclusion drawing}

On a general note, conclusions were drawn in accordance with the researcher's epistemology (see section 2.1) - i.e., hermeneutic cyclic investigations and explorations of the gathered theoretical and empirical data. Alvesson and Skjöldberg (2014, pp. 131-132) describe two levels of conclusions drawing on empirical data: a low-level and a high-level conclusion. Low-level conclusions are derived from the researcher's interpretations and conclusions that align with the collected data. That is, low-level conclusions aim to be as inductive or logically deductive as possible when interpreting and presenting results from the data. High-level conclusions, also known as 'grand theories' (Mills, 1959), are processes where the researcher's preunderstanding, intuitions, and imagination play a large part in the development of new hypothesises and theories (Alvesson and Skjöldberg, 2014). Miles et al. (2014) suggest 
that qualitative data analysis uses low-level or a mix of low- and high-level conclusions depending on the goal of the research. Thus, low-level conclusions are primarily part of the initial understanding of the data, whereas high-level conclusions are manifested itself at a later state when the researcher connects findings from several sources (i.e., theoretical and empirical) to generate a holistic understanding.

This research uses the mixed-level approach, where conclusions originating from the case studies and the workshop (i.e., high-level conclusions) lie close to the collected data (i.e., low-level conclusions).

The theoretical method in Perspective 1 and Perspective 3 also formed lowlevel conclusions drawing from their initial phases. High-level conclusions occurred during the theory building phase in Perspective 1, when a found phenomenon, named aesthetic flexibility ${ }^{2}$ by the author, was developed into a new hypothesis that addresses factors that influence industrial design practice.

In Perspective 3, high-level conclusions were drawn using low-level partial findings from Perspective 1, Case B, and literature reviews, and these conclusions were developed into general theories regarding decision-making in industrial design practice and strategic organisation of design functions.

\footnotetext{
${ }^{2}$ The term aesthetic flexibility was chosen since style flexibility is a recognised concept in leadership and organization development literature. Form flexibility could have been used, but it was deemed to connect too much with bio-chemistry or manufacturing language. Visual flexibility was also an option, but the term is used in eye and vision research. The word "aesthetic" has a positive connotation and generates associations to values created by designers or artists and "flexibility" implies both present and future changes in ideas and artefacts.
} 


\subsection{Perspective 1 - Aesthetic flexibility in industrial design}

From methodological point of view, Perspective 1 (Figure 5) consisted of a continuous literature review regarding influencing factors on the industrial design practice. To narrow the scope, three literature areas were chosen: product modularity, brand management, and industrial design. This narrowing of focus was done because the first two areas were important external demands that influence the industrial designer's strategic decisionmaking process within the practice. These were prevalent factors for success in manufacturing companies with large portfolios and complex products. The third literature focus area was on reviewing the literature on industrial design practice and work processes.

The literature review sparked the development of a design method exploring the creation of current product designs (Monö, 1997). Conclusions and findings from the exploratory process led to the creation of Case study A (see Paper I.)

Findings from the case study were then investigated through a design workshop with design students and design researchers. Insights from the literature review for Case study A and the design workshop initiated the development of two theoretical concepts - aesthetic flexibility and strategic management of product portfolios by industrial designers.

The first concept aims at answering RQ1 and the second lays the foundation for the development of RQ2 and RQ3.

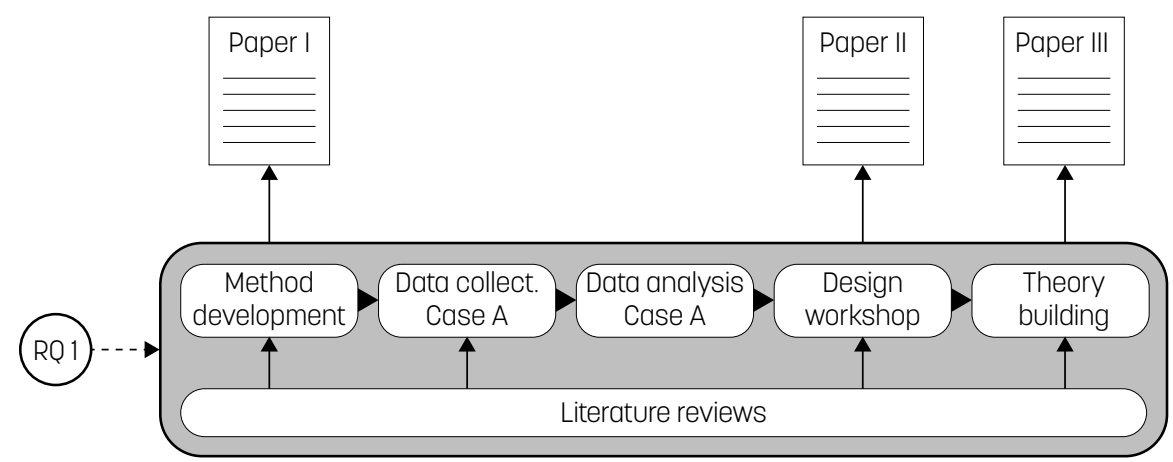

Figure 5. Visualization of the research processes and the methods used to explore RQ1. 


\subsection{Perspective 2 - Development of an Industrial design product portfolio model}

The finding in Perspective 1 generated a notion that the type of design project impacts the designer's decision process. This sparked the second research question (RQ2): How does industrial design in a manufacturing company foster strategic decision-making when participating in the management of a company's existing product portfolio?

The research process for Perspective 2 (Figure 5) was designed to investigate what type of strategic design choices an industrial designer or design teams face when developing product portfolios. The rationale behind this inquiry was initiated by findings made during the empirical data collection and literature findings in Perspective 1.

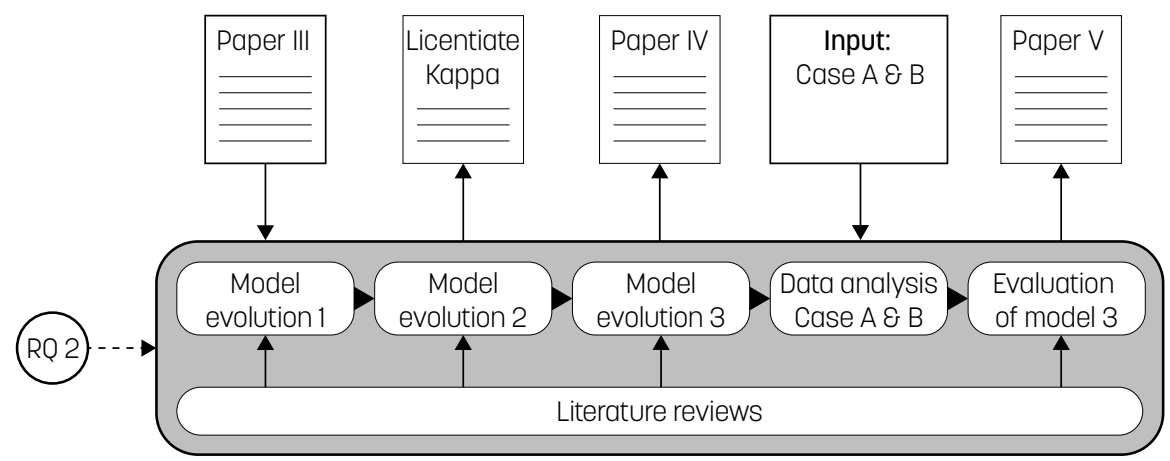

Figure 6. The research process conducted during Perspective 2 to answer the second research question. A progressive evaluation is conducted for a theoretical model and an empirical evaluation is conducted for the final version.

The data suggest that partial design updates and extensions of an existing product portfolio were not as strategically demanding and uncertain as when creating a totally new product.

The goal in Perspective 2 was to generate a general descriptive model aimed at clarifying existing design strategies and how they are related. The model was created through an iterative process where new theoretical knowledge, originating from literature reviews and a collection of product examples, was used to create a theoretical model. 
The literature reviews aimed at finding the most prominent types of product portfolio management methods in the fields of industrial design, product portfolio management, and brand management. The product examples were collected from companies that matched the research scope.

The final version, first presented in Paper IV, was qualitatively evaluated by experts in industrial and engineering design (the results from the evaluation are presented in Paper V). The qualitative evaluation was performed with respondent data from Case A and B. Specifically, the evaluation was conducted by sorting and coding the respondent's data, as described by Miles et al. (2014). The results from the qualitative analysis were then compared with the found strategies, which are further elaborated on in Paper IV.

\subsection{Perspective 3 - Investigation of design decisions in strategic design teams}

Findings from Case study A revealed that a large part of the respondents' design process relied on managing a variety of design decisions. The decisions constituted a mix of intuitive and rational decisions supported by inputs originating from their own investigations and other company functions. Because this had not been fully investigated in design research literature, a third research question (RQ3) was developed: How do intuitive design decisions and rational compromises in industrial design practice influence decision-making in strategic design?

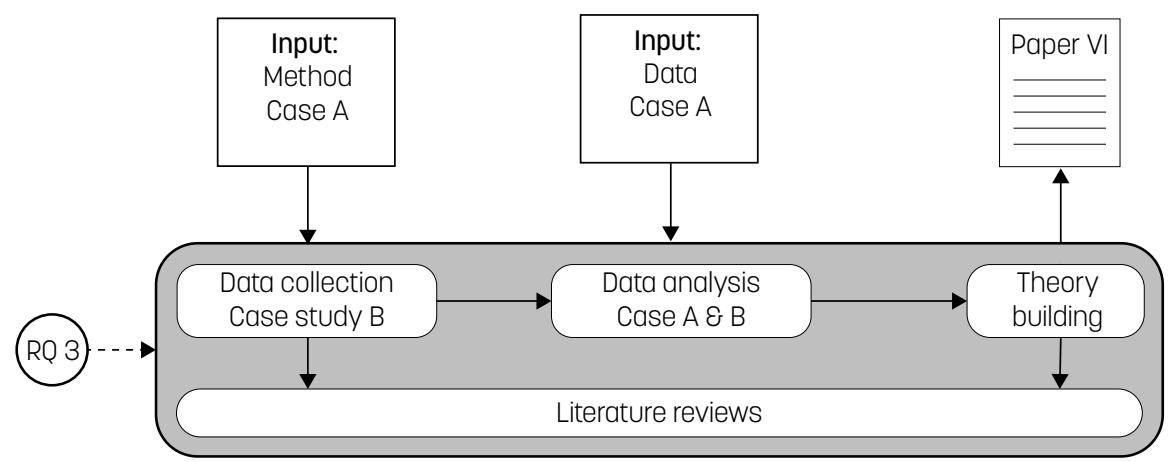

Figure 7. The research process used to answer the last research question. A qualitative research process supported by literature studies and ends with the development of new design theory. 
Perspective 3, a literature review, was developed to investigate RQ3, and Case study B was initiated to gather empirical and theoretical data (Figure 7). Two types of qualitative analysis were performed on the collected data from Case A and Case B. The first data analysis aimed at exploring how manufacturing companies organise their design decision process. This was done by analysing the design organisational structure of the five case companies and comparing this data with the interview material and the visual aids from each respondent. The composed data were then used to create a theoretical model consisting of four general design decision process maps.

The second analysis aimed at finding out what design judgments and multidimensional design decision processes could be found in the different functions within the selected manufacturing companies. Findings from the analysis were then compared with theoretical findings made during the literature review. Conclusions were then used to develop a theoretical model depicting the principal process of making design decisions. 



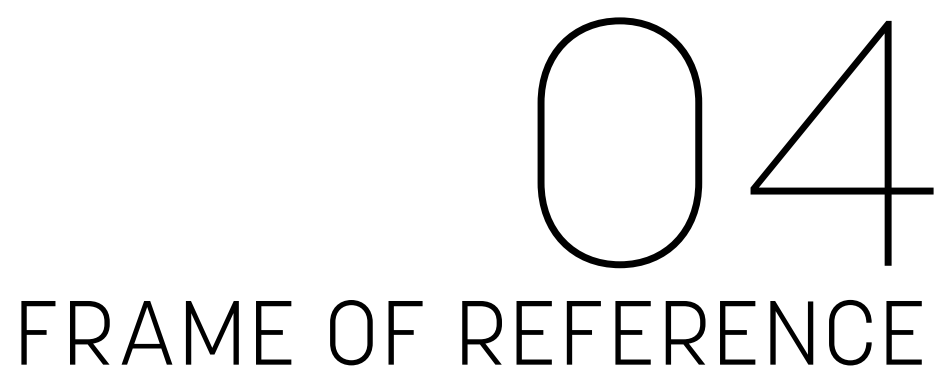

This thesis builds on four theoretical bodies of knowledge: modular product development, strategic design, decision making, and brand management (Figure 8). This chapter describes these areas to provide a foundation for the contribution and discussion sections.

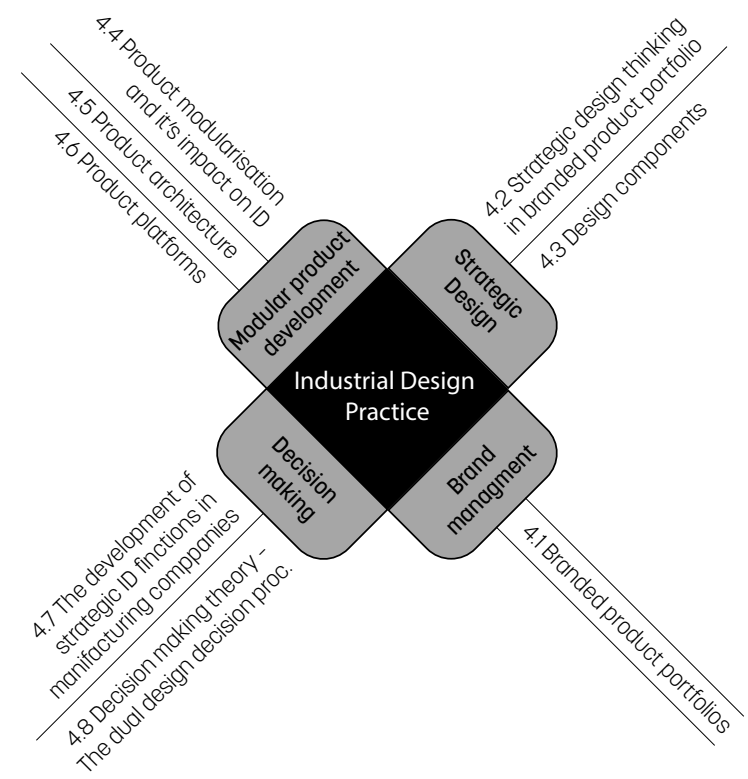

Figure 8. The diagram depicts the central focus of industrial design practice and its four main research areas. 


\subsection{Branded product portfolios}

A product portfolio is the entire collection of products and services that an organisation offers to its customers (Villamil \& Hallstedt, 2018; Ulrich et al., 2020). Product portfolios are organised into product categories containing several product lines (or ranges) and/or single products (Kapferer, 2014, p. 320; Keller et al., 2012, p. 563). Global companies that target different markets with a wide range of product offerings develop separate organisations and multiple simultaneous product portfolios. Kapferer (2014) states that companies typically develop single or multiple product portfolios using one of two may strategies: branded house and house of brands (Figure 9).
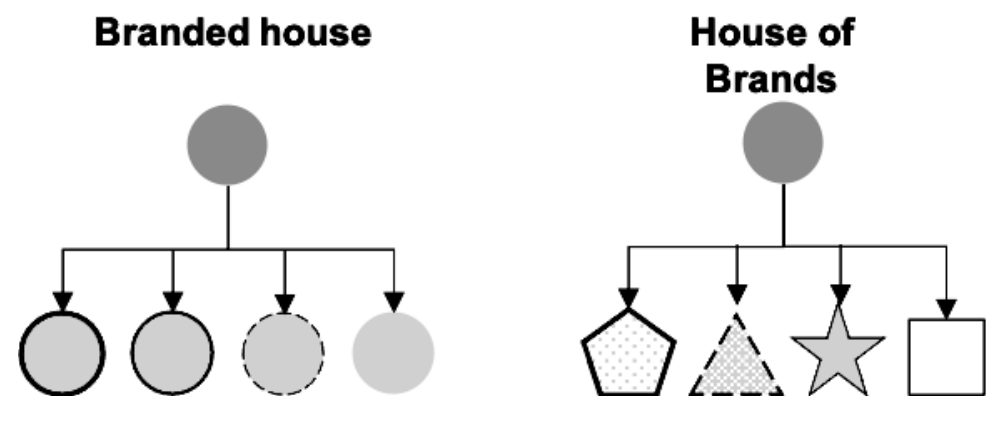

Figure 9. The model to the left depicts a branded-house strategy, where all products and services share a joint communication stream. The model to the right depicts a house-ofbrands strategy, where the product portfolio is divided into individual brands that have their own communication with customers.

In a branded-house strategy, an industrial designer coordinates all design efforts and creates a unified communication stream aimed at the company's customers along with coherent visual recognition across all of its products. For example, the power tool manufacturer Hilti (Hilti, 2020) has created a unified brand identity and coordinated all its products using a coherent scheme of colours, textures, and materials and recognisable design features.

In a house of brands strategy, a company manages several brands, each with a unique design expression. That is, depending on how a company is organised, it can have either one large product portfolio managed by one design function across all brands or separate design functions managing each 
product portfolio individually. This design management strategy focuses on maintaining visual diversity and alignment between the different brands rather than adopting a communal "house style". For example, Unilever, which focuses on several categories of products, including beauty and personal care, food and refreshments, home care, and water purifiers, has several distinctive product lines in the ice-cream market, including Ben \& Jerry's, Magnum, and Cornetto (Unilever, 2020). As illustrated, a product line is a brand consisting of several closely related products and in many cases share the same design features with only slight variations. Keller et al. define a product line as 'a group of products within a product category that are closely related because they function in similar manner, are sold to the same customer groups, are marketed through the same type of outlets or fall within a given price range' (2012, p. 563).

Large and complex product portfolios impact other functions such as production and engineering design, creating a need for organisation and management of products and versions from their point of view. The engineering design literature employs a narrower definition of what binds a cluster of products (line or range), a product family (Simson et al., 2006, p. 29). Meyer and Lehnerd define a product family as a 'set of individual products that share common technology and address a related set of market applications' (1997, p. 39). This definition originates from the fact that engineering needs coherence within a product portfolio, stemming from an ambition to share functions, reduce the number of components, and build modules and platforms that can cater to different categories and product lines (ibid.; Simpson, 2004) to reduce costs, time to market, and development time (Ulrich et al., 2020). That is, a product family does not have to follow a product line or product category, which would create disparate managerial objectives. 


\subsection{Strategic design thinking in branded product portfolio}

In addition to aligning products within a branded-house portfolio, an industrial designer also has to make the product 'stand out from the crowd' (Kotler \& Rath, 1984) - i.e., a design should help consumers differentiate a company's products from its competitor's products. According to Person et al. (2007a, 2007b), Schoormans and Robben (1997), and Karjalainen and Snelders (2010), product design should create recognition for a brand in commercial markets, attracting consumers' attention to a company's products. Warell (2006) and Arvola et al. (2010) state that a product can create recognition mainly through perception, and this is based on the resemblance or similarity it invokes with regard to prior knowledge of the product and brand. Another way a company creates recognition is through design that differentiates itself from competitors (Karjalainen \& Snelders, 2010; Krippendorff, 1989). For example, a Lamborghini is a car, but it does not look or behave like a Volvo XC90, which is recognised as an SUV, not a sports car. This approach is closely aligned with concepts of iconicity through the use of iconic signs in the PPE model (Warell, 2008) and 'current product sign' (Monö, 1997, pp. 66-72).

Raymond Loewy (1951, 2002, p. 277-283), the first industrial designer to describe this balance between differentiation and recognition in a product segment, coined the phrase 'Most Advanced, Yet Acceptable' (MAYA). MAYA is a way to find the commercial "sweet spot" when developing a new product design. Keller et al. (2012, pp.112-127) demonstrate that the same considerations are relevant in the management of brands and their portfolios, a concept encompassed in the phrases 'Point of Difference' (POD) and 'Point of Parity' (POP). The concepts POD and POP imply that brands and their products need to be distinct from as well as similar to competitors' designs to attract consumers.

Keller et al. (2012, p. 112) define POD as 'strong, favourable and unique associations' that consumers relate to the product portfolio and the company brand that would not be found in a competing brand. Like Loewy's (1951, 2002) 'Most Advanced' concept, POD assumes a product has to be perceived as characteristically different (revolutionary) from its competitors. Keller et al. (2012, p. 126) also state that branding is developed by using a company's history and evolutionary product design to develop positive POD associations. 
A more common name for POD is design DNA. This metaphor refers to company's who have successfully built coherence and positive associations over time and who have developed a set of characteristics or traits that are "genetically" unique to a specific brand (Hestad, 2013; Person \& Snelders 2010; Warell, 2006; Karjalainen \& Snelders, 2010; Kapferer, 2014, p. 164). Person et al. describe this strategic development as creating a consistent and distinct brand image to 'facilitate recognition and [...] transfer beliefs that consumers have concerning one product to another falling under the same brand name' (2007b).

POP, on the other hand, is described as 'associations that may be shared with other brands' (Keller et al., 2012, p. 114). POP comes in two forms: Category POP and Competitive POP. Like Loewy's concept 'Yet Accepted', Category POP describes associations essential for a brand in order to create recognition against a category of similar products. For most companies, it can be just as important to belong to a strong category as it is to be perceived as unique (Monö, 1997; Kreuzbauer \& Malter, 2007; Goode et al., 2013; Kapferer, 2014; Paper I; Ranscombe et al., 2012). In competitive situations, POP can also be a way to 'defuse' rival PODs by creating similar brand associations in order for them to 'break even' (Keller et al., 2012, p. 114). For example, the leading smartphone brands now look and interact in very similar ways. This means that POD and POP are important strategies when industrial designers are developing the way in which they want consumers to perceive a company's brand through its products. 


\subsection{Design components}

Design components are the 'building blocks' that designers use when drawing attention to a product through sensory effects, imposing brand identity, and creating visual coherence throughout a portfolio (Hollins \& Pugh, 1990; Lewalski, 1988; Warell, 2006; Karjalainen \& Snelders, 2010; Ranscombe et al., 2012; Person et al., 2007b). A design component can be both explicit and implicit according to Karjalainen (2004) and Kapferer (2014, pp. 38-43) (Table 3).

Explicit design refers to the tangible components of a product that create the visual recognition of a brand and differentiate the product from its competitors. In this thesis, these components are called design elements. This definition shows a strong resemblance to Keller et al.'s (2012, p. 112) POD model. Researchers (Warell, 2002, 2006; Monö, 1997; Sanchez, 2002; Karjalainen \& Snelders, 2010) have recognised that designers work strategically with these features when they want to create coherence throughout a product portfolio. Sharing design elements across a portfolio tends to increase brand recognition and visual divergence from competitors. An explicit element has the intention of being immediately perceived as belonging to a specific brand, such as the kidney grille and the Hofmeister Kink on a BMW car. What Karjalainen (2004) and Kapferer (2014, pp. 38-43) do not address are the explicit elements connected to the Category POP or 'the current product sign' as described by Monö (1997, pp. 145-146). These types of explicit elements link the brand to a specific product category. For example, Jeep is categorised as a small SUV by EuroENCAP (2018), which is visually expressed in the design by having high ground clearance (Catalano et al., 2006) and a very square main form.

Implicit design refers to components that are unconsciously perceived, creating the overall feeling or 'gist' of a product (Krippendorff, 1989; Paper I). The importance of implicit design is reflected in BMW's design team's belief that '[e]ven small kids have to recognize a BMW' (Vihma, 2010, Karjalainen, p.184). Implicit design teams are called design features in this thesis. Because these types of features are harder to define, they are described more generally in the literature as they are emotionally- and behaviourally-driven features where the interpreters' prior knowledge plays an important role in decoding the features.

Table 1 shows a compilation of how the design research literature describes 
and systemises design features. The left-hand column is inspired by Hestad (2013, p.65) and the right-hand column consists of equivalent descriptions by other researchers.

Table 3. Design characteristics found in the literature from Paper I, Hestad (2013, p. 65);

Davis (1987); Bloch (1995); Kellaris and Kent (1993); Krippendorff (1989); Keller et al. (2012);

Klimchuck \& Krasovec (2012, p. 155).

\begin{tabular}{ll} 
Grouping & \multicolumn{1}{c}{ Explicit elements } \\
\hline Main form & Description \\
Details & Shape, silhouette, proportion, scale, pattern of organisation. \\
Finish & Lines, ornamentation. \\
Graphics & Reflectiveness, texture. \\
Colour & Logotype, graphical elements, symbols. \\
Materials & Associations triggered by different materials. \\
Graphical user interface & Many products have interfaces that consumers interact with. \\
\hline Implicit features \\
\hline Prouping & Description \\
Differentiation & The whole appearance of a product. \\
Brand story & What the product should not be associated with. \\
Emotional associations & The product's role in the brand and how to realise it. \\
Characteristic behaviour & How the product evokes emotions in consumers. \\
\hline
\end{tabular}

\subsection{Product modularisation and its impact on industrial design}

According to Starr (1965) and Miller and Elgård (1998), modularization is a way to handle the often-conflicting demands of mass customization: the need to create variety, use similarities, and reduce complexity in a manufacturer's portfolio of products. The commitment to modularize a company's product portfolio is a strategic decision made by senior management due to its impacts on the entire company (Sanchez and Collins, 2001). Modules have both physical elements and functional features (Ulrich et al., 2020; Sanchez, 2002; Miller \& Elgård, 1998; and Kusiak \& Huang, 1996). Physical elements are all the components, parts, and subassemblies that solve one or more functional needs. 
Functionality refers to how a product is operated and how it can transform or influence its surrounding. Ulrich (1995) and Sanchez (2004) even suggest that the design can be its own module and have aesthetic functions that are not measurable using engineering standards: 'While most functional elements involve the exchange of signals, materials, forces, and energy, some elements do not interact with other functional elements. An example of such an element might be harmonize aesthetically with vehicle.' (Ulrich, 1995).

According to Ulrich (1995), modularising of a product needs to be conducted in at least three phases. First, all functional elements need to be identified, arranged, and clustered into groups. Second, the functions and functiongroups need to be mapped with physical elements, creating modules. Finally, the way the interfaces are designed between the components and modules need to be specified. The specification of interfaces is important because it makes it possible to change one module without needing to change the whole product. All three phases are illustrated in Figure 10.

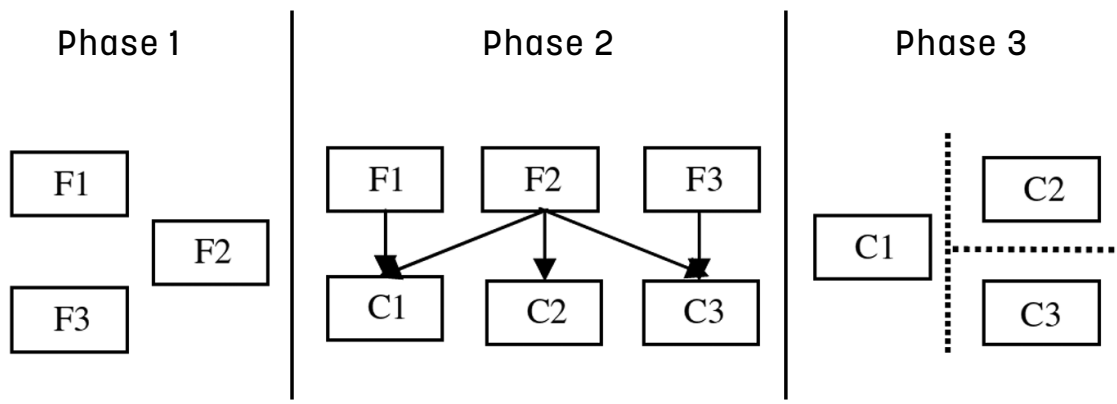

Figure 10. Person छ Åhström's (2006) interpretation of Ulrich's (1995) modularisation process: Phase 1 illustrates arrangement of functional elements, Phase 2 the mapping from functional elements to physical components, and Phase 3 the creation of interfaces between physical components. F1-F3 represent functions and $C 1 \neg-C 3$ represent components.

The decision to divide a product into modules and to determine interfaces between the modules is made for several reasons, ranging from manufacturing and usability to marketing benefits. Pauhl et al. (2007, p. 515) describes the goal of product modularization as less about creating modules than about creating the optimal amount of modularization connected to the defined objectives the product. Each module creates an interface that has to be defined as these interfaces affect initial costs and development time and can result in barriers 
to radical product changes. Ulrich et al. (2020) provide several examples of how to reason when deciding how to create modules:

- Parts of the product need to be upgraded before the product life-cycle ends.

- Parts will be added to the product.

- The product needs to be adapted to different market needs.

- Parts on the product will wear out before the whole.

- The product has parts that control consumption, e.g., printer cartridges.

- The product's use is flexible, e.g., interchangeable camera lenses.

All these reasons influence the industrial designer and promote the creation of aesthetic variations of a design or adding redesigned products to a portfolio. According to Miller and Elgård (1998), a product becomes truly modular when it is part of a product family that is systematically organised. These systems are named product architecture and product platform in product development literature. To separate the two systems, this thesis defines product architecture as the primary focus on the product and its versions. Product platform is defined as the sharing of modules and components within a product family.

\subsection{Product architecture}

A product architecture can be described as the blueprint, layout configuration, and topology of a product where functions embody physical elements, including set variants (i.e., versions) of the product (Sanchez and Mahoney, 1996; Jiao et al., 2007). That is, a product architecture not only describes the technical parts but also includes design elements and features the final product and its variants. According to Ulrich et al. (2020) and Erens and Verhulst (1997), product architecture can be either modular or integral. 


\subsubsection{Modular product design architecture}

Modular architecture has the following characteristics: modules have parts that can be changed (i.e., they are flexible); interfaces between modules are well defined; modules can be changed or upgraded without interfering with other modules; modules preferably have a one-to-one relationship between a function and component; and modules support the primary function of the product (Jose and Tollenaere, 2005). Sanchez (2002) identifies six interfaces or activities between design modules and components: attachment interfaces; spatial (volume) interfaces; transfer interfaces; control and communication interfaces; user interfaces; and environmental interfaces.

\section{Attachment interfaces}

The attachment interfaces between the modules and components can be slot, bus, or sectional, (Ulrich et al., 2020). In slot modularity, all interfaces are different so they cannot be interchanged. Bus modular architecture has a common bus (such as the motherboard in a computer or the platform a car is built upon) where different modules can be attached through a mutual interface. Sectional modularity is similar to bus modularity, but it does not have one component or module that acts as a platform.

\section{Spatial (volumetric) interfaces}

The space or volume a component or module occupies in a product is the result of the interface modularization decisions made in Phase 3 of the modularisation (Figure 9) in combination with design element decisions (Table 3). These decisions create fixed volumes that a designer needs to relate to when creating a new design as these decisions dictate the proportions and the gist, or gestalt, of the final product (Figure 13).

\section{Transfer interfaces}

What goes into a module and what is transformed into another output (e.g., an electric motor where electricity is converted to motion) is defined by the transfer interface.

\section{Control and communication interfaces}

How components and modules communicate with each other to accomplish a task or function is described by the control and communication interface (e.g., 
the communication between rain sensors and the whippers on a car).

\section{User interfaces}

User interfaces describe the way a user interacts with the product or module to achieve a goal or task (e.g., the human interaction between the keys on a keyboard and the computer).

\section{Environmental interfaces}

Environmental interfaces refer to how each component in a product will interact with the intended ambient environment and how they may interact with each other in unintended ways. (e.g., the environmental interface between Italian-designed trams (model M32) in Gothenburg and the accumulation of hoarfrost on powerlines, which interferes with the operation of the trams) (Göteborgs-Posten, 2021).

\subsubsection{Integral product architecture}

An integral or integrated product architecture has a fixed architecture aimed at optimising product performance, where changes of one component inevitably interfere with other components. The design has multifaceted interactions between functions and components (Jose and Tollenaere, 2005). In reality, many products use both modular and integral architectures, resulting in a mixed system (Pahl et al., 2007, pp. 496-7).

\subsubsection{Branded product architecture}

According to Sudjianto and Otto (2001), there are two viewpoints on how to construct a modular product brand identity: the atomistic view and the gestalt view. The atomistic view can be compared to modularity as its designed components have a one-to-one coherence with brand identity. That is, a consumer can identify the brand through a single design component.

The gestalt view, on the other hand, describes the opposite: all designed components have to be integrated to create a brand identity. As Pahl et al. (2007, pp. 496-7) conclude, many technical product architectures that are mixed are modular designs. Sudjianto and Otto divide design components into 
three types: brand-platform, brand-specific, and does-not-matter components: 'neither part of a dominant theme nor part of a brand signature (i.e. design element) may be communized into a product platform' (2001). Brand-specific components are carriers of design elements and features that connect the product to the brand. These can be shared across a product architecture and platform to transfer visual brand identity.

The does-not-matter components are not important for brand differentiation and should be turned into a brand-platform or brand-specific component. A second option is to place the does-not-matter components in a concealed position such as the undercarriage of a car.

Sanchez (2002) concludes, in his paper 'Using modularity to manage the interactions of technical and industrial design', that industrial designers are both influenced and contribute to the strategic partitioning of components and modules in a product architecture (Figure 12).

The composition of modules and components create spatial interfaces that an industrial designer has to comply with while simultaneously create design concepts that "bundle" these and aid in the strategic partitioning of products. Sanchez (2002) describes how Philips, in the product Mistral 2000 (Figure 11), separates varying (brand-platform and brand-specific) and common (doesnot-matter) components into their irons (Figure 12).

The varying components are unique to each iron brand variant while the common components are shared across all irons (Figure 12). In effect, by separating the designed from the non-designed parts, Philips created several product variants that adhere to different market needs without increasing cost and development time very much.

Similarly, Sony used modularisation strategies in its portable music player, the Walkman. Between 1980-91 the developer managed, through a consistent use of modular architecture and product platforms, to design over 260 versions of the Walkman, ultimately dominating the product segment (Sanderson and Uzmeri, 1995). 


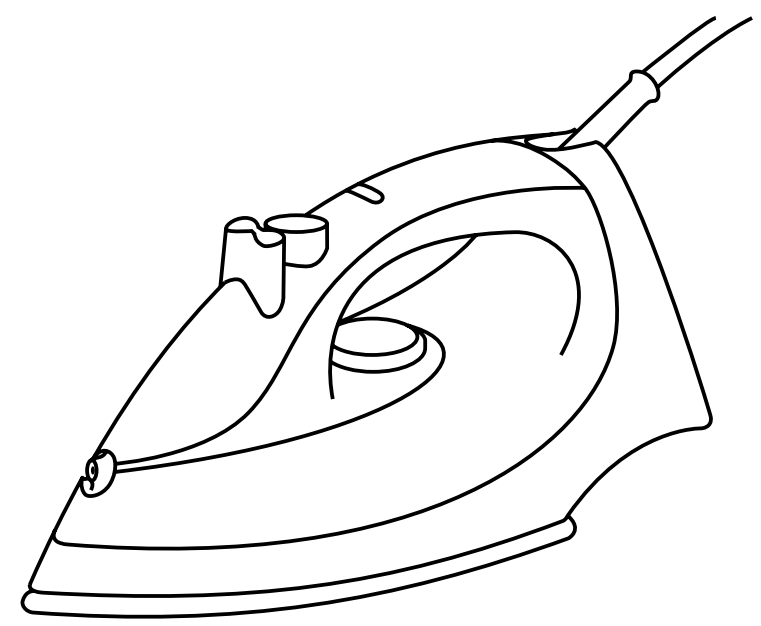

Figure 11. Illustration of Philips Mistral 2000 iron.

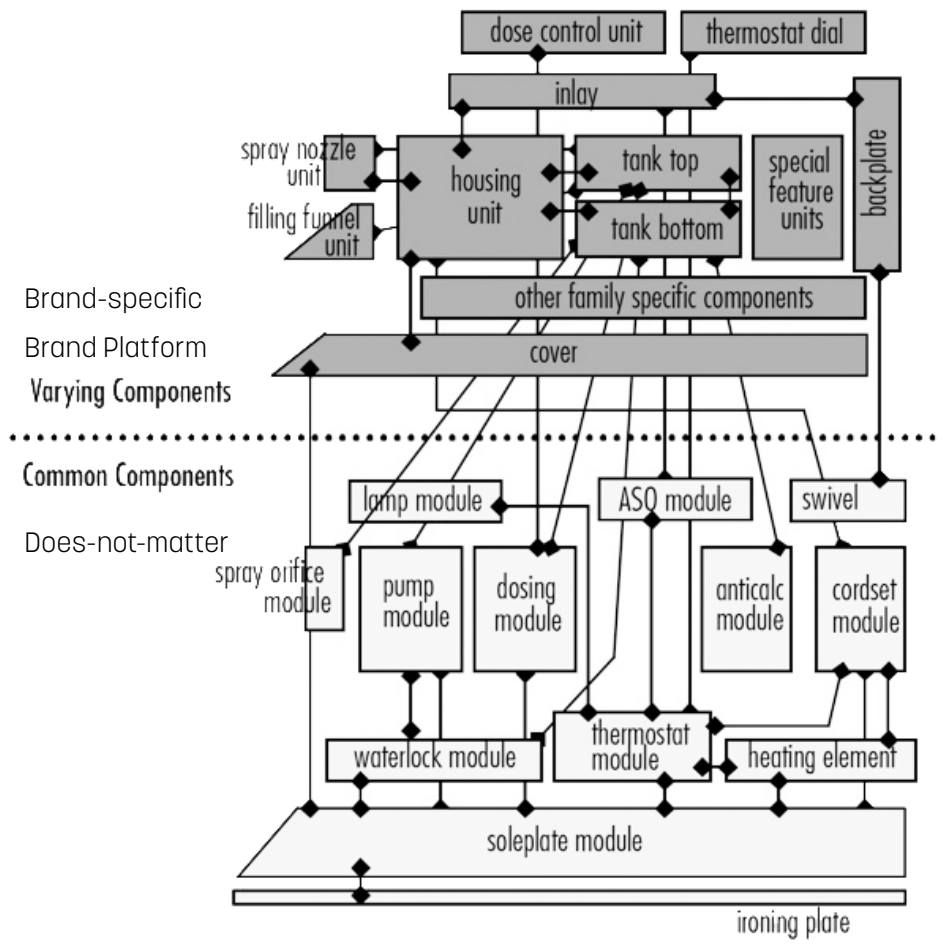

Figure 12. Sanchez (2002) strategic partitioning of modular architecture for Philips Elance and Mistral iron product lines including Sudjianto and Otto's (2001) division of design components. 


\subsection{Product platforms}

Product platform is the organisation and sharing of modules and components between existing product architectures within a product family and aids in the development of new and derivate products (Robertson and Ulrich, 1998). For a product platform to be efficient, it needs to contain design rules that direct the development of shared modules (Baldwin and Clarks, 2000). The design rules should consist of modular architecture, interface strategy, and standardisation of integral parts.

Jiao et al. (2007) conclude that there are two prevailing ideas associated with product platforms. One refers to platforms as a physical collection of modules and components shared by several products. In the automotive industry, these communal modules and components are even named "the platform" and are used across several brands within the global company. The second stems from Meyer and Lehnerd's definition of product platforms as 'a set of subsystems and interfaces developed to form a common structure from which a stream of derivative products can be efficiently developed and produced' (1997, p. 39) (Figure 13). That is, a product platform is governed by a shared logic and communal architecture (Jiao et al., 2007).

Meyer and Lehnerd (1997) conclude that the organisation and development of product platforms are strategic processes that ultimately are governed by senior management. In their book The Power of Product Platforms (1997), they connect market segment matrix strategies (Proctor and Kitchen, 1990) to product family strategies (Meyer and Utterback, 1992) as a means to strategically direct the development of products.

Both these ideas can be found in the development of modular product design. The first idea can be connected to the industrial designer's goal to develop design modules and components that are interchangeable within a product portfolio.

The second idea adheres to the development of a design strategy that incorporates the company's design DNA (i.e., common structure), which govern the development of new products and derivates. That is, all design interfaces of brand-specific and brand-platform modules and components may need to be coordinated within the entire product portfolio while simultaneously adhering to a company's design DNA. Not all designed products in a product portfolio are equally valuable to a company as even high-cost product segments can be 
positioned within a hierarchy. These high-value products are usually named hero products and need special attention. Therefore, in the organisation of product platforms, an industrial designer can contribute to how much designed modules and components hero products should share with other platform products (Sanchez, 2002).

\section{Market Segmentation Grid}

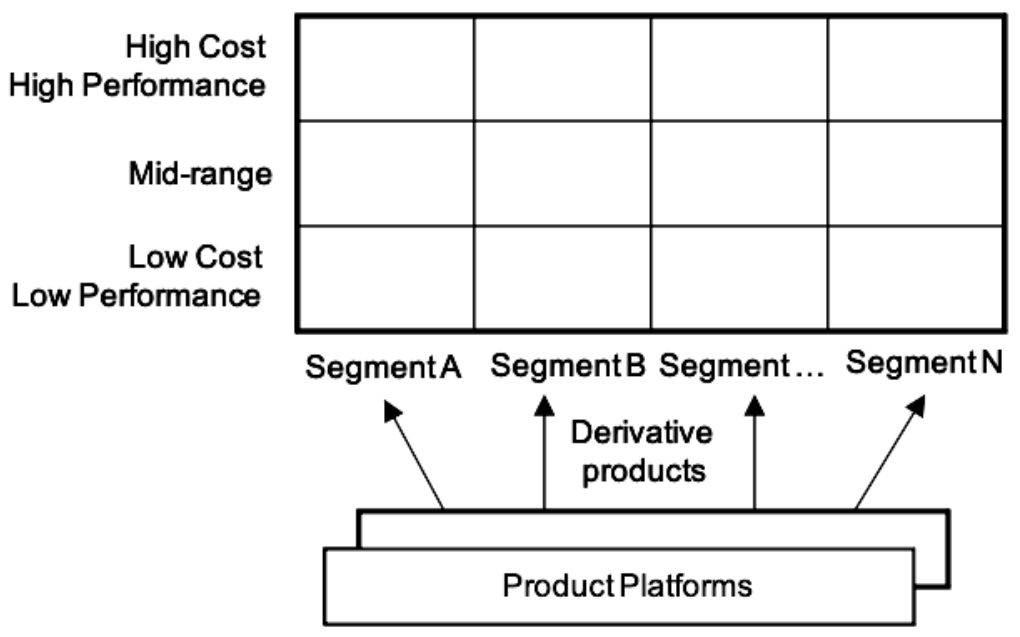

Figure 13. Meyer and Lehnerd's (1997) model of product platform management depicts the merge of GEC-McKinsey's market segmentation matrix (Proctor and Kitchen, 1990) and product family development (Meyer and Utterback, 1992). 


\subsection{The development of strategic industrial design functions in manufacturing companies}

In the early 20th century, General Motors (GM) developed the first strategic in-house design group. The president of General Motors, Alfred P. Sloan, hired Harvey Earl in 1927 to set up and lead a new GM corporate function - The Art and Colour Section. Sloan realised that the new function needed protection from the traditional automotive body engineers and coach builders and made the new function part of the corporation's general staff organisation, with Earl in an advisory function. This strategy gave the new function legitimacy and independence within the organisation without disrupting other corporate functions. When the first strategic design function was fully developed, it was organised with a small team led by Earl, which made strategic design decisions for all GM brands that trickled down to smaller design studios responsible for specific GM car brands (Gartman, 1994; Clarke, 1999). Recently, the function of strategic design in corporate organisations has become more multifaceted than just being a group of creative specialist; these employees are now process leaders - key interpreters of user data and mediators between functions (Tovey, 1997; Giannini et al., 2006; Buxton, 2007; Johansson and Holm-Svengren, 2008; Verganti, 2009; Stompff and Smulder, 2013).

Recently, companies such as Johnson \& Johnson, Philips, and Apple have appointed chief designers to their boards, known as Chief Design Officers (CDO). CDO assist with the development of competitive product portfolios. Industrial design is often used as a strategic tool to create new and often innovative products aimed at achieving recognition (i.e., unique designs) and coherence (i.e., similarity within a branded product portfolio). That is, industrial designers cooperate with several functions ( $R \& D$, marketing, brand management, production, etc.) within a company to consolidate different requirements of portfolio products.

Micheli et al. conclude that modern companies and organisations can elevate design function from functional operations to strategic operations by changing the designer's scope so they can 'influence decisions and set direction over issues that affect the long-term sustainability and competitiveness of an organization, such as development of and communication of a brand's core 
values, positioning, and creation of new markets' (2018). That is, design teams should be given the power to make strategic decisions. This responsibility requires the following conditions:

- Senior management needs to clearly express how the organisation will benefit from design and, gradually, grant autonomy to the design function.

- The design function should state how it will contribute to the organisation.

- The organisation should be modified so that it can carefully balance formalisation and flexibility.

- Designers need the authority to join cross-functional teams to advocate for design.

\subsection{Decision making theory - the dual design decision process}

The dual process was first suggested by the researchers Wason and Evans (1974) as a means to describe a finding where the solution of a problem occurs intuitively and then is consciously rationalised after the insight. Their conclusion was that the respondent's assessments could be divided into two processes: one fast intuitive system and a second slower reflective system. The process is now a broadly accepted theory by judgment and decision-making researchers (Sloman 1996; Stanovich and West, 2000; Kahneman and Fredrick, 2002; Evans, 2008; Stanovich, 2011; Evans and Stanovich, 2013). Hodgkinson et al. (2008) investigated how well social cognitive neuroscience corresponded with the dual system and found that cognitive, affective and somatic mechanisms all supported the system. It became widely communicated to the general public by the Noble prize laureate Daniel Kahneman (2011) in the book Thinking Fast and Slow, where he described the dual process and the heuristic bias that can occur between the two during a decision. The two components of the dual process were first named System 1 and System 2 by Stanovich (1999). As the interest in research on the dual-system theory increased, so did the criticism. The lack of coherence and constancy of the proposed attributes of system 1 and system 2 created a need for clarification. Evans and Stanovich 
(2013) responded to the critique of the dual process, clarified the attributes and redefined them as type 1 and type 2 . There were many reasons behind this change, but a prominent one was that it would allow for a wider interpretation of how the two types interacted with each other than the notion of two parallel systems. The attributes of the two types build on the original ideas of system 1 and 2. They describe them as:

Type 1 is an intuitive process that 'does not require working memory' and functions autonomously. It is an information process that in evolutionary terms is older in the human brain and is referred to as follows: fast, high capacity, parallel processes, nonconscious, holistic evaluation, needs contextualised information, responds automatically, creates associations and uses experienced-based decision making. The type is described as being less cognitively taxing, found in most animals, utilises more basic emotions and implicit knowledge.

Type 2 is a more mentally stimulating process that 'requires working memory'. The cognitive process evolved late and is seen as a distinctively human practice. It can create a cognitive decoupling - i.e., an abstract mental model that can be used to solve a problem. The type can be described as a slower analytic process that utilises serial processes, makes greater demands on cognitive resources and complex emotions, doesn't rely on context, and where one uses rational, explicit knowledge and rule-based ways of making decisions.

In unity with Kahneman (Kahneman, 2011; Kahneman and Frederick, 2002), Evans and Stanovich (Ibid) conclude that the dual process is a defaultinterventionist process, meaning that the premier response to a task or problem is first tested in the quicker type 1 process. There the judgment is made as to whether an automated response can be utilised or whether it needs to involve type 2 thinking. This is due to type 2 being more cognitively taxing and the human wanting to preserve its options, thus preferring to utilise type 1 (Evans and Stanovich, 2013; Kahneman, 2011). Furthermore, Evans and Stanovich (2013) conclude that bias can occur in both types, disrupting the notion that type 2 thinking is preferable for avoiding bias.

In recent years, researchers have challenged the dual default interventionist process by proposing a three-stage model within the dual process (Pennycook 
et Al., 2015, Pennycook 2017; Swan et al., 2018; Bago and Neys 2020; Neys and Pennycook 2019). They propose that the judgment process between type 1 and type 2 is actually its own step that exists within the type 1 process. The first stage is a purely type 1 process, stage two occurs in parallel with the first stage and is a "conflict monitoring/detection stage" that, if it is triggered, enters stage three and type 2 . This indicates that one can make either an intuitive decision (type 1) or a hybrid decision where both type 1 and the rational type 2 are involved.

These two types of decision practices, an intuitive and a hybrid process, are in line with what Nelson and Stolterman (2002, 2014) and Dane and Pratt (2009) describe as an intuitive design judgment (type 1 ) and a more multidimensional design decision process described by Michlewski (2008), Baxton (2007), Del Coats (2003), and Allen and Thomas (2011), where both type 1 and type 2 processes are involved in the decision making.

\subsubsection{Design judgment}

Nelson and Stolterman (2002, 2014) and Dane and Pratt (2009) describe the design decision process as a judgment process where designers draw from their prior experience and combine it with their creative intuition to holistically determine design decisions in relation to specific company products. It is a decision-making process that is built on intuitive processes, where the experience of the participants and the context and the type of problem are part of the foundation. The shared conclusion amongst intuition researchers is that intuitive decision making, or intuition, falls under type 1 (Dane and Pratt, 2009; Epstein, 2008; Hogskinson et al. 2008; Salas et al., 2010; Hogarth, 2010: Stanovich and West, 2000; Kahneman and Fredrick, 2002; Evans, 2007; Stanovich, 2011; Evans and Stanovich, 2013). In addition, these researchers believe that intuitive decision processes are affective and that it is for most part a rapid process.

Dane and Pratt (2009) found that intuition could be separated into three types: problem-solving, moral and creative intuition. Problem-solving intuition relies heavily on 'pattern matching' or heuristics, where an expert has trained to execute a process when he/she recognises a situation (Tversky and Kahneman 1974; Kahneman, 2011). Moral intuition stems from social intuition research (Haidt, 2007), and focuses on ethical dilemmas where the 
respondents have to make subconscious decisions and where the results are appraised through cultural biases, customs and interpretations (Hadit and Kesebir, 2008). Creative intuition on the other hand has similarities with problem-solving in the sense that creative experts, for instance industrial designers, develop heuristics that they then use in their decision process. Schön (1987) describes this type 1 process as a reflection-in-action, where the subconscious mind is used not only for temporary intuitive decisions but also as a continuous pondering action to solve problems and explore new possibilities. In addition, it is described as relying on affective processes where the person who makes the judgment has an emotional and even a physical reaction that it "just felt right" (Hayashi, 2001, p. 60; Durling 1999; Nelson and Stolterman 2014; Michlewski, 2008). This emotion can instantly be intuitively valued as "good", or preferably render a "wow" appraisal (Tovey, 1992; Shusterman 1997; Desmet et al., 2007: Millard, 2006; Hudson and Viswanadha, 2009; Palmer et al., 2013):

"I say that the search for the miraculous is the best part of being in the creative arts. What you really want is not functionally 'oh that works', you want something where somebody looks at it and says 'wow'."

- Milton Glaser, 2017

Dane and Pratt's (2009) definition of creative intuition correlates well with how professionals and design researchers describe intuition as part of a design judgment process where the outcome cannot be rationally explained or verified, and as a necessary part of creating new products or forecasting future trends (Blaszczyk and Wubs, 2018; Coates, 2003; Cross 2001; Tovey 1992; Schön, 1987; Michlewski, 2008). Exceptional designers are often skilled and attuned to the importance and nuance of good design judgment that surpasses the company brands they are working with, - e.g.,. Harley Earl, Raymond Loewy, Dieter Rams, Jonathan Ives, and Phillipe Starck (Nelson and Stolterman, 2002; Gartman, 1994; Coates, 2003).

In summary, design judgment is primarily a fast process (type 1) where experienced practitioners make an appraised decision that, at the time, cannot be explained or verified. It is a holistic evaluation process where the focus lies in the synthesis of a range of factors, creating a decision applicable in the future to render a "wow" reaction. 


\subsubsection{Multidimensional design decision}

The use of multidimensional in the description of this hybrid design decision process originates from an article written by the management and organisation researcher Michlewski (2008). In 2005, Michlewski conducted an exploratory interview study with design managers, senior designers, and consultants from four different companies that used a strategic design team. Two of the four companies were manufacturing companies and the other two were design consultant companies. He conducted 15 interviews focused on the design attitudes that could be found within the design cultures of the four companies. Michlewski found that one practice the designers described was to "consolidate multidimensional meanings'. With this label he meant that by combining "art" and "science" a designer integrated all the "technical, financial, operational and emotional pieces together' (2008).

Other researchers concur with this description and add that employed industrial designers cooperate with non-designers (e.g., engineers, managers, and marketing people) during development and decision-making processes in projects (Ulrich et al., 2020 pp. 154-5; Lawson and Dorst, 2009; Cross 2003; Del Coates 2006; Buxton 2007). In line with Michlewski (2008), they even state that the merging of intuitive emotional design judgments with rational information and measurable data is a responsibility of the industrial design function. In their article on A Dual Process Account of Creative Thinking, Allen and Thomas (2011) examine how the process of creative thinkers is influenced by the dual process. They argue that both type 1 and type 2 thinking are used in all stages of a creative thinking process, especially during long creative projects where 'one moves between the stages of creative thinking, altering between Type 1 and Type 2 thinking.'

A similar argument is presented by Kannengiesser and Gero (2018), who note that many dual-process studies (e.g., Kahneman, 2011; Kahneman and Frederick, 2002; Pennycook et al, 2015) take less than a few seconds, sometimes even milliseconds, to complete. This short time span is far from a regular design assignment at a university, let alone a professional industrial design project that may span over several years. Kannengiesser and Gero (2018) and Evans and Stanovich (2013) state that they have found several theoretical and empirical studies demonstrating that intuitive design judgments (i.e., type 1) play a role in these types of slower decision processes. Experiments by Dijksterhuis et al. (2006) and Dijksterhuis and Nordgren (2006) found that by 
delaying the decisions until the next day (i.e., letting the participants sleep on them) could improve unconscious processes. Similarly, Atkinson and Claxton (2000, pp. 39-40) found that creative scientists use slow reflective intuitive processes when processing data and extracting results.

In summary, a multidimensional design decision is a mentally stimulating process where both type 1 and type 2 thinking are used in the decision-making process. Multidimensional design is a slow process requiring compromises between emotional needs, aesthetic needs, and rational information. This theory is relevant for understanding the findings made in Perspective 3. For further reading, see Paper VI.

\subsection{Three Perspectives on correlation to the theory}

The described theory has been used in different ways throughout this thesis to evolve the three Perspectives and when the findings are discussed in chapter 6. Perspective 1 and Perspective 2 are primarily discussed in $4.1-4.6$ and Perspective 3 is primarily discussed in 4.7- 4.8.2. A matrix (Table 4) was constructed to illustrate how the different theoretical areas correlate with each of the three Perspectives.

Table 4. The theory's connection to the three Perspectives and discussion.

\begin{tabular}{l}
\hline \\
$\begin{array}{l}\text { 4.1 Branded product portfolios } \\
\text { 4.2 Strategic design thinking in branded product portfolio }\end{array}$ \\
4.3 Design components \\
4.4 Product modularization and its impact on industrial design \\
4.5 Product architecture \\
4.5.1 Modular product design architecture \\
4.5.2 Integral product architecture \\
4.5.3 Branded product architecture \\
4.6 product platforms \\
4.7 The development of strategic industrial design functions in \\
manufacturing companies
\end{tabular}




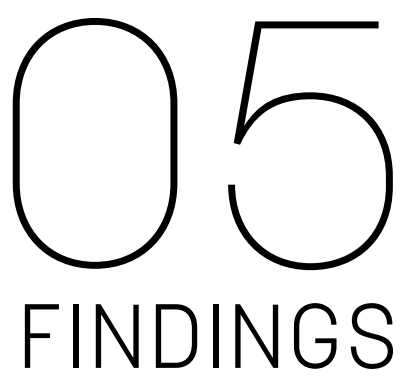

This chapter presents research conducted using the three perspectives, each aimed at answering a single research question. The three perspectives, presented in order, contain findings from the conducted empirical and theoretical studies. On a general note, industrial design, product modularity, branding, and decision-making within a manufacturing company influences industrial design practice. Furthermore, the findings made in the studies are summarised and presented at the end of each perspective.

\subsection{Perspective 1 - The influence of product modularity and branding on the Industrial design practice}

The research conducted in Perspective 1 (Figure 4) was designed as a series of three studies and literature reviews, which are presented as follows: a method development called Product Gist, Case study A (an investigation of aesthetic flexibility), and the carry-over workshop (an investigation of whether design students use aesthetic flexibility). For further reading on these studies, see Papers I, II, and III. 


\subsubsection{Method development - Product gist}

This first study explores how competing products influence a new design when a company is expanding its product portfolio into a new category of products to create an affinity with that category. The result of this study is presented in Paper I. Understanding what creates affinity with a product category is one half of the design practice MAYA (Loewy, 1955:2000) and an important concept in branding (Keller et al., 2014). When developing this affinity, the designer needs to explore what design features create coherence or Point of Parity (POP) within the category in question. Previous studies such as Warell (2001; 2006), Karjalainen and Snelder (2010), and Ranscombe et al. (2012) have shown how companies develop design features and how these features create visual coherence within a product portfolio, but these studies do not show how these features generate affinity with a product category. However, Kreuzbauer and Malter (2005) investigate how existing category design features can be used to expand a product brand into a new category, although they do not show how they created or found the existing category features.

Oliva Torralba (2006) hypothesises that because the brain maps visual information from its surroundings, visual examples can be used to create an analysis method to investigate commonalities in products that uncovers features related to a category. An analysis method was developed by examining overlay photographs made by Dana K. (alias in Paper I) and Oliva and Torralba (2006). Their results were developed into visual analysis method focusing on the investigation of products originating from a category. The new method's process (e.g., a generic step-by-step procedure) was documented and tested, and is further described in Paper I.

Results from testing the analysis method (named Product Gist) suggest that visual information that is related to a product category is detectable and that the information can be subjected to empirical analysis. Figure 14- nine side views of battery-powered drills - shows the outcome of the test. All the products share similar product architectures: the same modular battery-pack below a handle with the motor and chuck above the grip.

Four ways of manipulating and overlaying photographs were explored. The first photograph in Figure 14 is of photographs of the drills; they show the main shapes, design details, colour schemes, and graphics. 

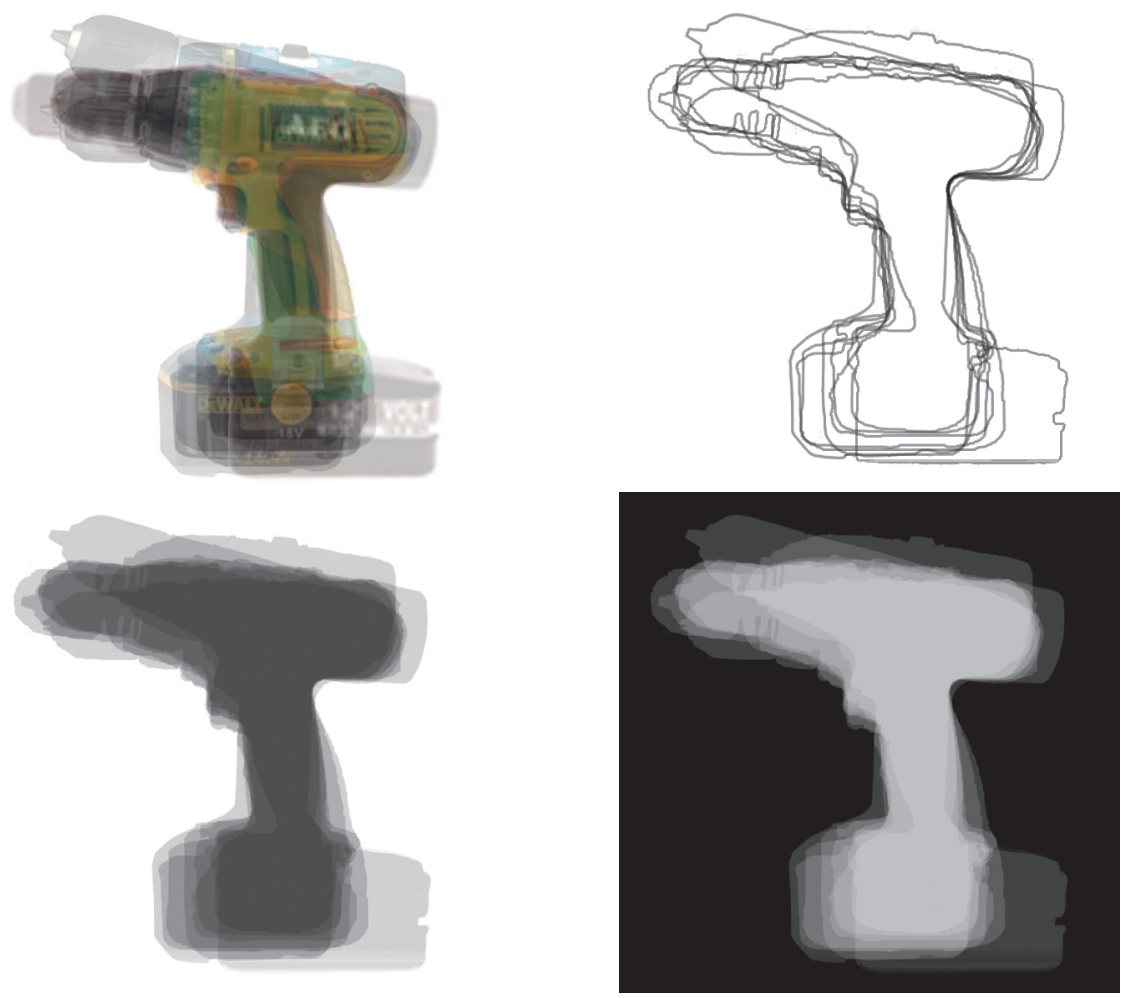

Figure 14. Four overlaid photographs of nine power drills that were outcomes of the test. The first figure shows overlaid opaque photographs, the second shows overlaid outlines, and the third and fourth show overlaid silhouettes.

The overlaid photograph indicates some commonalities in the schemes such as dark colour on the battery pack and chuck. Before overlaying the photographs, their opacity was reduced to make them more or less transparent. The remaining three photographs in Figure 14 used the products' outlines to focus on the general form and product layout. The second photographs from the left (the line-art illustration) contains the most explicit visual information of the four images. General silhouettes of the current product sign ${ }^{3}$ (Monö, 1997) protrude clearly in the second illustration, and at the same time two of the products' designs stand out from the rest. Therefore, the method can also be used for analysis if products distinguish themselves from the total number of investigated products in a selection.

\footnotetext{
${ }^{3}$ Monö (1997) describes current product sign as: how the market currently perceives a specific product category.
} 
That is, the analysis method reveals that the designers rely on the POP of a product category and in some cases had a higher level of visual differentiation in the product brand. For a more detailed description, see Paper I.

\subsubsection{Case study A - Aesthetic flexibility: a design strategy to cope with modular-platform brands}

Results from an initial literature review, as depicted in Perspective 1 (Figure 4) and in Paper I, indicated that designers need to consider features and design elements originating not only within the company but also from competitors when they create a new design. The literature review revealed several important aspects that influence the creation of new design elements: the design history of a company (or design DNA); the structure of the current product portfolio; the design features that create coherence within a product category; and the correlation between a new design and a company's existing brand values (Monö, 1997; Kreuzbauer \& Malter, 2007; Goode et al., 2013; Hestad, 2013; Person \& Snelders 2010; Warell, 2006; Karjalainen \& Snelders, 2010; Kapferer, 2014). Case study A was designed to investigate how professional designers viewed these aspects and whether more design-related aspects could be identified. The study was based on a hypothesis that a company's development process, product type, and product portfolio assembly would influence how designers make decisions (Baxton, 2007; Del Coats, 2003; Paper VI).

In Case study A, interviews were conducted with the chief designer, surface designers, and a senior engineer at a manufacturing company in Sweden (Table 2). The interviews revealed that the chief designer was involved throughout the whole development process, both as a developer of new designs and as a supervisor who made sure that the designs were followed through in the remaining development process. Results derived from how designs were developed and led to the conclusion that the designer used, or was inspired by, old design features deemed to be part of the product's heritage (i.e., design DNA). New design features were created, and visual coherence as regards to both the product portfolio and the product lines were incorporated into the new designs.

A key finding from the study was that the designer used more complex design practice strategies than had previously been described in design literature. 
It can be concluded that strategic design, as Micheli et al. (2018) describe it, is primarily the result of a company's development process. The studied company used branded product architecture strategies, as described by Sudjianto and Otto (2001) and Sanchez (2002), to expand and develop its portfolio. For example, designed modules and parts were shared across the portfolio, a strategy that affected the design of the products. The interfaces between modules created spatial divisions in the designs, and in some cases designed modules that had become brand-specific were given their own designs. Brandplatform parts and design-specific modules could then be shared across the portfolio or be reused in new products. The study revealed three key findings.

First, designers and product managers decided and planned what brand-platform parts and modules were to be reused from out-of-date products or reused from existing product lines. Therefore, designers needed to think about how the reused modules would influence and be incorporated into a new design.

Second, designers needed to be visually flexible when creating new brand-specific parts to facilitate spatial design changes at a later stage, a consideration that generated quicker design updates without the need to redesign the whole product.

Third, due to the diversity and size of the company's product portfolio, some brand-platform modules were created to be reused in several products in order to lower the total number of units.

These findings showed that brand platform designs and complex products create the basis for a phenomenon where designers have to consider not only present and future design opportunities but also how to implement a visual design strategy across a portfolio, a phenomenon called aesthetic flexibility. Aesthetic flexibility is a design strategy that considers and allows for change in current and future design variations of the product. The concept is further elaborated on in Paper III. 


\subsubsection{Carry-over Workshop - Evaluating an aspect of aesthetic flexibility}

The third study was constructed to investigate how some of the findings from Case study A influenced the strategic practices of industrial designers. The focus was on findings that show that the reuse of brand-platform modules and parts (Sudjianto and Otto, 200; Sanchez, 2002) in new designs influence the design process. The idea was to create a design workshop that emulated a redesign process in an in-house design function (Gartman, 1994; Tovey, 1997; Micheli et al., 2018). The design workshop - "Carry-over Workshop" was organised to further investigate the second aspect revealed in Case study A - i.e., how re-using brand-platform modules visually influence the design of a new product. The participants were tasked with redesigning an electric toothbrush consisting of three brand-platform modules - the brush-head, the handle, and the charging station. The workshop was divided into two phases to simulate a carry-over process, where one part from the first phase was reused in the second phase. These conditions were explained to the participants at the beginning of the workshop. We hypothesised that these conditions would allow participants to plan their designs during the study. This arrangement meant we could follow the strategic design decisions in the studies and corollate these decisions to the collected data.

The workshop included second year industrial design students from Konstfack (2020) and design researchers with no practical design experience. I hypothesised that if these novice participants finished the workshop as intended and adhered to some form of planning for changes in their design process, then this would indicate whether aesthetic flexibility is a natural part of the design decision-making process or if it needs to be consciously planned and experienced. Table 5 shows some of the findings from the workshop. Although eight participants chose to reuse one part of the design from phase one, five did not redesign their concept in phase two - they either continued refining their design from phase one or created new designs. These participants were marked in the table as 'No Choice'.

More than half of the participants chose the toothbrush (TB) head as the carry-over detail and redesigned the toothbrush handle in phase two (Figure 15). One participant chose to redesign the button panel on the toothbrush 
handle rather than the whole module. Because this was only a part of a module, the concept was marked with an asterisk in the TB handle column.

Table 5. The table show what modules the participants chose to redesign in phase two of the workshop. TB-head stands for toothbrush head and TB-handle stands for toothbrush handle.

\begin{tabular}{|c|c|c|c|c|}
\hline Particip. No. & TB - head & TB - handle & Charging station & No choice \\
\hline $\mathbf{1}$ & & - & & \\
\hline 2 & $\bullet$ & & & \\
\hline 3 & & & & $\bullet$ \\
\hline 4 & & & & $\bullet$ \\
\hline 5 & & & & - \\
\hline 6 & & & & $\bullet$ \\
\hline 7 & & $\bullet$ & & \\
\hline 9 & $\bullet$ & & & \\
\hline 10 & $\bullet$ & & & \\
\hline 12 & & & & $\bullet$ \\
\hline 14 & $\bullet$ & & & \\
\hline 16 & & & $\bullet$ & \\
\hline 19 & & $*$ & & \\
\hline
\end{tabular}

Fieldnotes, photographs, and design diaries revealed that there were two main directions of thought among the eight participants who performed the redesign task: unplanned and partially planned. Unplanned reflected the participants initial decision not to reuse a part in the second phase. Comments like 'I'll deal with that later' or 'it's important to let go of the past' were interpreted as signs that those participants did not plan their designs for reuse in phase two. This attitude could also be traced in their design proposals from phase one; the designs had protruding transfer features (Sanchez, 2002) such as non-generic major forms with grooves, ridges, and spherical shapes on the connecting modular surfaces. These forms were considered to constrain the respondents redesign process by directing them to follow prior designs, narrowing their possibilities expand to more diverse forms.

Partially planned design thinking was traced indirectly in the participants' designs. Their designs had fewer protruding transfer features across the modules, and by making spatial interfaces (Sanchez, 2002) flat, circular, and generically shaped, they had more options to create variations in the forms in phase two. 
The results from the workshop indicated that the understanding of aspect two of aesthetic flexibility is not strong among participants as only eight of the thirteen participants fulfilled the workshop as intended and several had no clear strategy for dealing with this challenge in phase two. This finding suggests that the participants had not previously been exposed to the task of partly redesigning a product, indicating that aesthetic flexibility may be part of the professional industrial designer's practice rather than part of design school curricula. A further discussion of the results from the study is presented in Paper II.

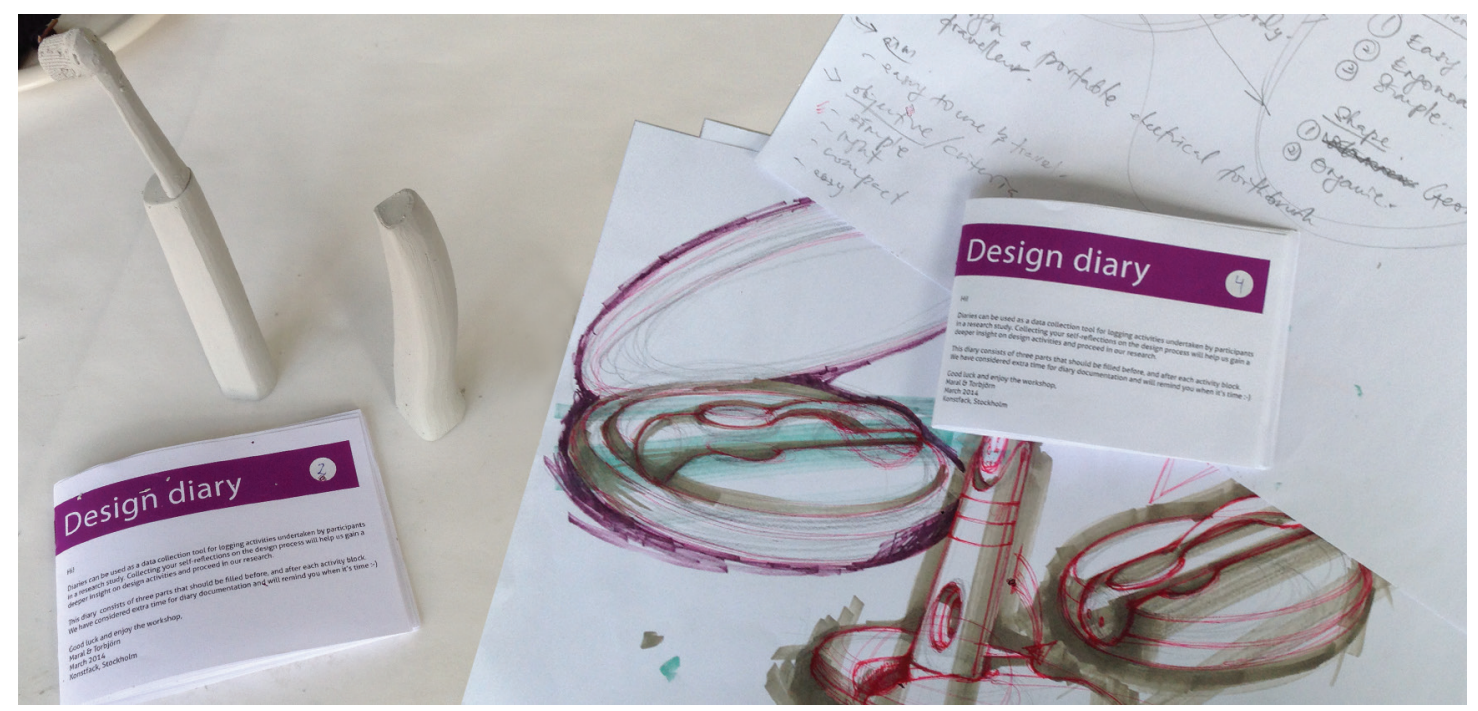

Figure 15. Results from the design workshop. The photograph show sketches and clay models. The modelling clay is called TecClay and comes from the company Kolb Design Technology GmbH छ Co. KG. 


\subsubsection{Summary of findings in Perspective 1}

The conducted literature reviews conclude that industrial designers need to create a consistent visual recognition of a brand so potential customers can rapidly identify the brand (Loewy, 1951, 2002, p. 277-283; Monö, 1997, pp. 66-72; Warell, 2008; Karjalainen \& Snelders, 2010; Keller et al., 2012, pp. 112-127; Kapferer, 2014). Simultaneously, industrial designers need to create new designs that are distinct from both competitors' products and existing products in the company's portfolio so customers will view the company's products as new, relevant, and desirable (Hestad, 2013 Warell, 2008; Karjalainen \& Snelders, 2010; Keller et al., 2012, pp.112-127; Kapferer, 2014).

The first study investigated if this ambivalence could be evaluated through abductive measures. The preliminary results corroborate the notion that the branding ideas of POP and POD (Keller et al., 2012, pp. 112-127) together with the industrial design concept of MAYA influence (Loewy 1951, 2002, pp. 277283) design practice. The finding that in Case study A the participants relied on aesthetic flexibility implies that brand platform modularity plays a crucial role not only at the operative product level but also at the design strategic level. The sharing of designed parts across brand platforms in a portfolio reduces cost as well as development time. Simultaneously, a product can be seen as desirable as a result of visual recognition of a brand (Warell 2008; Karjalainen \& Snelders, 2010). For more, see Andersson 2016 and Paper III.

The last study, the carry-over workshop, inductively inferred that aesthetic flexibility is an industrial design practice found among professional designers and presumably this concept is not taught in design schools. For more, see Paper II. 


\subsection{Perspective 2 - Industrial design product portfolio development}

Aesthetic flexibility found in Case study A and the literature reviews within Perspective 1 (Figure 5) suggests designers' strategic decision-making processes while developing products in a portfolio have not been investigated. That is, the same conditions that influenced the individual designer's practice simultaneously influenced management's strategic planning and advancement of a company's product portfolio. This generated the second research question: How does industrial design in a manufacturing company foster strategic decision-making when participating in the management of a company's existing product portfolio?

The research conducted in Perspective 2 (Figure 6) was designed as a literature review where a theoretical model was developed over several iterations. The development process of the theoretical model, Industrial Design Product Portfolio Management (IDPPM) model, and the empirical evaluation of the final version are presented below.

\subsubsection{Industrial design product portfolio management strategies}

Seven portfolio development strategies were extracted from the literature reviews and then organised into two main themes: extension and updating strategies (Figure 16). When evolving an existing product portfolio, a manager can choose between extending the portfolio (i.e., adding new products) or updating the portfolio (i.e., changing existing products).

\section{Update strategies}

Updating existing product designs is done to meet new market demands, to reduce costs, or to conform to new regulations. Updating products can be a more challenging than extending products because updating impacts current brand and design values and sometimes, depending on the outcome, changes a company's entire production system. These strategies aim to differentiate not only from competitors' but also from a company's existing product portfolios. 
The strategies found within this category are minor design updates and facelifts, redesigns, and revitalisations.

\section{Extension strategies}

An extension of a product portfolio preserves the majority of existing products and creates new designs for the portfolio. Extension strategies are less risky than updating strategies because they allow a company to reuse existing technology, designs, and brand values, decreasing development time and costs (Cooper et al., 2004a; Keller et al., 2012; Kapferer, 2014). The strategies found within this category are category extension, line extension, vertical extension, and new-to-the-world.

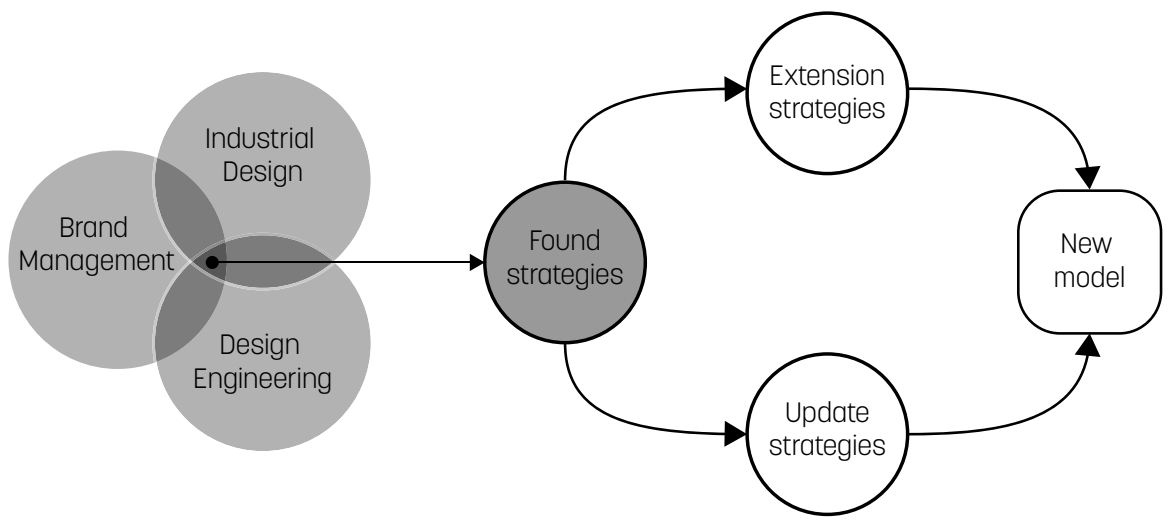

Figure 16. Findings from the three research areas are cross-examined and a list is of seven strategies is established. These are then divided into two main categories: update and extension strategies. The two categories and the seven strategies are the building blocks of the proposed products.

Table 6 (on next page) depicts a matrix containing the books and articles describing different product portfolio development strategies. The left-hand column lists books and articles and the next column describes which research field they originate from $(\mathrm{BM}=$ Brand management, $\mathrm{ID}=$ Industrial design, and $\mathrm{DE}=$ Design engineering). In the remaining columns, the $\mathrm{X}$ marks which of the seven strategies the article or book describes. The identified strategies are further described in 5.2.1. None of the three research fields displayed a conclusive model or approach that describes which of the existing strategies could be used to further develop a product portfolio in a particular way. 
Table 6. Results from the literature review, with the identified strategies mapped to corresponding articles. The point marks which strategy the article or book describes.

$\mathrm{BM}=$ brand management, PPM=Product portfolio Management, ID=Industrial design.

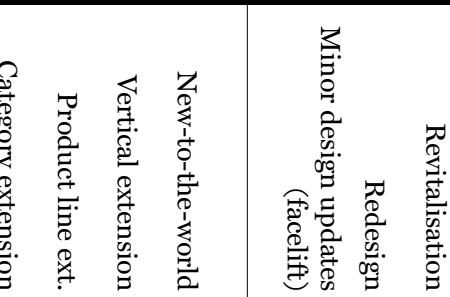

\begin{tabular}{|c|c|c|c|c|c|c|c|}
\hline Tovey (1992) & ID & & & & & - & \\
\hline Gartman (1994) & ID & $\bullet$ & $\bullet$ & $\bullet$ & $\bullet$ & $\bullet$ & \\
\hline Aaker (1997) & $\mathrm{BM}$ & & & $\bullet$ & & & \\
\hline Christensen (1997) & $\mathrm{BM}$ & & & $\bullet$ & & & \\
\hline Meyer and Lehnerd (1997) & PPM & & $\bullet$ & $\bullet$ & $\bullet$ & $\bullet$ & $\bullet$ \\
\hline Monö (1997) & ID & $\bullet$ & $\bullet$ & & & $\bullet$ & \\
\hline Cooper et al. - II (2004b) & PPM & $\bullet$ & & $\bullet$ & $\bullet$ & $\bullet$ & \\
\hline Kim and Mauborgne (2005) & BM & & & $\bullet$ & & & \\
\hline Persson and Åström (2006) & PPM & & & & & $\bullet$ & \\
\hline Buxton (2007) & ID & & & $\bullet$ & & $\bullet$ & \\
\hline Kreuzbauer and Malter (2007) & ID & $\bullet$ & & & & & \\
\hline Person et al. 2007a & ID & $\bullet$ & $\bullet$ & $\bullet$ & $\bullet$ & $\bullet$ & \\
\hline Lawson and Dorst (2009) & ID & & & $\bullet$ & & $\bullet$ & \\
\hline Thomas and Kohli (2009) & $\mathrm{BM}$ & & & & & & $\bullet$ \\
\hline Karjalainen and Snelders (2010) & ID & & & & $\bullet$ & $\bullet$ & $\bullet$ \\
\hline Keller et al. (2012) & BM & $\bullet$ & $\bullet$ & $\bullet$ & & & $\bullet$ \\
\hline Goode et al. (2013) & $\mathrm{BM}$ & $\bullet$ & & & & & \\
\hline Kapferer (2014) & BM & $\bullet$ & $\bullet$ & & & & $\bullet$ \\
\hline Ulrich et al. (2020) & PPM & $\bullet$ & $\bullet$ & $\bullet \bullet$ & $\bullet$ & & \\
\hline
\end{tabular}

\subsubsection{The evolution of the IDPPM model}

The model went through a series of iterations and all used a reflection-in-action (Schön 1987) process that included 2D sketching on paper and whiteboards and visualisation software (Adobe Illustrator and Google Sketchup). A great source of inspiration of the model was Rune Monö's (1997, p. 146) visual idea of a three-dimensional model representing the 'social life' of a company's product family. The principal idea of his model was that an industrial designer needs to consider both competitors and existing company products to differentiate a new design. Monö's (ibid) model (Figure 17) describes how the development of product $\mathrm{P}$ (origin) is influenced by competitive products (z-axis), the company's existing products (x-axis), and historical products (negative $y$-axis). The output, 
or future generations of product $\mathrm{P}$, is depicted on the positive $\mathrm{y}$-axis (ibid). Figure 18 shows the first and second version of the IDPPM model, which are presented and in Paper III and the licentiate thesis (Andersson, 2016).

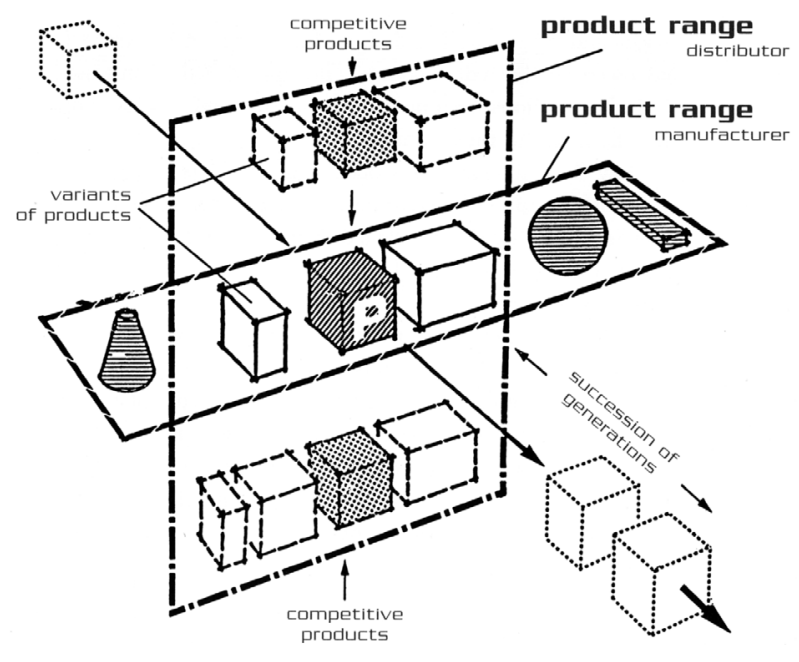

Figure 17. Monö's (1997, p.146) model of 'the product sign's relationship to the product range sign'.

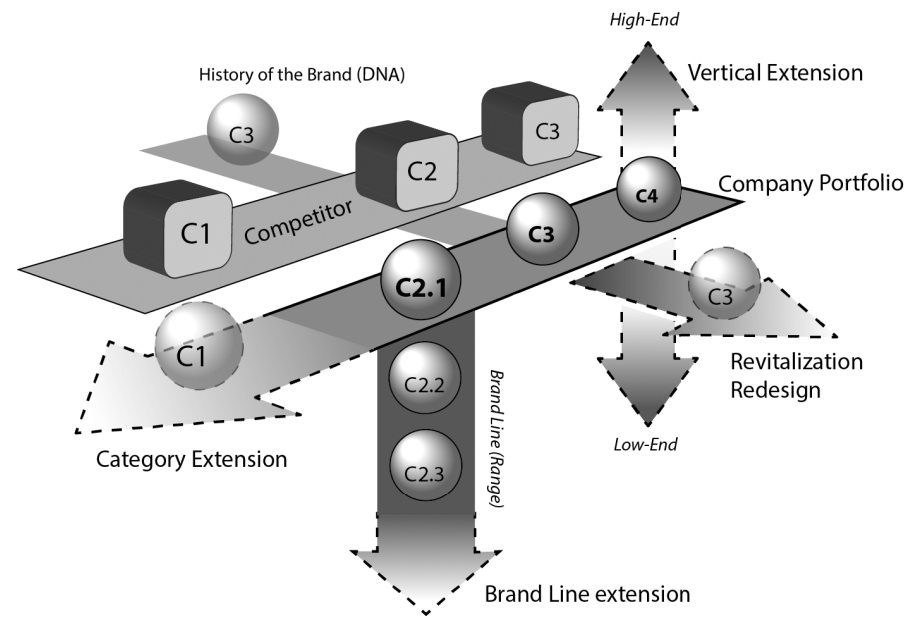

Figure 18a. First version of the IDPPM model and is found in Paper III. 


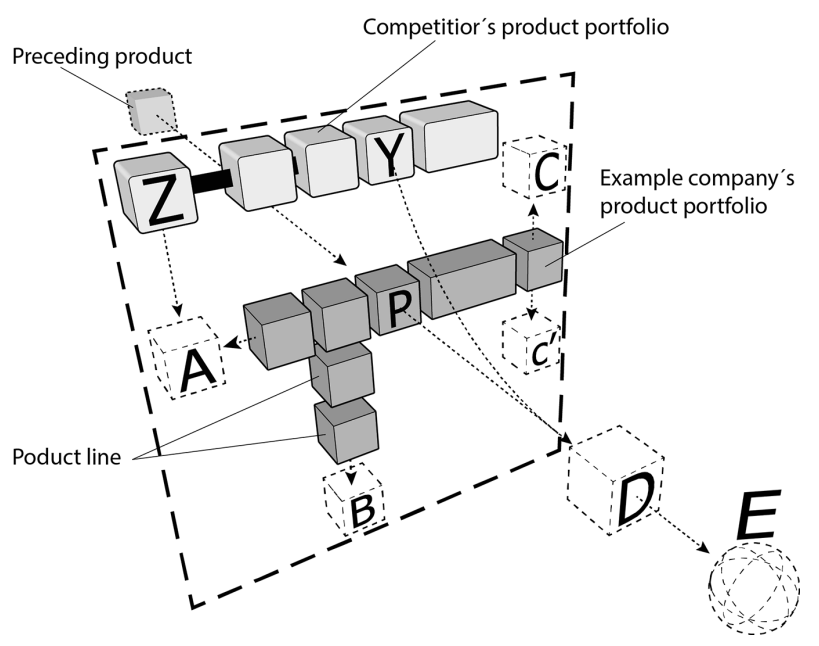

Figure 18b. Second version of the IDPPM model and is found in the licentiate thesis.

\subsubsection{Final version of the IDPPM model}

The two themes - extension and update - and the seven strategies were mapped on a Cartesian coordinate model to aid in exploring and understanding how the identified strategies interconnected. Thus, the themes could influence the development process of new designs in both New Product Development (NPD) and incremental development processes (Roper et al., 2016; Ulrich et al., 2020).

\subsubsection{Validation of the seven industrial design strategies and findings of the impact on industrial design practice.}

In this section, the validation of the IDPPM model was conducted in two steps. First, an internet search on existing company product portfolios was performed to find authentic examples of the seven found strategies. The found products were then used to elaborate on the strategic influence of the seven strategies and their impact on an industrial designer's practice when designing products for a visually coherent portfolio. 


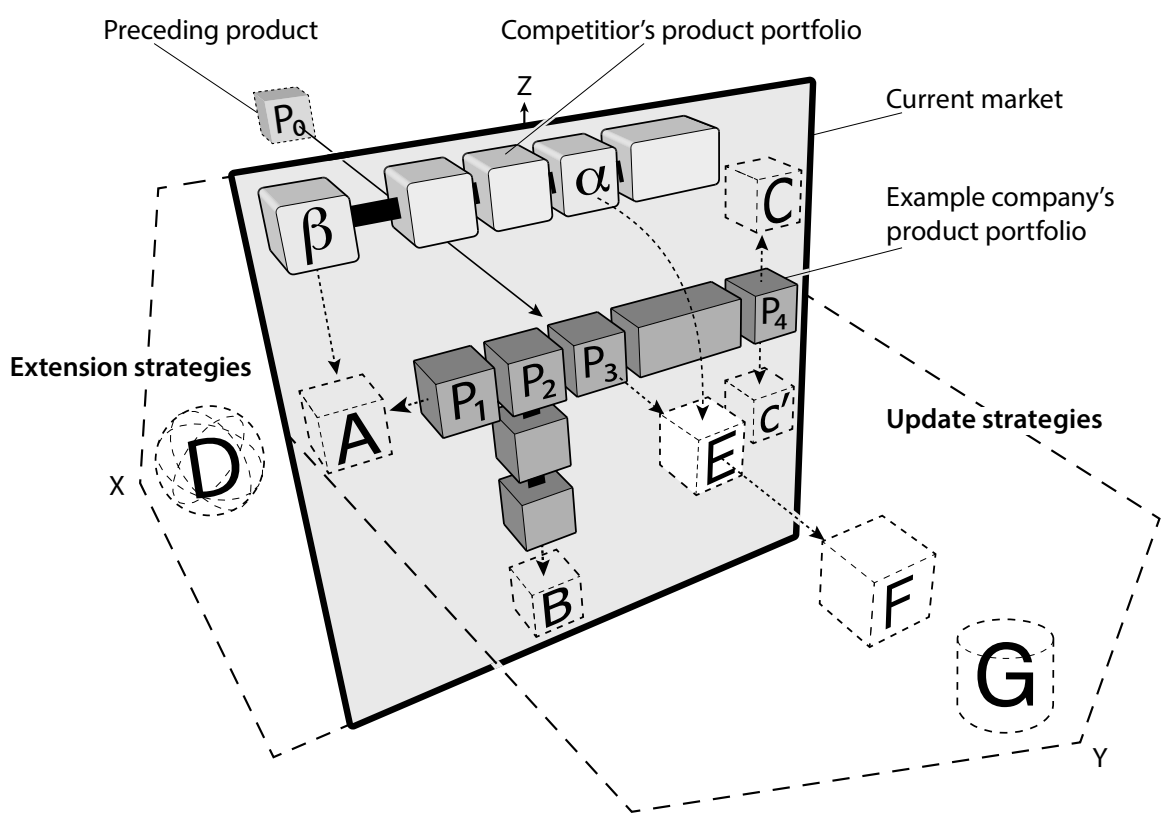

Figure 19. Final version of the Industrial Design Product Portfolio Management model (IDPPM model) illustrates how extension and redesign strategies are used to expand or update an existing portfolio.
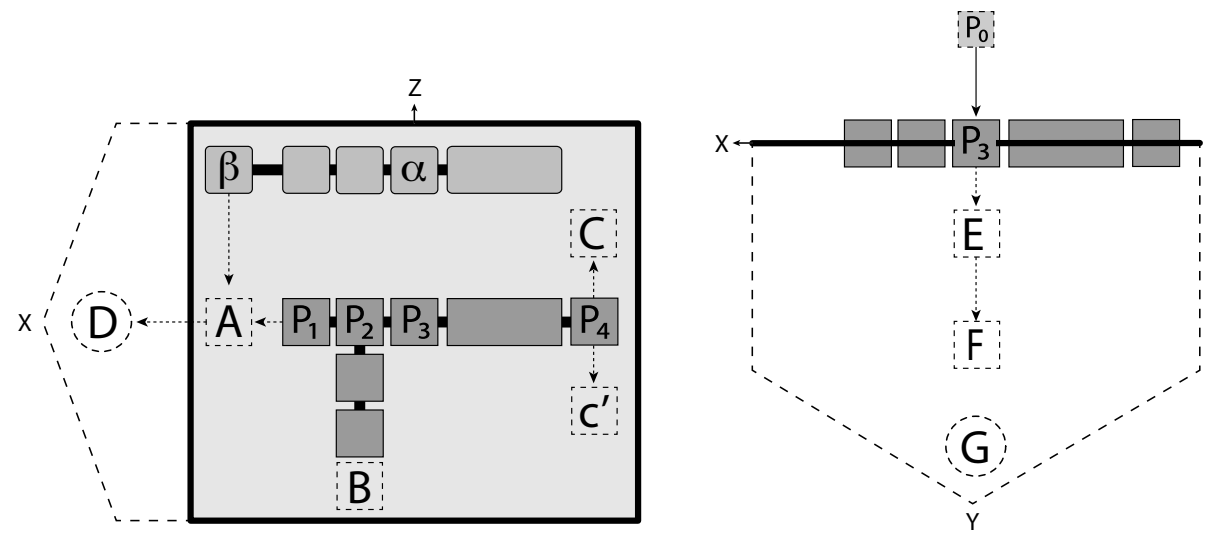

Figure 20. The two planes from the front and top view of the IDPPM model. The figure on the left shows the front side of the model, with the black square representing extensions to an existing portfolio within an existing market and the [D] represents new-to-the-world (Cooper et al., 2004a). The figure on the right shows the top view of the IDPPM model, where the black line represents the existing market and the dotted arrow-shaped rectangle represents changes to an existing portfolio. 
Second, an empirical evaluation of the IDPPM model was conducted using the gathered data from the two case studies (Case A and Case B) and compared using the strategies described in the theoretical model. The data were analysed using two method. First, the data were analysed using a qualitative process (see 3.2.5, data condensation) where relevant quotations were identified and coded using the IDPPM model as a guide. Second, responses that could be mapped to each strategy were counted and summarised in each column. These numerical results were divided by the number of participants in each case company to create an average that could be compared across cases. An " $X$ " indicates that there were no direct quotations in the material, but the authors could infer a connection from the company's historic product portfolio (Warell, 2006; Arvola et al., 2010). A “-” indicates no data were found in the collected material. Below, empirical findings corroborating each design strategy are described and presented with representative quotations.

Table 7. Comparison of IDPPM strategies and respondents' answers.

\begin{tabular}{|c|c|c|c|c|c|c|c|c|}
\hline & 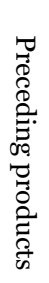 & $\begin{array}{l}\Omega \\
0 \\
0 \\
0 \\
00 \\
0 \\
0 \\
0 \\
0 \\
0 \\
0 \\
0 \\
0 \\
0 \\
0 \\
0\end{array}$ & 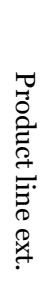 & 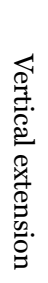 & $\begin{array}{l}Z \\
0 \\
2 \\
1 \\
1 \\
0 \\
1 \\
1 \\
0 \\
0 \\
1 \\
1 \\
0 \\
\vdots \\
0\end{array}$ & 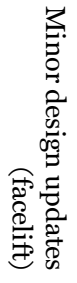 & 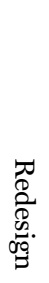 & 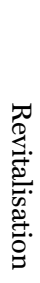 \\
\hline I - Automotive & 10 & 5 & 10 & 22 & 15 & 20 & 7 & - \\
\hline II - MedTech & $\mathrm{x}$ & 11 & 18 & 18 & 6 & 7 & 17 & - \\
\hline III - Consumer goods & 2 & 15 & 10 & 19 & 7 & 9 & 9 & - \\
\hline IV - Commercial vehicles & 1 & 7 & 8 & 2 & 3 & 15 & 6 & - \\
\hline V - Material Handling & 3 & 1 & 4 & - & $\mathrm{x}$ & 13 & 23 & - \\
\hline Summary: & 16 & 39 & 50 & 48 & 31 & 64 & 62 & - \\
\hline
\end{tabular}

The results show that the respondents could validate six of the seven design project strategies. No trace was found of the revitalisation strategy [G] in the collected data (Table 7). Preceding products was not a strategy per se, but was added to the findings because it was mentioned by several respondents and is part of the IDPPM model (Figure 19 and Figure 20). Table 7 presents an empirical connection between each case company and the strategies found in the IDPPM model. For more, see Papers III-V. 
Each description of design practice in the preceding products and the seven found strategies $[\mathrm{A}-\mathrm{G}]$ includes results from the two evaluations, authentic product examples, and the empirical evaluation. The order of the findings follows the table layout in Table 7 and the descriptions of the strategies followed by the respondents' responses.

\section{Po - Preceding Products}

Preceding products [Po], as depicted in the IDPPM model, represents a company's outdated products that are no longer in production as well as a company's historical design development. [Po] can be a resource for building brand identity and developing a company's future products primarily through redesign $[\mathrm{F}]$ and revitalization $[\mathrm{G}]$. That is, $[\mathrm{Po}]$ can be a source of inspiration that leads to reinterpretation of historical design ideas, elements, and features. Consider this revision: A prime example of this is the reinterpretation of the Volkswagen Beetle (see revitalization) based on the brand's tradition and reputation (Keller et al., 2012; Kapferer, 2014).)

Respondents from most of the case companies mentioned the need to account for preceding products when updating or designing a new product. They not only looked at preceding products but also at design features found in the product category with an eye toward their company's design traditions, building on the company's design DNA and brand identity. Two respondents (company II and IV) noted this appeal to design traditions was not always the case. That is, designers sometimes decide whether existing design features should be used or if new ones should be created instead:

'What prior products have we had (in our portfolio), what (design) do we want to bring along, and in what (design) direction do (we) want to go?'

- Senior designer, case company III. 


\section{A - Category extension}

The category extension strategy extends a portfolio into a new category of products, where competing products already exist (Cooper et al., 2004a; Keller et al., 2012). In many categories, the existing products have created a shared visual identity, Point of Parity (POP), that links them. This identity consists of design features that are not connected to a specific company but are shared by most.

When a company [ $\left.\mathrm{P}_{1}\right]$ extends into the existing category [A], the designers need to consider the pre-existing POPs created by the competitor's product $[\beta]$ before deciding how they should be incorporated into the new product. At the same time, the new product [A] needs to be tied to the company's existing products [ $\left.\mathrm{P}_{1-4}\right]$. This bond is established by creating recognition (Warell, 2008) by reusing Point of Departure (POD) design features from products [ $\left.\mathrm{P}_{1-4}\right]$ in the current portfolio, and by merging these products into the new product category $[\mathrm{A}]$.

Makita (Figure 21), a power tool manufacturer, provides an example of a category extension strategy. By expanding into the garden tool category, the company started to compete with existing producers in this category. Makita used design features of the garden tool category but altered these features so they expressed the design DNA of Makita's existing portfolio. For example, Makita's battery-powered garden tools use Makita's existing battery technology, saving development time and reducing costs.

According to the respondents (case companies I-V), a category extension can either be part of a strategic plan from management or an unauthorised project (i.e., "skunkworks") from the design team. According to a senior engineer at case company I, planned category extensions usually have strategic needs such as "we miss or need this" in our product portfolio. Respondents from company III describe skunkworks where they found undeveloped product categories and created design proposals before getting authorisation from management to develop a new category design. One respondent from the same company stated that the company also used original design manufacturing (ODM) companies by purchasing and rebranding "blank" products to quickly expand into an existing product category. 
The rebranding was done by aligning the ODM products with the company's existing colour, materials, and graphic layout schemes:

'We identified an opportunity to do a great product with a strong design, then we could (be the first company to) lift the product category'

- Senior design manager, case company III.

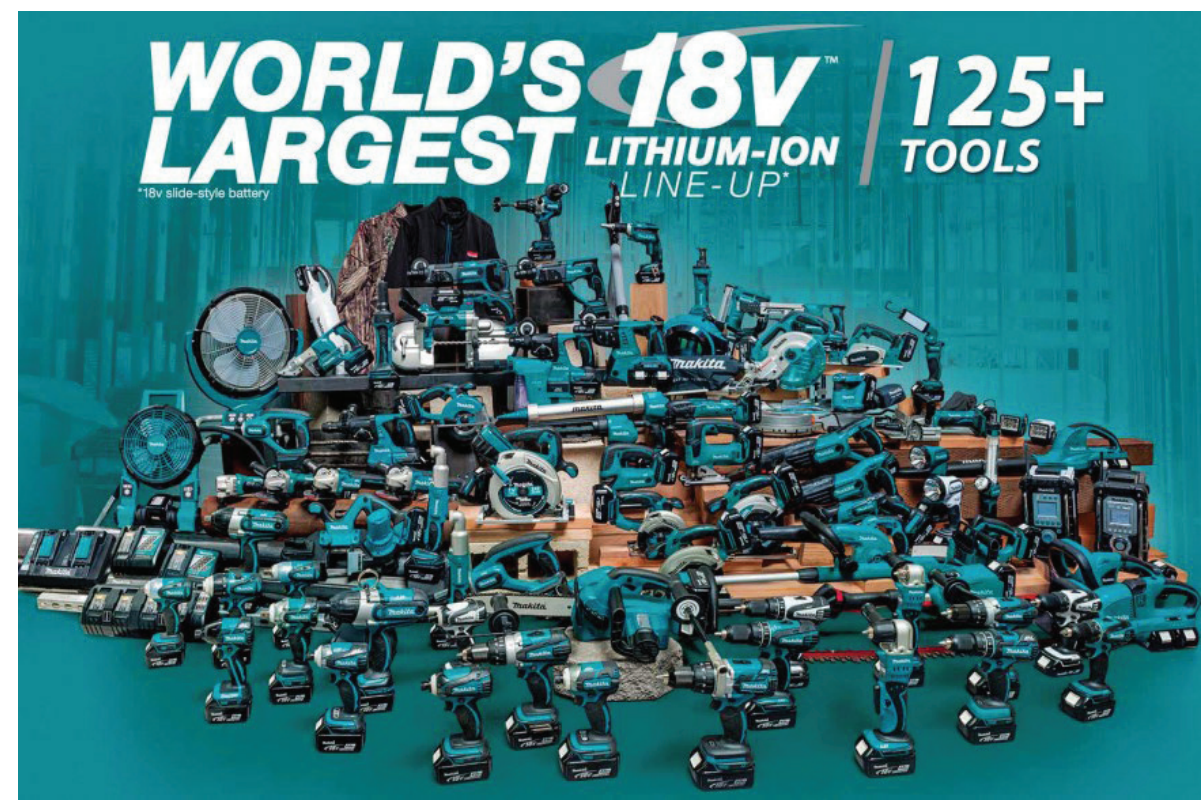

Figure 21. Makita utilises POP features to expand its product range into new categories. The brand is characterised by the use of POD features to make it recognisable. (Image source: Makita, 2018) 


\section{B - Product-line extension}

A product line is created when the various products within a brand are developed into a series of versions that share several features: design features, parts, modules, functions, and brand values. Product lines are created to satisfy different customer demands, which may range from functional demands, such as more power, add-on products, and product sizes to variations (Keller et al., 2012; Ulrich et al., 2020).

When the example company extended its product line $\left[\mathrm{P}_{2}\right]$ by introducing a new product $[\mathrm{B}]$, it reused parts from $\left[\mathrm{P}_{2}\right]$ as much as possible. The new design of the product $[\mathrm{B}]$ maintained coherence within the line to create a visual kinship (i.e., design DNA). Line extensions are widely used in the food industry, where different flavours of a food item have their own packaging but are linked through package shapes, colour schemes, and graphic layouts (Klimchuk \& Krasovec, 2012). An example of a brand-line extension is found in the Husqvarna Group range of chainsaws (Husqvarna, 2018). Husqvarna launched battery-powered chainsaws that extended its existing product line of combustion-powered chainsaws (Figure 22).

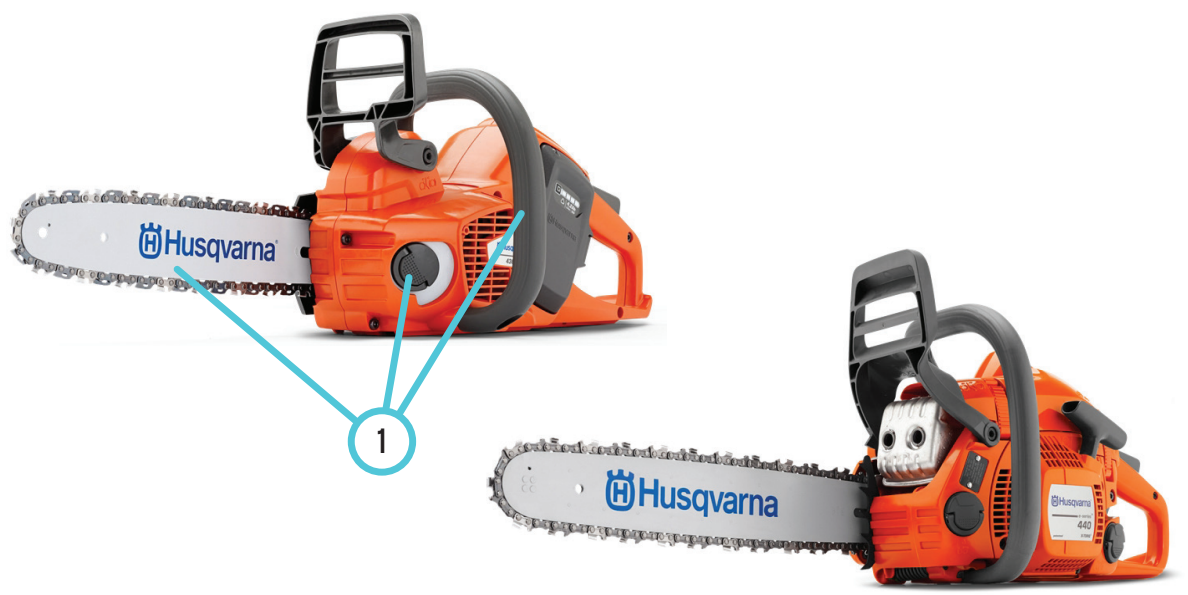

Figure 22. Two versions of Husqvarna chainsaws: on the left is a petrol-driven 440 e-series and on the right is a battery-powered 436 Li-Battery. Parts that are reused in the batterypowered chainsaw are the, blade, handlebar, buttons, and caps (1). From the petrol-driven chainsaws, design features such as proportions, graphics, design lines, material finish, and colour-schemes are also reused. (Image source: Husqvarna, 2018) 
The line extension consists of three products that reuse several of the existing brand platform elements, such as handlebars, buttons, and caps. These new chainsaws also reuse design elements from the combustion-powered chainsaws such as proportions, graphics, character lines, material finish, and colour schemes. The battery pack was reused from other battery-powered products in the company's product portfolio, creating a visual and functional link - i.e., the brand platform module (Sudjianto and Otto 2001) - between the two lines of chainsaw products.

Respondents from all case companies described that they had knowledge of creating versions (line extension) of existing products. The process of creating line extensions were either part of product planning or occurred during the design process. Planned extensions derived from performance needs include vacuum cleaners aimed at allergy and pet owners or trucks altered into fire trucks, garbage trucks, and mining trucks. The line extensions were made by designing a few new brand-specific parts, changing the colour or material schemes, and creating new product names (Becerra, 2016). This was done to distinguish different performances in the line products. Case company IV developed its design into a modular design architecture (Sanchez, 2002); that is, it constructed a library of brand-platform parts that were used to create different volumes of the same design. The design library allowed the design team to rapidly create several product versions and easily customise its products to consumer needs. Case company II described that during the initial design research phase, a new user group was found that needed its own product version. This was accommodated for in the product development process and through a few technical adaptations, new colours, materials, graphic layout, and graphical user interfaces (GUI), ultimately creating two products:

This (second design) should be displayed in the product, even in the software (GUI) we had to manage both visual identities at the same time.

- Senior designer, case company II

(Design) modularisation is our way of creating a cost-efficient ways to make small, large, and prolonged truck cabins accommodating all configurations on the frame and axles.

- Chief designer, case company IV 


\section{C - Vertical extension}

In some competitive markets, vertical extension (sometimes known as differentiation) is used to create a value range within an existing range of products. Two types of differentiation have been identified in the literature. The first is where a company decides to create a high-tech (professional) [C] or a low-end (Do-It-Yourself) [c'] product alongside its existing products (Aaker, 1997; Keller et al., 2012). The second type is a strategy where a company simultaneously creates three or more value levels of the same product: basic (low performance), low mid-range, high mid-range, and/or premium (high performance) (Meyer \& Lehnerd, 1997). This means that each version [C, P4, $\left.c^{\prime}\right]$ competes for attention not only with the competitor's products (a, b), but also with its "siblings" $\left[\mathrm{P}_{1-3}\right]$ in its own company's portfolio. The new product extensions need to incorporate existing POP values connected to the company, the category they adhere to, and create an association in the desired directions [C and c'] of the different values (i.e., basic, mid-range, and premium). The common strategy is to make flexible design features that can be added or removed and produced in different materials and colours (Becca, 2016). If this is done successfully, it reduces production costs and time to market and appeals to a wider range of consumers. Th Atlas Copco (Atlas Copco, 2018), which produces pneumatic tools, has vertically extended its professional range of hand-held pneumatic drills.

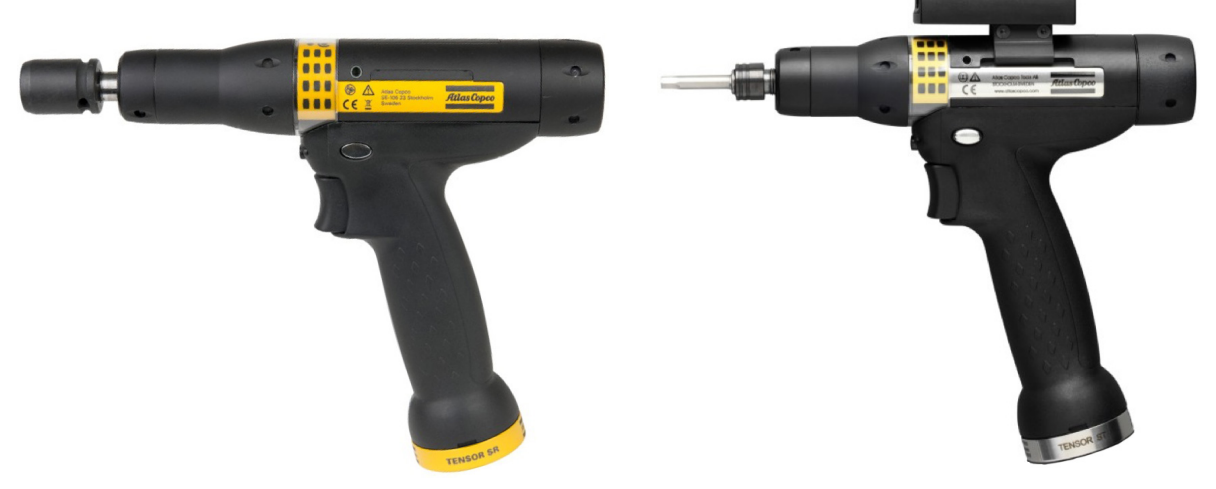

Figure 23. Two versions of Atlas Copco's pneumatic power drills. The left-hand drill (Tensor SR31) is the regular line and the right-hand drill is from the Pro line (Tensor ST31). The Pro line has an increased feeling of quality through greater precision and robustness, and minor visual changes to the design through colour and material changes to parts. (Images source: Atlas Copco, 2018) 
These were differentiated through an increased feeling of quality in precision and robustness and minor visual changes to the design, with new materials on some parts. This Pro line is also available in a battery version. This strategy created two visual identities for the same type of product, aimed at different target groups (Figure 23).

Respondents from all the case companies except Case $\mathrm{V}$ described vertical extension strategies. Respondents from case company I and III described using four vertical steps: premium, high mid-range, low mid-range, and basic. Respondents from the other two described a dual differentiation: case company II expressed an aim at developing a basic version of their bestselling product, and a respondent from case company IV stated that they had developed a premium version. The main differentiating factors are price, digital services, and functionality. These are achieved through changes in the design primarily by assigning each level its own colour variants, materials, finish, GUI, functional performance, and design elements and features. Premium levels use more expensive natural materials (metals, leather, wood), intricate patterns, paint, and lacquered and glossy finishes, and have highperformance technical parts, GUI, and internet-of-things (IoT) services. The basic level uses cheaper materials (plastic, cast metals, and printed patterns emulating materials), no or few paint schemes, matt or a natural finishes, and nobs, handles, and analogue dials rather than GUI and digital services. Respondents from case companies I and III describe that they combine line extension and vertical extension to appeal to more customers. Case companies I and III are global companies with several brands targeting different markets and geographical areas in the world. To accommodate all these brands and maintain cost-efficient production, the companies' products are separated through different brand identities - i.e., separate colour and material schemes, graphic layout, GUI, and a few design elements:

You can choose if you want (your car) to be super cool, cool, low-key, or exclusive. - Senior studio engineer, case company I

Prize. On expensive premium products is it obviously; better performance, features, GUI, spin-speed, energy consumption, customer experience, more lighting, more glass, more metals, larger vegetable box (in refrigerators).

- Senior design manager, case company III 
New-to-the-world extension goes by several names in the literature. In portfolio management literature, it has been referred to as 'new-to-the-world' (Cooper et al., 2004a), brand literature refers to it as a 'blue ocean' strategy (Kim \& Mauborgne, 2005), and product development refers to it as 'fundamentally new products' (Ulrich et al., 2020). This strategy focuses on the creation of products that have not previously appeared on the market. That is, they have no preceding products with established visual identities or design DNA.

A company that decides to use this strategy has the opportunity to create new explicit and implicit design features that serve as visual precedents for the appearance of the new product category. If successful, designers working for the company will have the advantage of dictating the gist (Monö, 1997; Paper I) of the product category in terms of look and feel. That is, the company will have a greater chance of becoming the first producer in a consumer's mind when searching for a new type of product (Kapferer, 2014; Keller et al., 2012). A classic example of a successful new product was the introduction of the Sony Walkman on 1 July 1979 (Figure 24).

When it was launched, it changed how music was consumed and Sony's developers managed to create a new Category POP that competing companies had to follow. Sony even succeeded in naming the new product category, the "Walkman" (Sanderson and Uzmeri, 1995).

Respondents from Case companies I, III, and IV explicitly described that their companies had made new-to-the-world products or components. The analysis of the historical products of the remaining two companies (II and V) revealed that the companies had created products that at the time were cutting-edge.

The strategy has many similarities with category extension: it can be either part of a planned innovation process or a skunkworks where one or a few employees develop a concept that then is approved by management. From a visual design perspective, this means new designs did not refer to design cues taken from predecessors. 
Respondents from case company III described that technology and consumer readiness are vital for success, and they had developed new products that were too early and had to be scrapped. Approximately 15 years later, when the consumers were ready and technology had matured, they reanimated the products:

'We were first on the market with a robot vacuum cleaner; it was at least 14 to 15 years ago, but we were too early'

- Senior design manager, case company III.

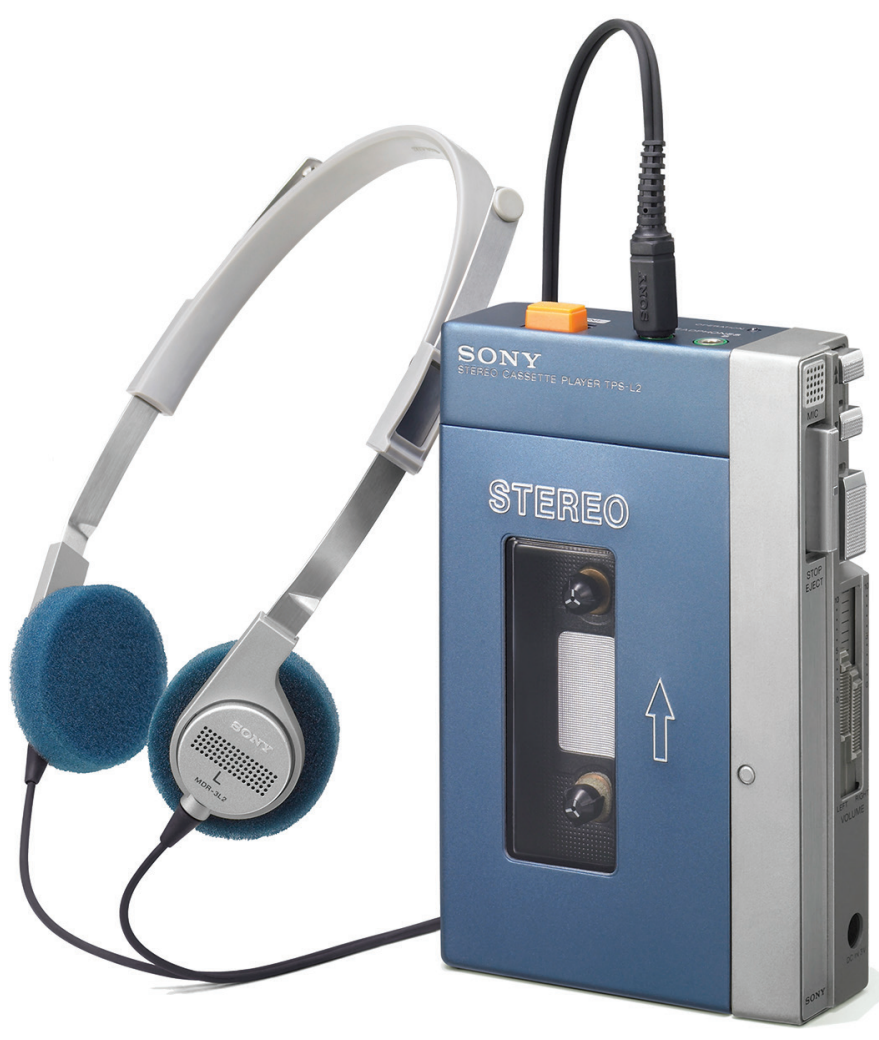

Figure 24. First generation SONY Walkman model TPS-L2. The design redefined how people listened to music by in essence combining a dictaphone with stereo headphones (Sony, 2021). 


\section{E - Minor design update and facelift}

The facelift strategy carefully modifies existing products to create a feeling of newness, to adapt to new trends in the market, or to showcase non-visual updates, such as technical and software improvements. This approach is often used to fend off competition in the market, especially for products that have been available for some time and are facing increasing competition (Cooper et al., 2004a; Persson \& Åström, 2006). In the automotive industry, facelifts are often carried out in three-year intervals, approximately halfway through a generation cycle. They are used to create visual coherence with the most recently designed products. The most common strategy is to update colour schemes, materials, and plastic trim parts; the high-cost parts, such as hard body parts (i.e., sheet metal components), are usually not changed (Becca, 2016; Persson \& Åström, 2006).

These types of changes are apparent in third-generation year models of the Volvo V70 (Figure 25). The bumper on the older versions (photograph on the left) of the V70 was redesigned for the 2014 model, creating differentiation between year models and a feeling of newness for consumers. The most prominent differences in the bumper can be seen in the grille (1), the air intake (2), and the character line (3).

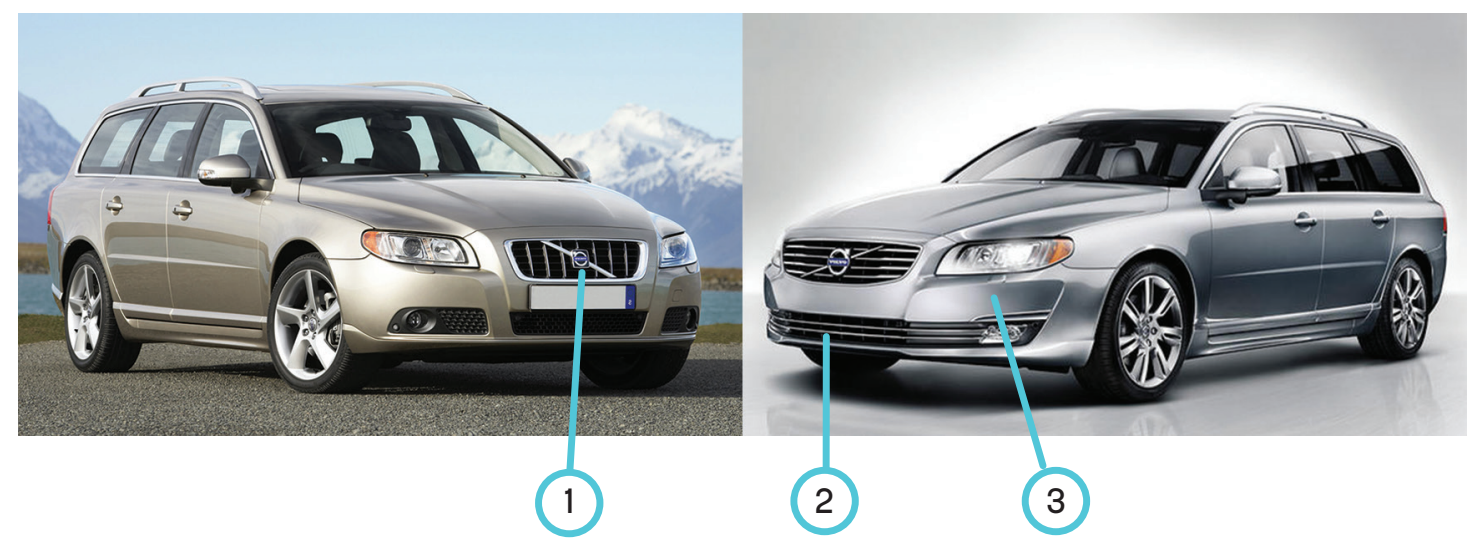

Figure 25. Third-generation Volvo V7O 2010 and the updated version from 2014. Facelifts of the bumpers can be seen in the 2014 version. The most prominent differences are in the grille (1), the air intake (2), and the character line (3). (Images source: Volvo Cars, 2015) 
This strategy was mentioned by respondents from all five case companies. Minor updates and facelifts were described as either part of product planning and changed regularly every $3 \neg-4$ years or part of an ongoing improvement process. In the planned product changes, the goal was to make as few alterations as possible to the form, focusing on changes in the colours, materials, finishes, GUI, and services. Changes to the form were primarily made on visible and design intensive components to get as much "bang for the buck" as possible. The goal was to update older products so that they had some design features in common with the newest products in the portfolio. Technical improvements that were not part of a product update market launch were bundled with design updates to create a package, which could then be marketed and generate a rationale for consumers to invest:

We could modernise textiles, new colours, and materials, but it was very unusual to do updates that required changes to existing tools or the need for new tools.

- Senior studio engineer, case company I

(The strategy is to make) incremental changes all the time. We bundle improvements (with a facelift) so that it creates a new year-model.

- Chief designer, company $V$ 
Redesign means making larger changes to design features and, if necessary, also making minor changes to the brand values of a company's existing product $\left[\mathrm{P}_{3}\right]$ or to an entire product line $\left[\mathrm{P}_{2}\right]$. According to Keller et al. (2012, p. 731), Ranscombe (2012), and Warell (2006), redesign is a common way to change or update a product portfolio. Redesign, mainly a planned process, is undertaken to create a feeling of novelty, to differentiate from competitors' products $[\alpha]$, to introduce new technology, or to change undesired brand associations. This can be seen in the visual differences between the 2015 designs and the 2017 designs of the Volvo SUV XC60, each representing a generation of the product category. The industrial design team changed the main volumetric forms, character lines, and lights so that the generations differ more radically from each other. This means that Volvo's design DNA (i.e., the Volvo look) has also been altered to convey a more modern direction (Figure 26).
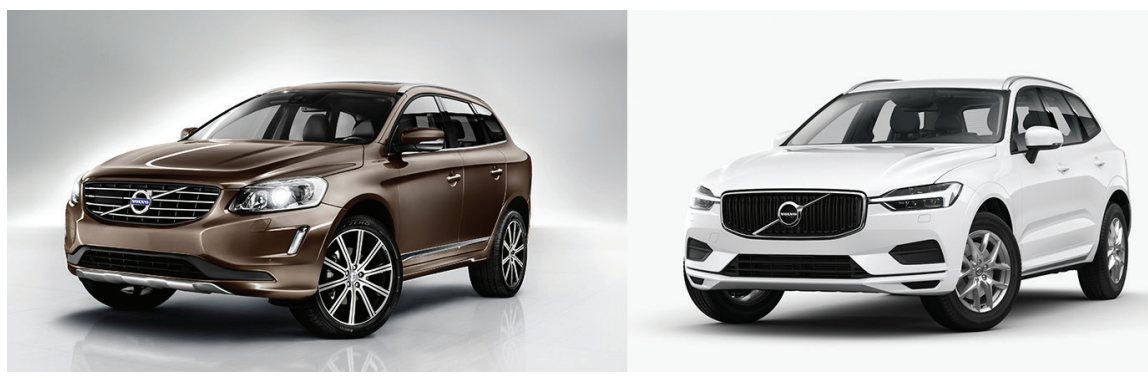

Figure 26. The photographs shows the results of a planned redesign process between the first (brown colour) and second (white colour) generations of Volvo's SUV XC6O. All surfaces in the main form (1), lights (2), and character lines (3) have been altered to create a "new look". (Images source: Volvo Cars, 2018)

Just as with minor updates, a redesign can be either a generation plan or a more sporadic occurrence. Case companies I and III described that redesign of products in the company's portfolio was planned to occur every six to eight years. Case companies II, IV, and V described a need-based decision process where a redesign was initiated due to competitors' advancements, new customer needs, technical advancements, managers think a product looks old, or mangers want to advance the entire product portfolio into a premium level. 
As a result, several products from company II have not been redesigned for 15 to 20 years and it took ten years for company IV to redesign its modular design system:

We have a generation plan - products that were launched 2012 were replaced in 2018. It's usually six- to eight-year cycles between each product. - Global design manager, case company III

The design team has the market team as a powerful partner; when they do their product planning and market analysis, they can state that 'OK, this needs to be done.' - Chief designer, case company IV

\section{G - Revitalisation}

Revitalisation or rejuvenation (Kapferer, 2014, p.387; Keller et al., 2012, pp.742746) is a version of redesign [F], but it also includes a more profound change to a company's design DNA. This strategy is employed when there is a need to create new positive associations and a change to the brand (Karjalainen \& Snelder, 2010; Kapferer, 2014, p. 387; Keller et al., 2012, pp. 742-746). During the revitalisation process, the design effort should be handled with caution due to the risk of moving negative associations into new designs when reusing design features from existing products.

An example of revitalising a company is the British clothing company Burberry. During the 1990s, the brand unintentionally became a favourite of British soccer hooligans. While travelling to European cities to watch matches, the hooligans were influenced by the local supporters' branded clothing such as Lacoste, Sergio Tacchini, and Fila. The hooligans began to buy or steal these clothes from local supporters, but soon the more "patriotic" supporters decided to buy clothes from the British high-end brand Burberry. These clothes became a uniform for "chavs", as the young hooligans were called, and wearers were turned away by bouncers and taxi drivers.

These negative associations led to a decline of the Burberry company until the brand was revitalised by repositioning itself towards high fashion and by discontinuing mass-market products such as its popular cap. Burberry also reduced the use of its check design feature (a camel, red, and black check) on the new designs (The Economist, 2011; Keller et al., 2012, pp. 739-740). 
A less drastic version of revitalisation is the rejuvenation of an old product. This is when a company chooses to redesign a preceding products (PO) instead of an existing product (P1-4). The advantage is that an old product design has an iconic design history with a strong coherence towards the existing brand and updating it to modern technology standards can be a safe way to create a bestseller. According to Brown et al. (2003), the introduction of the "new" Volkswagen (VW) Beetle at the Detroit Motor Show in 1998 can be seen as a prime example of rejuvenation, or "retro-marketing" as these authors describe it. The Beetle (model T1) was first produced in 1938 and was not superseded in sales until the VW Golf was introduced in 1974. In essence, the new design incorporated the most prominent design features from the old Beetle into the modern VW Golf technology (Brown et al., 2003).

No comments or traces of revitalisation could be found in the collected data or in the product history of the selected case companies.

\subsubsection{Summary of findings in Perspective 2}

The findings conclude that industrial designers working with developing and managing strategic product portfolios can apply seven strategies to evolve design: minor design updates and facelifts, redesign, revitalisation, category extension, line extension, vertical extension, and new-to-the-world. These strategies were sorted into two general themes: extension and update strategies. The strategies and themes were developed into a Cartesian model (Cooke, 2012, p. 403) that places each strategy in relation to each other and a fictive competitor company. The results lay the foundation for evaluating and adapting the existing theoretical model developed by Rune Monö (1997), resulting in a new theoretical model - Industrial Design Product Portfolio Management (IDPPM). This model and the respondents' comments illuminate strategic decisions made within industrial design practice. For more information, see Paper III-V.

The final model was evaluated in two ways: internet searches aimed at finding existing branded products that could be inferred to be one of the seven strategies described in the IDPPM model and the empirical evaluation of seven strategies uncovered in interviews with experienced professionals working in design functions. The evaluations revealed that the respondents described (directly and indirectly) six of the seven strategies. For more information, see Paper V. 


\subsection{Perspective 3 - Design Judgment in manufacturing companies}

As a result of the literature reviews, interviews in Case study A, the design workshop, and experience as a practicing industrial designer, another hypothesis was formed: designer's strategic decision-making included intuitive processes that could not be rationalized. The hypothesis led to the final research question (RQ3): How do intuitive design decisions and rational compromises in industrial design practice influence decision-making in strategic design?

The research conducted in Perspective 3 (Figure 6) started with a literature review focusing on design judgment and decision-making. Case study B used the same interview design as in Case study A. The raw data from both cases were analysed using qualitative methods and the findings were organised into two parts. The first section presents, on a general level, the ways in which Swedish manufacturing companies organise their design efforts - in-house or externally (i.e., consultants). The results are deduced from the collected research data and the discussion focusing on how organisations make decisions regarding processes that interact with non-design functions. The second section expands on how experienced design decision-makers from the two of the organisations described in the first section make strategic design decisions. The described dual-decision processes, design judgments, and multidimensional design decisions are used as principal themes in this analysis.

\subsubsection{Part 1 - Design functions organised to facilitate design decisions}

Analysis of the collected data and the literature review on strategic design functions resulted in four general organisation maps. These described three ways a manufacturing company could organise strategic design needs and a fourth describing how external design services (EDS) can be used to satisfy design requirements (Figure 28).

Three strategic design team sizes were identified: major team, single team, and employed individual designers. The largest (major) design teams were 
found in companies A, C, and D; according to the respondents, the team sizes ranged between 150 and 200 employees. In companies $\mathrm{B}$ and $\mathrm{E}$, the team had the size of a normal work group, between seven and ten people, hence the name single design team. The last team size originates from anecdotal evidence described by respondents from companies B and E, who had been employed by the case companies before the formation of the single design teams. That is, they had to make many strategic design decisions (Gartman, 1994; Tovey, 1997). These data suggest that Micheli et al.'s (2018) description of what is needed to formalise a strategic design function in a company is influenced by the size of a design team.

The first two organisational maps are named major strategic design team (MSD) and single strategic design team (SSD) (Figure 27). In addition, a few individual strategic designers (ISD) can act as design policymakers within an organisation (Figure 28). In MSD, SSD, and ISD, the grey coloured boxes represent strategic design function and the white boxes with filled lines represent non-design functions within a company. Figure 27 depicts how EDS influences the design decision process (chequered boxes). Filled arrows represent the design decision channels between company functions and dotted lines represent external design services.

In a major strategic design team (Figure $27, \mathrm{I}$ ), the designers are organised in both hierarchical and operational structures. The hierarchy consists of several levels of management, ranging from CDO, group leaders, and design managers to senior and junior designers. The hierarchy makes it possible to organise senior decision meetings such as the design council and design review board (Figure 27, I). In the design council, the decision meetings are held with board members or other high-ranking executives, and the design review board is an internal decision process that approves what concepts should be presented before the design council.

Due to a large product portfolio or complex products, the design function is divided into sub-teams, illustrated in Figure 27 by the three boxes Team A, Team B, and Team C. This research has found three major ways sub-teams can be organised by using the physical structure of the products (i.e., the interior and exterior shape), by following the product portfolio structure, or by how the market is divided. Apart from the three ways teams can be organised, the respondents described a specialised team that mainly worked on trend forecasts, focusing on colour, material, and finish (CMF) (Becerra, 2016). 

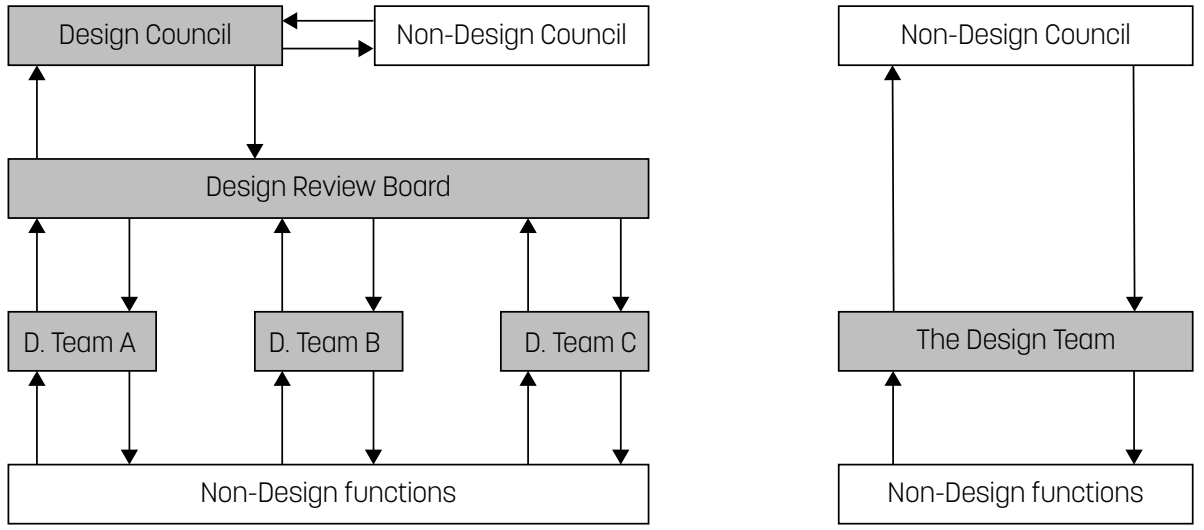

Figure 27. The grey colour represents decision processes made within the design function and white represents non-design company functions. For MSD, the organisation chart illustrates how interactions and decision flows were interpreted in a matrix design organisation. For SDT, the organizational chart illustrates a design function that consists of only one single design team.

III) Individual Strategic Design

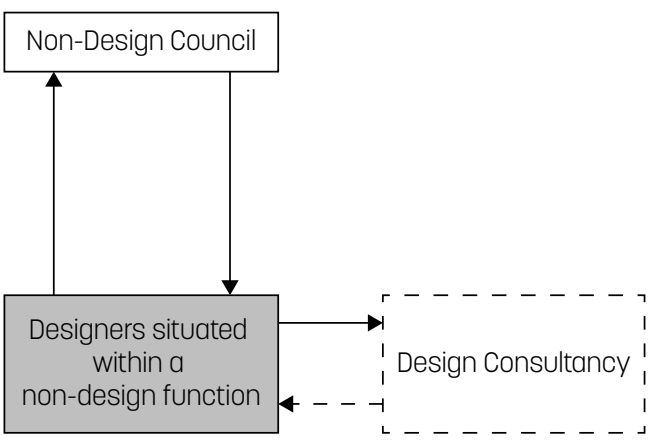

IV) External Design Sevice

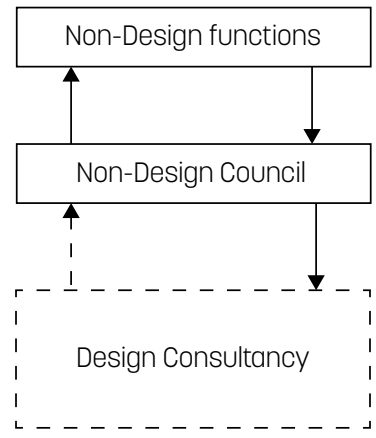

Figure 28. The grey coloured squares are the design function and the white are other company functions. For ISD, the design function organisation has no stipulated design group, but only employed designers incorporated in other functions. For EDS, the last illustration depicts an organisation where the company has no design function in-house but uses design consultants to handle all design. 
To solve the need for continuous cross-functional decision making (Micheli et al., 2018), the MSD teams used non-designers to work as integrated members. These are design engineers (also called studio engineers), surface designers, project managers, and specialists who need to work closely with the designers. During a product development process, official and informal meetings are conducted where the design team presents its progress to other non-design functions. On these occasions, the design team's responsibility is to champion the design proposals and simultaneously make feasible compromises.

The single strategic design team (Figure 27, II) closely resembles the major strategic design organisation, except that it does not have sub-teams and a designated design council. The design team has less hierarchy, with one design chief, or CDO, and can have one or more group leaders. The strategic design decisions are made by the chief designer as part of a non-design council, and design reviews are conducted within the team. Depending on the crossfunctional need of the design team, engineers and other specialists can be a part of the team or brought in temporarily from other functions. The single strategic design team makes the same compromises with non-design functions as the MSD team.

Individual strategic designers (Figure 28, III) include one or several designers who are employed by an manufacturing company that has no central design organisation. They are situated inside an existing function such as research and development, marketing, or even senior management. In design strategic companies, the individual designer's responsibilities range from undertaking design projects for the company and acquiring and managing external design services to making design decisions that influence the brand.

External design services (Figure 28, IV) are used when a company chooses not to pursue a strategic design function. In this situation, the non-design council or high-ranking executives select what design companies to hire and subsequently judge if the end result is in line with the company's product portfolio and brand strategy. 
As can be seen in Table 2, three of the five case companies used a major strategic design function (A, C, or D), and two used a single strategic design function ( $\mathrm{B}$ and $\mathrm{E}$ ). The decision process in the case companies $\mathrm{A}, \mathrm{C}$, and $\mathrm{D}$ were organised into two levels - a design review board within the design organisation and an external design council where design chiefs meet with board members or VPs to decide on the design proposals (Gartman, 1994; Tovey, 1997). Because company $\mathrm{C}$ had a much larger product portfolio, more hierarchal levels were present than in companies A and D. In addition to the described levels, company $\mathrm{C}$ had two sub-teams, each containing a separate decision process that acted before the design review process.

In single strategic design in companies $\mathrm{B}$ and $\mathrm{E}$, the team was more heterogenous in its composition. The members had a variety of design backgrounds - e.g., industrial design, graphic design, interaction design, user experience, surface designers, ergonomics, and design engineering. Companies $\mathrm{B}$ and $\mathrm{E}$ did not have a design council, so the design teams had to discuss and represent their results to non-design councils. In company B, the design chief identified five levels of hierarchy before he reached the board of directors. The design chiefs also described having more responsibility for design decisions. The design chief in company B had to formally sign off on design decisions. In contrast, the major strategic design functions had zero or one level between them and the board of directors.

Due to the scale of the case companies' organisations and the complexity of the portfolio and products, all the case companies had non-designers on their teams, including specialists, design engineers, surface designers, material engineer experts, marketing experts, and project managers. They were organised as separate teams within the design organisation or as part of subdesign teams. The respondents described them as having two main functions: to aid the designer with technical problems, regulations, project management, and cost calculations and to communicate between other non-design functions such as engineering construction or production development:

(A) lot of communication and mediating, within the role... and keeping the dialogue alive between the design department and the construction, production, purchase, simulation departments ... a lot of communication is the keyrord, I think. - Senior studio engineer, company D 
Three of the case companies (A, C, and E) had design studios situated in countries other than the location of the main design teams. These external studios functioned as a separate team and made many decisions on their own. For example, they managed local product brands, provided regional trend forecasts, adjusted designs to align with regional regulations, tastes, and performance requirements, and aided the main design office when it needed extra design capacity.

\subsubsection{Part 2 - Dual design decisions in major and single strategic design teams}

The companies in Case study A and Case study B were either od a major strategic design (MSD) or single strategic design (SSD) type (Table 2). No indepth data analysis was conducted regarding dual design decisions processes in ISD or EDS, so they have been excluded from this section's findings.

Dual design decision processes in industrial design practice were investigated by qualitatively analysing the empirical data gathered during the case studies. The qualitative analysis methods are described in 3.2 and in Paper VI. The analysis follows a three-step process where codes are developed in two steps before being compared to the found theoretical dual decision processes. Figure 3 depicts a cross-examination of the findings and the described dual design processes. The results are illustrated in Table 8 , which depicts a cross-examination of the first- and second-order codes, with the two design decision processes found in the literature review, design judgment, and multidimensional design decision.

From the aggregation in Table 8, distinct decision patterns emerged where the respondents describe the occurrence of fast and slow evaluation acts during industrial design development projects. The fast design judgments (Type 1) were found in two versions - a positive and a negative. The third slower decision process encompassed design compromises within the strategic design function but also within non-design functions. This process was deemed a multidimensional design decision process (Type $1+$ Type 2) due to a cognitively taxing process where compromises had to be made between emotional, aesthetic, and rational information, which was often data-driven. 
Table 8. Organisation of the coding and cross-examination with dual-process design decisions

\begin{tabular}{llc}
\hline First-order codes & Second-order codes & Dual design decisions \\
\hline $\begin{array}{l}\text { Looks and feels right - gut feeling } \\
\text { "stick to their guns" }\end{array}$ & $\begin{array}{l}\text { No compromises with } \\
\text { non-design functions }\end{array}$ & $\begin{array}{l}\text { Design judgment } \\
\text { (Type 1) - positive }\end{array}$ \\
\hline
\end{tabular}

Too expressive a design for the consumer

Design conventions in the product category

Design expression

compromises

Cultural influence on design decisions

Competitors influence on the design

Competitor considerations

Visual coherence across a portfolio

Brand compromises

Trends influence on design

User influence on the design User compromises

Multidimensional design decision

(Type $1+$ Type 2)

Cost influence the design process

Cost compromises

Product portfolio cost differentiation

Engineering feasibility influence on design

How product architecture limits the

design space.

"Carry-over" parts influence on the

Engineering

design process.

compromises

Standards and regulations.

The designers do not accept the

compromise

No compromises with

Design judgment non-design functions.

(Type 1) - negative

The findings were developed into an assessment model (Figure 29) depicting a continuum where a major goal for the strategic design team was to achieve design judgment as positive as possible despite necessary compromises (see Paper VI, Appendix, comments 2-6, 8). The objective is to create a design proposal that evokes a gut-feeling response of "wow!" in executives, customers, and employees. The "wow" factor is a known concept in design and marketing literature. In marketing, getting a "wow!" from a customer regarding a new service offer is seen as one of the highest positive evaluations a proposal can receive (Millard, 2006; Hudson and Viswanadha, 2009; Palmer et al., 2013). A combination of innovation and newness creates a positive and physical feeling. Design research literature uses the word in a similar way and states its importance in both redesign and new development processes (Desmet, 
2007; Zec, 2007). A respondent in company A uses the word "wow" to describe the ultimate gut-feeling goal, where the design council judges that one or several design proposals have what it takes to represent the company. This is demonstrated with the upward pointing arrow in Figure 29.

The second mission for the design team was to champion design proposals during the compromise process and prevent them reaching a negative design judgment. Crossing the lower limit in Figure 29 meant that compromises had gone too far, and the aesthetics and identity had been lost. This process is represented by the downward pointing arrow and was named the 'shame limit' by a respondent (Paper VI, appendix, comments 40-42). The term 'shame limit' is a direct translation of the Swedish word skamgräns, which means the absolute lowest level of acceptance for something. The use of the word in this context is done to emphasise that it is a negative intuitive design judgment within a compromised situation and a threshold that should not be crossed.

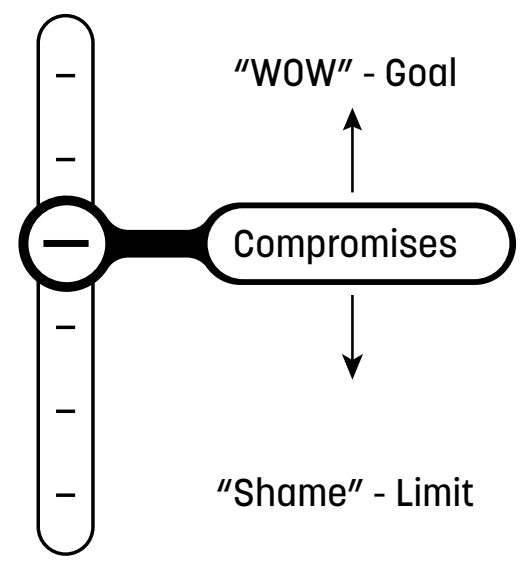

Figure 29. The design-decision process is described as a bar where the design team has an upper "wow" goal and a design "shame limit". In between, compromises are made regarding both intuition and evidence-based factors. The goal is to be as near to the upper "wow" limit as possible.

When the balance is between compromises and the positive and negative judgments, the design team has achieved an acceptable multidimensional design decision. All respondents in the multi-case study reported that they had made compromises in the design and development process, that it is a natural 
part of the process, and that they plan for it (Paper VI, Appendix, comment 10). In their design process, they included development time for adjusting the designs so that the compromises could be incorporated into the final proposals; in a worst case scenario (i.e., a negative design judgment), they scrapped them and created totally new designs. Table 8 shows that compromises were made by both intuitive and rational processes. The intuitive compromises identified mainly described visual criteria that are subjective and challenging when it comes to numerical evaluations (Paper VI, Appendix, comment 1, 3, 4).

Respondents described how the evidence-based compromises derived mostly from metric-based evaluation methods. These were results from user tests, cost calculations, and engineering feasibility studies as well as from marketing and product planning (Paper VI, Appendix, comments 15, 17, 21, 23, 26, 30, 33, 36 , and 39). As the metrics were described as difficult to question or oppose, it was very important for the design function to influence the board of directors or executives so that they could address negative design judgments (Micheli et al., 2018). Companies that used the major strategic design teams created this relationship in the design councils. For a more detailed review of the findings, see Paper VI.

\subsubsection{Summary of finings in Perspective 3}

The findings show that design functions that have design councils and a good connection to senior management have a greater chance of being included in strategic decision-making. Furthermore, the qualitative research supports the hypothesis that designers working in design functions make intuitive design judgments and negotiated multi-dimensional design decisions.

The design judgments are made not only to decide what designs should represent a company's brand but also what designs should be dismissed. Intuitive design judgments are essential for industrial designers, which may create friction in the interaction with non-design functions in a company.

By establishing clear design decision-making pathways in an organization, it becomes easier for a strategic design function to champion promising design proposals and stop non-design decisions that would destroy a proposal. Additional material can be found in Paper VI. 



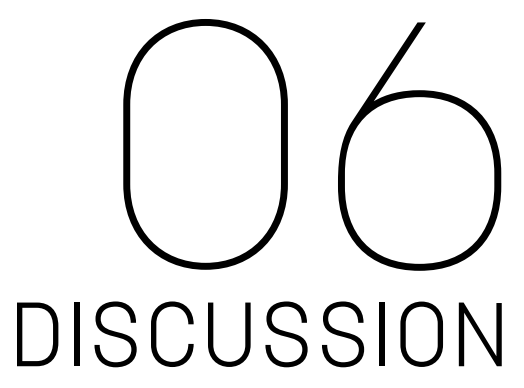

The thesis demonstrates that advances in research fields such as modular product development, decision making, and brand management have over the years led to development of more complex industrial design strategies in, for example, consumer goods, high-tech, and automotive product segments. The incentive for scientific advancements in design research originated from a desire to accommodate the described progressions in the other research fields and how they influence industrial design practice.

The conducted research shows that some industrial designers working under the conditions stated in this thesis transformed their design thinking and evolved a more flexible design strategy. Aesthetic flexibility is the answer to how the described influences have evolved the industrial design practice. The following discussion will use the three perspectives to focus on how this change has impacted industrial design practice.

Each perspective is examined in one section, 6.1-6.3, followed by a general reflection on the conducted design research process. In addition to the three perspectives, the research has also been framed by the scope (see section 1.2), manufacturing companies with strong brands, in-house design functions, practicing designers, and large or complex product portfolios. 


\subsection{The influence of product modularity in the development of aesthetically flexible product portfolios}

This research has found that engineering product modularity strategies such as those described by Starr (1965), Ulrich (1995), Erens and Verhulst (1997), Miller and Elgård (1998), Jiao et al. (2007), and Ulrich et al. (2020) and product platforms (Meyer and Lehnerd 1997; Robertson and Ulrich, 1998; Baldwin and Clarks, 2000) have profoundly influenced the practice of industrial design. The concept of aesthetic flexibility, as it emerged from my initial data, was corroborated by the latter case studies and aligns with the previous work by Sanchez (2002; 2004) and Sudjianto and Otto (2001). Quotations from respondents describe the need for reusing designed parts and the development of branded product architecture where brand-specific and brand-platform parts are shared across both time and product lines:

'What prior products have we had (in our portfolio), what (design) do we want to bring along, and in what (design) direction do want to go'.

- Senior designer, case company III

Designing for existing product portfolios resembles designing for a constantly evolving ecosystem. That is, practitioners need to consider both the present design task and how it can influence or create conditions for future design updates that are not yet imagined.

The strategy can be seen in products such as in the automotive (Figure 25 and Figure 26) and truck industries, where a prime example of this is Scania's trucks (Figure 30). Through collaborations between engineers and designers, companies in these two sectors have created a branded product architecture (Sudjianto and Otto, 2001; Sanchez, 2002) that allows for sharing of designed elements that serve as a template when new products are designed.

This arrangement can be both a blessing and a burden in redesign and rejuvenation projects. Positive design elements can be easily reused between generations; however, rigid brand architectures can hinder expressive design changes, for example, when a company is in decline (Kapferer, 2014, p. 387; Keller et al., 2012, pp. 742-746). 


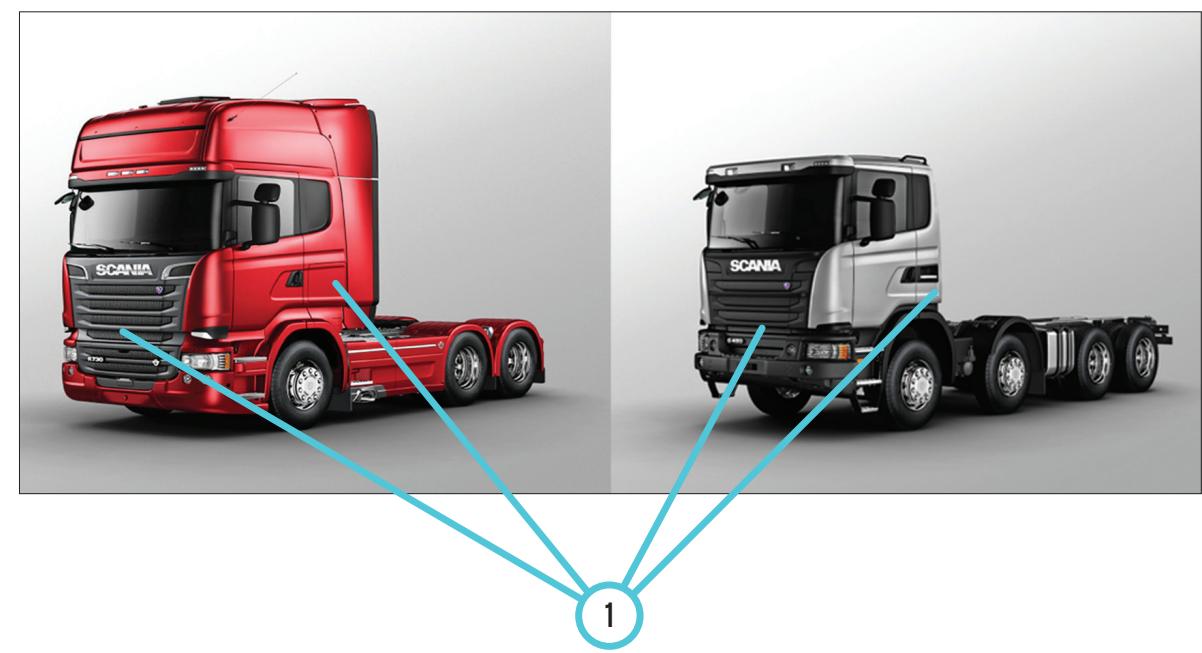

Figure 30. Scania uses modularity to create five versions by reusing body parts, yet maintaining the same design DNA. Several body parts have two or more size variations (1) and contain the same design features. (Image source: Scania, 2015)

A second way of applying aesthetic flexibility is when a company plans for future extensions in a product portfolio as new designs are being developed. This can be described as lateral strategic thinking in the design process.

Lateral thinking manifested itself through the need to consider how new designs create a unique visual recognition (Hollins \& Pugh, 1990; Lewalski, 1988; Warell, 2006; Karjalainen \& Snelders, 2010) in a portfolio and how parts of the new design can be incorporated into existing product categories and product lines. That is, interfaces with new design elements have to be made so they can be spatially incorporated in existing products, transferring new PODs into an existing product. It also gives an opportunity to redesign a product for the most effect - i.e., if a product is divided up, redesigning can be conducted on parts that are deemed to be more important for the creation of product identity rather than for the creation of the whole product.

This strategy improves design consistency and therefore visual brand recognition (Hollins \& Pugh, 1990; Lewalski, 1988; Warell, 2006; Karjalainen \& Snelders, 2010).

According to Diffner (2011), there are drawbacks with this strategy such as when a module breaks or a product falls into disrepute, as with the Burberry example described in Paper IV and Paper V. This influences the rest of the portfolio and increases the risk of damaging the brand. Consequently, this will render larger costs for redesign or even increase the need for revitalisation 
of a brand. Therefore, designers and managers need to understand when to incorporate aesthetic flexibility and when not to. Examples of a present, future, and lateral strategic thinking can be seen in the Makita (Figure 21), Husqvarna (Figure 22), Atlas Copco (Figure 23), and the Volvo (Figure 25 and 26) cases, evidence that validates the fact that aesthetic flexibility is present in contemporary products. The five product cases show that aesthetic flexibility strategies are present when attachment modules (Sanchez, 2002; Ulrich et al., 2020), such as a battery unit (Figure 21), have become both a brand-platform and brand-specific module shared across a portfolio that influences new designs in both extensions and updates.

Future design updates are reflected in the responses regarding design strategies that simultaneously look to older versions of products for inspiration (e.g., the Volvo car model in Figure 25 and Figure 26) and track the redesigns or facelifts (e.g., designing new plastic bumpers but not designing new expensive metal body parts).

Aesthetic flexibility implies that product portfolio management and brand management strategies have had a great impact on professional designers' strategic thinking. This finding corroborates Ulrich's (1995), Buxton's (2007), and Sanchez's (2002) understanding that industrial designers influence the way products are modularized because they determine the shape and functions of products that impact a user's experience with the product. The concept of aesthetic flexibility broadens the understanding of what professional designers consider when developing new product designs for portfolios.

From an academic point-of-view, aesthetic flexibility can be used to diversify research approaches by giving researchers the means to categorise different design practices and to develop methods and tools adapted for different flexibilities. Less complex products using production means that are easily adaptable have fewer incentives to create brand architectures that share components. The drawback of modularizing a design can be greater than the cost of making diverse integrated designs (Ulrich, 1995; Erens and Verhurlst, 1997). In addition, educators can use the concept to broaden design students' notions of what industrial design practice is and can use the concept as a stepping stone for students to investigate flexible uses of design rather than focusing on typical one-off design projects.

The conducted research demonstrates that aesthetic flexibility is best suited for planned development processes of products where a congruent brand is 
the goal. These conditions make it possible not only to repeat design elements and features (Hestad, 2013; Warell, 2006; Karjalainen \& Snelders, 2010) but also to reuse brand-specific and brand-platform modules (Sudjianto and Otto, 2001; Sanchez, 2002), ultimately decreasing development time, lowering costs, and enabling gradual variation.

Therefore, the challenge for designers lies in creating enough aesthetic flexibility in designs to benefit from branded product architecture strategies, but not so much that it creates lock-in effects and therefore hinders development of new designs.

\subsection{The Industrial Design Product Portfolio Management model - strategic product portfolio management from a design perspective}

The second perspective focused on investigating what general design strategies existed in industrial design practice under the defined general research scope (section 1.2). The findings were used to adapt a visual model first developed by Rune Monö, who did not name the theoretical model, but described it as 'The product sign's relationship to the product range sign' (1997, p. 146). That is, product signs are not merely a designer's interpretation of what makes one product usable and compatible as product designs are influenced by competitors' products signs as well. Monö's model is an effort to describe how design strategies, such as MAYA (Loewy, 1951, 2002, pp. 277283), are influenced by the branding of product portfolios. What the model lacks, however, is a theoretical foundation and a wider understanding of how industrial design practice functions today.

By interviewing industrial design practitioners and investigating brand management, product portfolio management, and industrial design, a new theoretical model was developed (Table 7) - the Industrial Design Product Portfolio Management (IDPPM) model (Figure 19). The IDPPM model attempts to identify and explain how the different design strategies that influence industrial design practice. Both Monö and this research frame the theory around an existing portfolio and not the creation of a new portfolio as 
investigating how new portfolios are developed implies the creation of a new brand (cf. Kapferer, 2014; Keller et al., 2012).

The IDPPM model demonstrates that the two main themes, extension and updated strategies, function as follow. The first is to extend products $(\mathrm{P} 1,2,4)$ into existing category [A] to create a totally new product [D] as variants of existing products by extending an existing product line $[\mathrm{B}]$ or creating "vertical" versions $\left[\mathrm{C}, \mathrm{P} 4, \mathrm{c}^{\prime}\right]$ that are the same type of product but are differentiated through value and performance. The second main strategy is to carry out minor updates [E], redesigns [F], or revitalisations [G] to existing products [P1-4] to create a feeling of newness for consumers and to fend off competitors. An in-depth discussion follows that focuses on each of the two main themes.

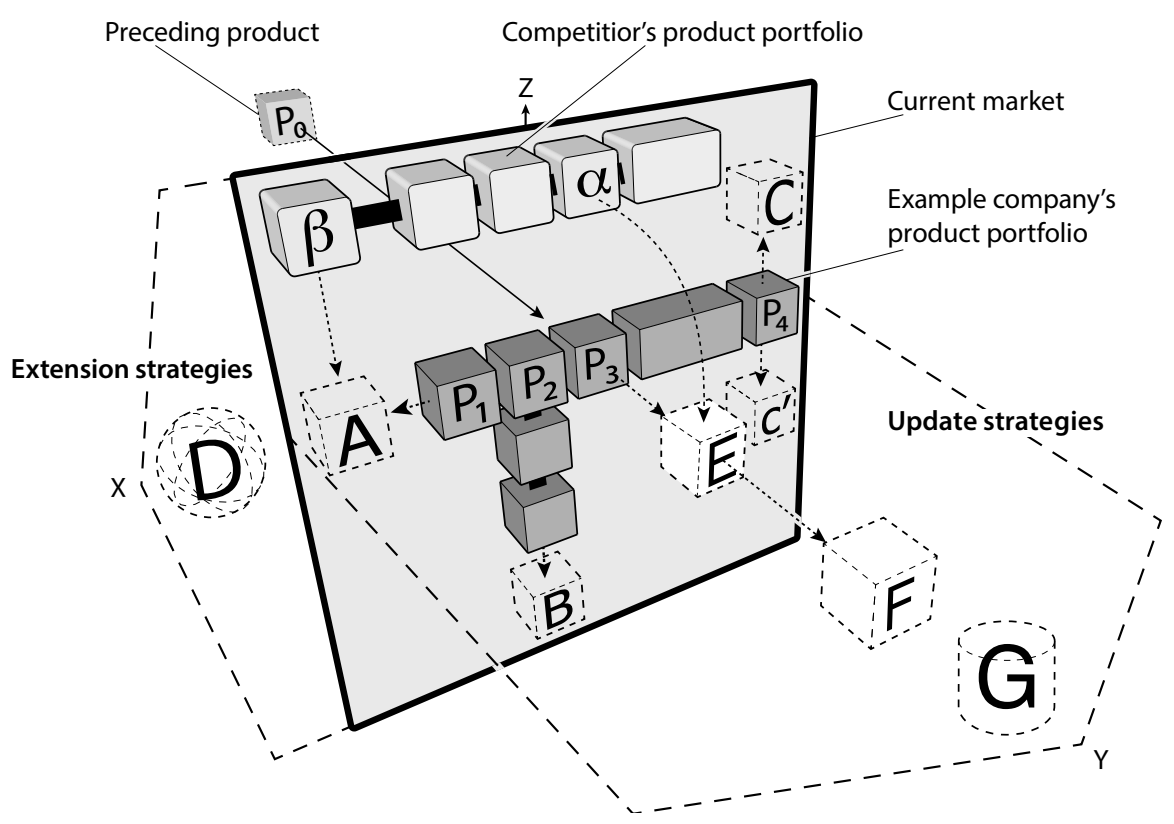

Figure 19. Final version of the Industrial Design Product Portfolio Management model (IDPPM model) illustrates how extension and redesign strategies are used to expand or update an existing portfolio.

Extension strategies, the grey square in the IDPPM model, primarily focus on maintaining a company's design DNA, features, elements (Warell, 2006; Person \& Snelders, 2010; Karjalainen \& Snelders, 2010; Hestad, 2013), 
and PODs (Keller et al., 2012) to preserve visual coherency throughout the portfolio. The general design strategy is to use positive associations and brand recognition as much as possible. Thus, the design teams aim to create visual coherence between new products and existing product architectures and platforms (Meyer and Lenherd, 1997) by adapting the design elements and features by reusing brand-specific and brand-platform parts (Sudjianto and Otto, 2001).

The main difficulty occurs when a company wants to move into an existing product category, or when it wants to create new-to-the-world products (Cooper et al., 2004a; Ulrich et al., 2020). In the first instance, the problem lies in adapting the design features with POP (Keller et al., 2012), which stipulates association to the product category. Second is to determine how much the feeling of newness (Ranscombe et al., 2012) needs to be infused into a category extension design so that the product can "live" at least seven years before it needs to be redesigned. The designer has to balance MAYA's reuse of brand-specific design features and brand-platform parts or reinterpret these to comply with new design trends. If the designers conclude that it is not feasible to carry-over existing design features, for example, because they are moving into a market $[\mathrm{A}]$ where existing designs $[\beta]$ does not allow for an easy adaptation, the designer should create a new design and only use a few design elements such as CMF and graphic design (Becerra, 2016). If this approach does not work or if the portfolio becomes overextended, a new brand should be created with its own product portfolio and product lines.

Vertical extension strategies [C] are costly and are predominantly applied if a product already exists in a market. Senior management could decide to initiate a vertical extension strategy if it deemed that the market is mature enough to handle the creation of diversified products (Aaker, 1997; Keller et al., 2012; Meyer \& Lehnerd, 1997). In this strategy, aesthetic flexibility needs to be used by designers to efficiently manage all versions, especially if the entire portfolio uses this strategy. To fully use this in all parts, both engineering and designing of the products need to be organised into architectures and platforms.

The design features need to be designed so that they can be scaled into value versions and at the same time create visual recognition in line with the overall design DNA. This is done by creating a main body shape that can cater to these changes while maintaining the product gist (Paper I), sharing graphics, colours, 
some materials, and general functions (Table 3) (Becerra, 2016, pp .57-63).

According to Sudjianto and Otto (2001), final design elements are then sorted into two types: brand-platform and brand-specific components. A second division is made to indicate the levels that constitute a market's vertical segmentation. Each level of brand-specific parts are separated by trim details, materials, accent colours, patterns, and functions. Brand-platform parts are only separated by colours and materials.

In the IDPPM model, a new-to-the-world (Cooper et al., 2004a) extension $[D]$ originates in the grey square to illustrate that it is expanding the existing product market into unexplored territory. This creates additional challenges. The strategy $[\mathrm{D}]$ is the most risky of the four extension strategies. When creating a totally new category of products (Kim and Mauborgne, 2005), the designer needs to invent new design features that can create both POD and POP associations (Keller et al., 2012) for the customer. It is also a huge opportunity for a company that wants to change its brand value. The new product and its versions can also be a way to enter a high-value level (Meyer \& Lehnerd, 1997).

In essence, the new-to-the-world or "revolutionary" strategy can be seen as a fusion of category extension $[\mathrm{A}]$ and redesign $[\mathrm{F}]$ processes, with a third element thrown into the mix: the designer's and engineer's own ingenuity. The description of this strategy has been criticised due to the fact that there is seldom, if ever, a completely new product brought to market, so it is difficult to draw distinct demarcations between the new-to-the-world strategy [D] and the redesign strategy [F]. In addition, although a new product might not have a direct predecessor, a competitor might offer a similar product or a cruder version with some of the same functionalities.

Lastly, the arrow labelled update strategies in the IDPPM model illustrates the second principal theme: a designer needs understand when a product portfolio is exposed to competitive markets. As described in 5.2, the two first strategies $[\mathrm{E}$ and $\mathrm{F}]$ are planned, but the last strategy $[\mathrm{G}]$ occurs only when necessary, primarily during a brand crisis.

When redesigning $[\mathrm{F}]$ products, a company needs to visually differentiate the new offering not only from competitors but also from the company's own product portfolio. That is, the company needs to decide what design features (i.e., elements) that constitute brand-specific components need to be changed 
and what brand-platform parts from older designs need to be kept. This is in line with what Raymond Loewy (1951, 2002, pp. 277-283) describe as Most Advanced Yet Acceptable (MAYA), but with the twist that the most advanced (MA) also needs to advance "away" from the current visual position while retaining the company's design DNA.

Depending on the type of product and the intentions of the management team, the redesign process can either reflect current trends or a more aesthetic exploration in order to create a new trend. For example, the visual product appearance of new smartphones in the European market has been more or less stagnant since the introduction of the iPhone, whereas the automotive, interior, and garment industries are constantly introducing new design updates that change consumers' visual brand perception. Thus, redesign strategies create a great opportunity to change or reposition existing brand's values and change the ways in which products are produced. If coordinated well, the new designs and new brand messages will impart the same values while reducing costs.

If this opportunity is missed, outdated parts are reused and unfavourable values are transferred into the new design and can even be reinforced (Keller et al., 2012). That is, companies need to create strategic design functions (Micheli et al., 2018) where designers can collaborate closely with management when developing new pivotal designs.

The interviews with the designers suggest two main strategies when redesigning a product portfolio. The first creates a separate design research project that focuses on creating a communal visual brand language (VBL) that guides product development within the portfolio. It consists of a CMF guideline (Becerra, 2016) and design proposals for a representative set of products. The VBL method makes it easier to create a coordinated product portfolio, especially when a company's design function is a major strategic design (MSD) function containing several design teams. A second redesign strategy is to constantly redesign prominent products, letting them be a guide for variant products, and make facelifts $[\mathrm{E}]$ of products in the portfolio that are not destined for a redesign within a three-year period. These are predominantly conducted as CMF updates of existing products to adjust products to new trends and in effect prolong the life-span of a product and create visual coherence between new and old products in the portfolio. 
Design updates, which focus on minor changes [E], need less strategic coordination with management than redesign [F], revitalisation [G], or creating products that are new-to-the-world, which can have a profound impact on a company's brand and resource allocation. The major difference between redesign $[\mathrm{F}]$ and revitalisation $[\mathrm{G}]$ is the condition of the company. If a company is in decline (Kapferer, 2014, p. 387; Keller et al., 2012, pp. 742-746), the designer needs to "reboot" the whole visual appearance of the portfolio and investigate new technologies.

Two main ideas can be seen here: the first is to draw inspiration from the company's own design history (i.e., design DNA), as in the Burberry example (The Economist, 2011) and VW Beetle example (Brown, 2003), and the second is to totally reinvent themselves, as in the case of Nokia, which shifted from making tyres and rubber boots to making mobile phones in the 1990s. The Nokia case is very similar to a new-to-the-world [D] strategy in that the designers had no prior design DNA to use, so they had to invent new PODs and product brands.

Finally, a designer has to be vigilant as new trends can render a portfolio visually obsolete and the overuse of explicit design DNA features can dilute the identity of strong products in the portfolio. Not all products in a portfolio are equally strong; generally, there are a few "star" (or hero) products that a consumer thinks of first when they hear a company's name (Kapferer, 2014, p. 43). These products need extra care and attention and should be differentiated from less well-known products in a portfolio. When a star product has its own design features, these should not be carried over into a new product category in order to preserve the star product's uniqueness. Companies that lack star products or only have weak ones should primarily focus on redesigning $[F]$ the portfolio's most noticeable products, moving into a new category of products $[\mathrm{A}]$, or creating a revolutionary product $[\mathrm{D}]$ that can become a star product, strategies that generate an opportunity or require creating a new design DNA. The goal for the designers within a management function is to champion the development of a few products with striking visual characteristics that can work as an eyecatcher for the whole portfolio. By doing so, the design function can elevate its status from executing other functions and demands to becoming a partner that influences the course of the company, a finding in line with Micheli et al.'s (2018) description of strategic industrial design function. 
In academia, the IDPPM model expands the notion of what types of product development projects can be conducted, furthering the current understanding of the connection between industrial design, brand management, and product development. Previously, each research field had its own vocabulary and definition of similar project types, creating unnecessary confusion in crossdisciplinarity research. From a teaching and professional point-of-view, the IDPPM model can be used to better understand the practices of industrial designers (Corradi et al., 2010), specifically the use of aesthetic flexibility. Design management in a company can more easily determine what direction a product in the portfolio should take and that it is not always necessary to redesign viable products as sometimes a facelift or a minor design update is sufficient.

By creating a visual theoretical model that fits all seven strategies, several disciplines can coordinate their aspirations in a design project. The different arrows and boxes create a visual understanding that new-to-the-world projects are expanding the current market so there might be a need for more resources and redesigns might require more resources as it is more difficult to determine if they will be successful, unlike facelifts.

\subsection{Decision-making in industrial design practice}

The last perspective, Design Judgment in Manufacturing Companies, investigated how general decision-making in the industrial design practice is conducted and how this influences the organization of strategic design functions in manufacturing companies. Research has concluded that industrial designers contribute both on an operative and a strategic level in manufacturing companies (Micheli et al., 2018; Tovey, 1997; Giannini et al., 2006; Johansson and Holm-Svengren, 2008; Verganti, 2009; Stompff and Smulder, 2013). That is, industrial design functions are often part of strategic decision-making that includes several non-design functions such as management, engineering, and marketing.

Evidence for all of Micheli et al.'s (2018) points for elevating a design function to a strategic level was found in four of the five case companies - in all of the 
major strategic design functions (company A, C, and D) and in one of the single strategic design functions (company E). The creation of design councils and the instalment of a chief design officer (CDO) on the board of directors were deemed as evidence of both granting autonomy to the design functions and formalising their position within the company. The layered decision process in major strategic designs (MDS) provides a formalised design judgment process (Tovey, 1997; Giannini et al., 2006; Buxton, 2007; Johansson and Holm-Svengren, 2008; Verganti, 2009; Stompff and Smulder, 2013) where experienced designers and other specialists have an opportunity to evaluate and improve the proposals. However, involving non-design functions can slow down the design decision-making process and prolong development time.

Respondents in MSD functions found that a formalised design council makes it easier to have focused design judgment discussions regarding whether concepts reach a desired "wow" level. Approval from senior management makes it easier to champion the design proposals when entering cross-functional discussions (Michlewski, 2008; Ulrich et al., 2020 pp. 15-45; Lawson and Dorst, 2009; Cross 2003; Del Coates, 2006; Buxton 2007), which lowers the design continuum. Furthermore, respondents from company $\mathrm{C}$ used the design council to influence development projects that 'needed design attention'. This is evidence of preventing development projects from surpassing the "shame level". A negative side of design councils may be that other functions feel side-stepped when chief designers' intuitive design judgment influences their rationally-based decisions.

The respondents from single strategic design (SSD) companies (companies B and $\mathrm{E}$ ) stated that a diversity of perspectives from other design and engineering disciplines can either positively or negatively influence the development of products. That is, a diversity of influences not only can bring new perspectives to a design but also can inhibit communication as the participants might not share the same frame of reference and technical knowledge. This indicates that design chiefs in SSD functions are more isolated in their design judgment than MSDs, making it harder to withstand influence from other non-design chiefs. The chief designer at company E described an Earl-and-Sloan-like collaboration (Gartman 1994) to gain support from senior management. A formalised design council and a CDO function on the board of directors is a good indicator that a design function has reached a strategic level (Gartman, 1994; Buxton, 2007; Johansson and Holm-Svengren, 2008; Verganti, 2009; 
Micheli et al., 2018). Informal personal collaborations between a chief designer and senior managers are deemed less strategic; if someone is replaced, the collaboration needs to be reinstated.

Because company B's single design function was still being formalised at the time of the interviews, it was not possible to determine the level of support they had from senior management. The five levels between the chief designer and the board of directors and no direct "back channel" indicated a marginal influence. One of the respondents in company B stated that when the person worked as an individual strategic designer (IDS) before the formalization of the current design, most dual design decisions had been made between the designer and consultant designers and only a few important design decisions had been made with management. The respondent also described that they had used several design agencies when developing different products in the portfolio. That is, a manufacturing company's design strategy could potentially be influenced by different judgment processes, impeding the creation of a coherent design DNA (Hollins \& Pugh, 1990; Lewalski, 1988; Warell, 2006; Karjalainen \& Snelders, 2010) and creating less incentive for aesthetic flexibility.

Design consultants only work on the product they are hired to develop, so there is no guarantee that they will be working on a facelift or a minor design update let alone the redesign - i.e., they have less motivation to consider the company's design DNA. Furthermore, consultants often do not have the time to fully understand the manufacturing company's specific issues, making it more challenging when compromises have to be made in the design compromise continuum phase.

Knowledge of how the design judgments and multidimensional design decisions were made are also restricted to a few key persons, creating a significant risk for a company. Therefore, manufacturing companies that only use external design services (EDS) are at a greater risk as all the design decision-making knowledge remains within the consultancy firm. However, it is easier for management to quickly change the design by hiring a new design consultancy firm. 


\subsection{Reflection on the conducted design research}

This thesis has taken an exploratory approach where my preunderstanding and experiences of the industrial design field have influenced the initial research in Perspective 1. The exploration lead to cumulative findings where discoveries in the earlier studies conducted in Perspective 1 have formed the basis for research objectives in Perspectives 2 and 3. This hermeneutic research approach, as described by Alvesson and Sköldberg (2017, pp.139-141), has made it possible to investigate and further develop the phenomenon, ideas, and theories in a structured manner. The explorations have been conducted as both theoretical and empirical investigations.

The development of new theories and the creation of theoretical models originated from both cross-disciplinary literature reviews (Wohlin, 2014; Badampudi et al., 2015) and empirical findings (Miles et al., 2014; Yin, 2014; Eisenhardt, 1989). The different literature fields had different amounts and types of published research literature. The design field had fewer relevant journal articles, so the literature review had to be expanded into non-peerreviewed books and conference papers (Wohlin, 2014). The other fields had more journal articles but few that directly touched on industrial design practice. Therefore, more indirect text analyses and conclusions had to be drawn to uncover connections between the different research fields.

The indirectness of the analysis means that the author's own judgments and biases may play a role in the results and final conclusions. Developing theoretical models (Hallberg 2020, pp. 76-80) was a good way to sort and organise theoretical findings in literature, which was especially true with the development of the IDPPM model. The use of several iterative sketch processes and adding new findings from literature and product examples meant that the relationships between the different found strategies could be intuitively explored (Schön, 1987) and rationally discussed with supervisors and other researchers.

A drawback with the theoretical visualization was that it was made in $3 \mathrm{D}$, which made it harder for some people to understand. As a result, $2 \mathrm{D}$ versions had to be made to accommodate all people. The sketching process was also an important method when developing high-level theoretical models (Chakrabarti \& Blessing, 2014, pp. 49, 54, 59) from the empirical findings in Perspective 3. 
The design judgment "wow - compromise - shame" model could not have been developed without the visualization of the coded data in the study described in Paper VI.

The empirical studies were conducted using case study methodology as described by Yin (2014) and Miles et al. (2014). The qualitative data process by Miles et al. (2014) was a useful framework in the conducted research as it created an outline for the two case studies and the design workshop.

The data collection processes focused on gathering as much diverse information as possible as the respondents were busy professionals. The semistructured interview process (Yin, 2014; Miles et al., 2014) made it possible for the researcher to use his own experience in the field of industrial design as respondents reacted positively to being interviewed by someone with the same background. The interview process was developed and tested in Case study A, so it was reused in Case study B. This made the researcher more confident during the interviews and the results from the two studies could be merged.

The use of mediating tools such as product photographs was necessary because the design studios were inaccessible to visitors. By using photographs of market-introduced products, respondents could discuss their design practice more freely; however, no future designs could be discussed.

Unfortunately, only artistically-trained respondents made comments and marks and they did not get any instructions on how much or what type of marks should be made. That is, some respondents marked the photographs extensively, some not at all.

The collected data were so rich that they could be used in all three Perspectives. The analysis of the semi-structured data was time-consuming as several sorting and coding attempts had to be conducted before patterns and themes emerged (Glaser and Strauss, 1967; Yin, 2014; Miles et al., 2014). The method was used to find answers to the research questions and to evaluate the theoretical model, IDPPM.

However, the gathered data originate from fairly homogenous companies, characterised by high-tech and complex products, with a solid form, modularized architecture, and a mature organization, characteristics that limited the evaluation slightly. Conversely, the narrow scope rendered it less efficient to draw general conclusions where design consultant agencies, other market segments, and novice designers are included. Also, the focus on Swedish 
design teams makes it impossible to draw conclusions about the influence culture has on design processes. On the positive side, the data originated from senior designers with more than 15 years of practical experience.

By using exploratory approaches in the initial coding processes (Glaser and Strauss, 1967; Miles et al., 2014), the researcher used knowledge gained both from theoretical studies and from experience with practicing industrial design. Second, two more directed meta-coding schemes (Micheli et al., 2018) were used, one in Perspective 2 and one in Perspective 3. The meta-coding methods consisted of the researcher using the different IDPPM strategies as codes (Perspective 2) and the dual decision theory found in the literature (Perspective 3). By using different coding processes, diverse results could be gained from the same data.

The iterative method of qualitative coding is time consuming and challenging as leaving the material unexamined for too long requires re-examining not only the codes but also the original transcriptions. Although this condition opens up for new interpretations, it prolongs the data analysis process. The findings from the empirical studies were then used to construct the theoretical models found in all three perspectives.

Designing and executing the workshop (Perspective 1) gathered implicit and explicit knowledge of actual performance of a design task, or what Schön (1987) calls doing-in-action. Taking a "fly-on-the-wall" approach, which primarily consisted of taking photographs, videos, and fieldnotes, was a useful way to collect data during the design workshop (Martin and Hanning, 2012). In addition, this approach to data collection meant the researcher did not interrupt the participants too much during the immersive phases of the two design tasks.

However, this the workshop was only three hours, an extremely short time for a real design project (cf. Kannengiesser and Gero, 2018). The participants lacked any real monetary or credit compensations other than coffee and cake for their participation in the workshop. That is, unmotivated participants left half way through the workshop, reducing the total amount of final participants in the study. This shortcoming needs to be addressed in future workshop studies. 


\subsection{Validity of research results}

Yin (2014) and Miles et al. (2014, pp. 45-49) describe four standards qualitative research needs in order to be judged as valid: construct validity, internal validity, external validity, and reliability. Construct validity concerns developing a relevant set of constraints that frame the research scope and that can be traceable and measurable.

The primary tactics are to use multiple sources of evidence, to create a chain of evidence during the data collection, and to have drafts of the case study sent to relevant persons for review and feedback. In this research, the scope was defined narrowly using six of Miles et al.'s criteria (2014, p. 29) to frame the gathered qualitative data and compare data from different respondents.

The focus on one type of organisational function (i.e., design) by primarily interviewing senior designers and design engineers about their design practice and several Swedish manufacturing companies is a testimony of construct judgment. Drafts of the case studies have been sent to supervisors for reviews.

Internal validity is primarily used when doing explanatory case studies of specific events where one action leads to another although it is also used as a means to determine the internal strength of inferences made during data analysis processes in other types of case studies. According to Yin (2014, pp. 47-48), specific tactics to determine internal validity are difficult to identify, but Yin recommends judging whether patterns match the data analysis and whether explanations and findings create coherent meanings, address rival explanations, and use logical models to explain the results. Internal validity in this research has been achieved through patten matching (Miles et al., 2014) in the empirical evaluation of the theoretical IDPPM model (Papers III and V) and when dual decision-making theories supported the empirical design decision-making (Paper IV). The method and theories developed in Paper I need further investigations, but the primary validation, using products sold in stores, indicates that the method and theory are effective tools for the phenomena under investigation.

External validity in multi-case studies means the findings can be generalized between each case and beyond the scope of all case studies. By using the same semi-structured interview guide and general interview method with mediating tools, general conclusions can be drawn between the cases (Eisenhardt, 1989; 
Miles et al., 2014). Findings in Papers III-IV were developed into high-level theoretical models that on a general level explains what product portfolio management strategies designers use in their day-to-day practice. The organisation of a design function and the model of what constitutes a design judgment are also applicable outside the research scope.

Reliability in research implies conducted studies can be replicated by later researchers using the described methodology. Absolute reproducibility cannot be achieved due to the hermeneutic approach taken by the researcher and the nature of design research itself (cf. Chakrabarti \& Blessing, 2014; Rodgers \& Yee, 2018). Therefore, here the reliability lies in that data gathering and the analysis methods, which are described in detail either in this thesis or in the seven papers that constitute this thesis, making it possible to replicate the research described.

In Perspective 1, the phenomenon was partially evaluated through the design workshop with industrial design students and researchers in design. It was evaluated on the premise that they could complete the workshop task and they had prior knowledge of the general conception of the phenomenon.

A basic counting of how often experienced practitioners described certain findings was used to verify the conclusions made in Perspective 2. The verification was supported with representative quotations. Conclusions made during Perspective 3 were verified by comparing theoretical concepts against empirical results originating from interviewees with the right background. 


\subsection{Limitations}

This research has several limitations that need to be considered. As described, this exploratory and qualitative research is based on a hermeneutic approach, which makes the generalizability of the findings problematic. In Perspective 1, the first study, the product gist method was only evaluated on one homogenous product category, rendering a distinct result that lends itself for clear visual analysis that corroborated the collected theory but produced less data on how to analyse heterogenic product categories. The method needs to be assessed by experienced designers to determine its usefulness. Because this multicase research project did not analyse several product gist results (Eisenhardt, 1989; Miles et al., 2014), the results may not be generalizable to larger or entire product portfolios. Hence, the method requires validation by other studies. In addition, the multi-case studies had a narrow scope, focusing on experienced in-house designers in leading positions; this rendered good insights into their design practice. Unfortunately, this approach also made it harder to draw general conclusion encompassing design consultants or other types of design practices such as furniture, garment, and graphic design.

By only researching design functions in Sweden, little can be said of cultural influence on design practice, although this culturally-limited focus also meant there was no need to regard cultural differences in the data analysis. All codes, quantitative results, and quotations were chosen and interpreted by the author, so an interpretation bias is possible. The quotations were translated into English by the author, whose mother tongue is Swedish.

Because the focus of the current study was not on management functions such as CEO or VP, this remains an area for future research regarding their perspective on the design function in decision-making and how they perceive their position within a company. Junior designers should also be part of future studies, as their perceptions of the design judgment processes could be insightful.

Extending the interview studies to design consultants would have rendered insights into what type of industrial design projects they encounter, how they interact with design functions at manufacturing companies, and how they make design judgments when they are in a dependent situation. These expansions of the case studies would have produced a more diverse dataset, but at the cost of needing to do more complex data analysis processes. 
Additional limitations in Perspective 1 included the performance the design workshop (Paper II). The participants were industrial design students and design researchers, so none had experience as practicing industrial designers. Their lack of professional experience limited the conclusions regarding how the carry-over strategy manifested itself in industrial design practice.

The number of participants was too high and the time was too short to do in-depth observation studies during the workshop; it became difficult to follow all participants' individual aesthetic choices and design decisions, making it challenging to find and track their entire design progress. However, the participants were immersed in the workshop, so the task seemed to inspire them.

The seven design strategies of the IDPPM model were validated by professional designers and brand managers who interpreted and analysed the collected data from Case Studies A and B. However, no direct questions or visual verifications of the model were used with the respondents. In addition, the model only encompassed how existing brands developed and not when new brands were created.

Although the notion is that some of strategies (e.g., New-to-the-world, redesign, and category extension) may be applicable, in altered versions, when developing or creating a new product brand.

A similar limitation arises in the organization of a design function and how it influences the decision-making process in industrial design practice. The design judgment study in Perspective 3 focused on what signifies established design functions and not on how novice functions are developed into strategic design functions.

The empirical data covers only very large or single teams, not midsize functions, so there might be more steps between major strategic design teams and single strategic design teams. As described earlier, the multi-case study does not include consultant agencies, so the investigation does not examine how these agencies are organised or how they interact with a manufacturer's own design function. 


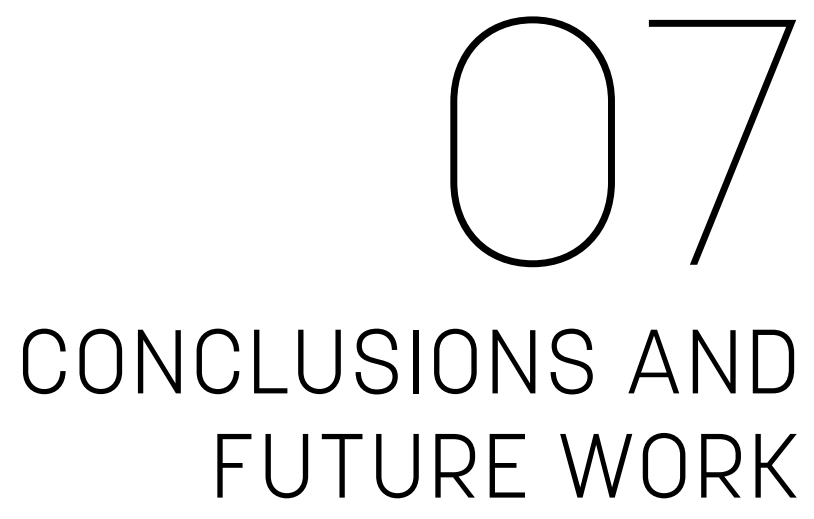

RQ1: How does the strategic thinking of industrial designers influence the development of products in large product portfolios?

This research has identified and described a new phenomenon within design practice - aesthetic flexibility. Aesthetic flexibility describes how industrial designers adapt when designing large product portfolios. It occurs when the design strategies such as MAYA, POP, and POD are influenced by the need to modularize a product portfolio.

Aesthetic flexibility is an advanced design practice as its manifestations were found in interviews with senior designers with more than 15 years of experience at several companies and not during the workshop, which included students and design researchers who had no work experience in industrial design. In addition, aesthetic flexibility requires practice to be effective in competitive market environments such as the automotive industry. The design practice has been described and connected to the proposed IDPPM model.

RQ2: How does industrial design in a manufacturing company foster strategic decision-making when participating in the management of a company's existing product portfolio?

This research concludes that industrial design projects can be strategically managed in seven ways to evolve existing product portfolio: category extension, product line extension, vertical extension, new-to-the-world, minor design update (i.e., facelift), redesign, and revitalisation. The research ordered them 
into two main themes - extension and update. These themes were evident in the literature, product examples, and interviews with professionals. The findings are presented and organised into a theoretical three-dimensional model - i.e., the Industrial Design Product Portfolio Management model (IDPPM).

The model describes how industrial designers use aesthetic flexibility, depending on if a product portfolio is extended or updated. On a general level, the research concludes that product modularity and brand extension of branded house portfolios use the same main ideas. Both strategies aim at expanding a portfolio using as few means and resources as possible.

The IDPPM is a powerful education tool for both professionals wanting to understand different design strategies and their possibilities as well as for junior designers and students. The model depicts not only the different strategies but also how the strategies relate to each other.

RQ3: How do intuitive design decisions and rational compromises in industrial design practice influence decision-making in strategic design?

The results show that intuitive decision-making was a core feature of design judgment and decision-making. The respondents described that the intuitive decisions needed to be rationally evaluated to be improved and to be viable for production. Thus, both intuitive design judgment (type 1) and multidimensional design decisions (type $1+$ type 2 ) were used to develop new products.

Intuitive design judgments were used both in positive and negative evaluations of concepts in order to safeguard the product brand so that no poorly-designed products entered the market.

A model was created from the findings to illustrate the impact of non-design functional inputs on design proposals. The model shows a compromise process between reaching a "wow" appraisal and avoiding a "shame" judgment. The empirically-developed model explains a keystone of the sense-making process intuitively performed by a practicing designer. 


\subsection{Future works}

This design research has generated several avenues for future studies of the industrial design practice. The phenomenon of aesthetic flexibility should be further explored in other fields of design to strengthen its generalizability and to investigate whether more design strategic aspects can be included. In addition, future studies should develop practical methods or tools to facilitate the increasing need of designing sustainable products where designed parts can be reused and shared to a greater extent, resulting in the use of fewer resources, both natural and financial resources. The aspiration is that the new method would be applicable for design students and professionals alike.

The product gist method should be tested more broadly by professionals and design students to improve upon its practicality. Using AI or machine learning, for example, might speed up the current methods and uncover trends that this fairly analogue method cannot.

In addition, the IDPPM could be integrated into existing product development models such as the one described by Ulrich et al. (2020). More interview studies should be conducted to validate the IDPPM; these studies should include nondesign respondents such as executives, managers, production managers, and mechanical engineers.

A metrics should also be developed for the model to more explicitly differentiate between the identified strategies. Lastly, the model's value as a pedagogical tool to explain the complex interlink between management, branding, product development, and industrial design when developing products for portfolios should be explored.

New case studies should be conducted to explore other countries and markets as this would allow for a broader comparison of organisational structures and decision-making processes. Additional interviews with senior management and other function leaders such as R\&D, marketing, and production would provide perspectives on and insights into the design function's different decision processes heretofore ignored. Separate case studies with design consultants and how they manage design decisions would further the knowledge of how design judgments are defended in a dependent situation or when the customer has no design experience. These studies may suggest ways to organise a design 
function and provide new rationales for design judgments and compromises, adding to the design-decision continuum in Paper VI.

To understand and apply aesthetic flexibility constitutes a key knowledge for industrial designer and design engineers who aim to work with complex products and large product portfolios. It entails a way of thinking in design practice that gives the practitioner increased insights into the possibilities of developing product systems where fewer design components are shared by several products without losing brand identity. 


\section{BIBLIOGRAPHY}

Aaker, D., 1997. Should You Take Your Brand to Where the Action Is? Harvard Business Revierw, Volume 75, Issue 5, pp. 135-143.

Allen, A. P., and Thomas, K. E., 2011. A Dual Process Account of Creative Thinking, Creativity Research Journal, volume 23, Issue 2, pp.109-118.

Alvesson, M., and Sköldberg, K., 2017.Tolkningoch reflektion, vetenskapsfilosofi och kvalitativ metod. 3rd ed, Studentlitteratur AB, Lund, Sweden

Andersson, T., 2016. Aesthetic Flexibility - Modularity of Visual Form in Product Portfolios and Branded Products. Licentiate Thesis, Linköping University, LiU-Tryck.

Arvola, M., Lundberg, J., and Holmlid, S., 2010. Analysis of Precedent Designs: Competitive Analysis Meets Genre Analysis. In Proceedings of the 6th Nordic Conference on Human-Computer Interaction (NordiCHI 201O), pp. 23-31. Reykjavik, Iceland, 16-20 Oct. 2010. New York, N Y: ACM Press.

Atlas Copco, 2018. Handheld pneumatic drills, Tensor SR31 and ST31. [Received 18 May 2018].

Atkinson, T., and Claxton, G., 2003. The Intuitive Practitioner, second ed. Open University, Press, Philadelphia, USA.

Badampudi, D., Wohlin, C., and Petersen, K. (2015, April). Experiences from using snowballing and database searches in systematic literature studies. In Proceedings of the 19th International Conference on Evaluation and Assessment in Software Engineering, pp. 1-10.

Bago, B., and Neys, W., 2020, Advancing the specification of dual process models of higher cognition a critical test of the hybrid model view, Thinking छ઼ Reasoning, Volume 26, Issue 1, pp.1-30.

Barapour, M., Rehammar, B., and Rahe, U., 2012. A comparison of Diary Method Variations for Enlightening Form Generation in the Design Process. DRS 2012, 1-4 July, Bangkok Chulalongkorn University Bangkok, Thailand. 
Baldwin, C. Y., and Clark, K. B., 2000. Design rules: The power of modularity (Vol. 1). MIT press.

Baxter, P., and Jack, S., 2008. Qualitative Case Study Methodology: Study Design and Implementation for Novice Researchers. Qualitative Report, Volume 13, Issue 4, pp. 544-559.

Becerra, L., 2016. CMF Design - The fundamental Principles of Colour, Material and Finish Design. Frame Publishers, Amsterdam, Netherlands. Blaszczyk, R. L., \& Wubs, B., 2018. The Fashion Forecasters, A hidden history of color and trend prediction, Bloomsbury Publishing, London, UK.

Boyd Davis, S., and Gristwood, S., 2016. The structure of design Processes: ideal and reality in Bruce Archer's 1968 doctoral thesis, Design research Society 50th Anniversary conference 27-30 June Brighton UK future focused thinking.

Brown, S., Kozinets, R. V., and Sherry Jr., J. F., 2003. Teaching Old Brands New Tricks: Retro Branding and the Revival of Brand Meaning. Journal of Marketing, Volume 67, Issue 3, pp. 19-33.

Buxton, B., 2007. Sketching User Experiences: Getting the Design Right and the Right Design. Morgan Kaufmann, San Francisco, CA.

Catalano, C.E., Giannini, F., Monti, M., and Ucelli, G., 2006. A Framework for the Automatic Annotation of Car Aesthetics. Artificial Intelligence for Engineering Design, Analysis and Manufacturing, Volume 21, p. 73-90.

Chakrabarti, A., and Blessing, L. T. M., 2016. An Anthology of Theories and Models of Design, Philosophy, Approaches and Empirical Explorations. Springer, London, UK.

Chow, R., 2010. What should be done with the Different Versions of Research Through Design. in Entwerfen. Wissen. Produzieren. Designforschung im Anwendungskontext, edited by C. Mareis, G. Joost, and K. Kimple. Bielefeld: Eine Publikation der DGTF. Transcript Verlag.

Clarke, S., 1999. Managing Design: The Art and Colour Section at General Motors, 1927-1941, Journal of Design History, Vol. 12, Issue 1, pp. 65-79.

Cooke, R., 2012. The History of Matematics - A Brief Course. 3rd ed, John Wiley\& Sons, Hoboken, New Jersey.

Cooper, R.G., Edgett, S.J., and Kleinschmidt, E.J., 2004a. Benchmarking Best NPD Practices - I. Research-Technology Management, 47(1), pp. 31-43.

Cooper, R.G., Edgett, S.J., and Kleinschmidt, E.J., 2004b. Benchmarking Best NPD Practices - II. Research-Technology Management, 47(3), pp. 50-59. 
Corradi, G., Gherardi, S., and Verzelloni, L., 2010. Through the practice lens: Where is the bandwagon on practice-based studies heading? Management Learning, volume 41, Issue 3, pp. 265-283.

Cotes, D., 2003. Watches tell more than time - product design, information, and the quest for elegance. McGaw-Hill, New York, USA.

Cross, N., 2001. Designerly ways of knowing: Design discipline versus design science. Design issues, Volume 17, Issue 3, pp. 49-55.

Cross, N., 2006. Design as a discipline. Designerly Ways of Knowing, p. 95103. Springer.

C. Whan Park, Milberg, S., and Lawson, R., 1991. Evaluation of Brand Extensions: The Role of Product Feature Similarity and Brand Concept Consistency. Journal of Consumer Research, Vol. 18 (Sept.), pp. 185-193.

Dane, E., and Pratt, M., G., 2009. Conceptualizing and measuring intuition: A review of Recent Trends. International Review of Industrial and Organizational Psychology, Volume 24.

Davis M.L., 1987. Visual design in Dress. Engelwood Cliffs, NJ:Prentice-Hall.

Desmet, P., M., A., Porcelijn, R., \& van Dijk, M., B., 2007. Emotional Design; Application of Research-Based Design Approach. Know Techn Pol, Springer, Volume 20, pp. 141-155.

de Neys, W., and Pennycook, G., 2019. Logic, Fast and Slow: Advances in Dual-Process Theorizing. Directions in Psychological Science, Association for Psychological Science, volume 28, Issue 5, pp. 503-509.

de Wit, B., and Meyer, R., 2010. Strategy: process, content, context: an international perspective. Cengage Learning EMEA.

Diffner B., 2011. Combining Flexibility and Efficiency in Automotive Assembly - Preparing for New Powertrain Vehicles. Licentiate thesis, Linköpings University, Linköping Sweden.

Dijksterhuis, A., Bos, M. W., Nordgren, L. F., and Van Baaren, R. B., 2006. On making the right choice: The deliberation-without-attention effect. Science, Volume 311, Issue 5763, pp. 1005-1007.

Dijksterhuis, A., and Nordgren, L. F., 2006. A theory of unconscious thought. Perspectives of Psychological Science, Volume 1, Issue 2, pp. 95-100.

Durling, D., 1999. Intuition in Design, A perspective on designers' creativity. Bulletin of $4^{\text {th }}$ Asian Design Conference International Symposium on Design Science. Nagaoka, Japan, October.

Eisenhardt, M. K., 1989. Building theories from case study research. Academy of Management Review, Volume 14, Issue 4, pp. 532-550. 
Epstein, S., 2008. Intuition from the perspective of cognitive-experiential selftheory. Intuition in Judgment and Decision making, pp. 23-37, New York: Lawrence Erlbaum Associates.

Erens F., and Verhulst K., 1997. Architectures for product families, Computers in industry, Volume 33, pp. 165-178.

Euroencap, 2018. www.euroncap.com [Accessed 06 April 2018].

Evans, J. S. B. T., 2008. Dual-processing account of reasoning, judgment, and social cognition. Annual Review of Psychology, Volume 59, pp. 255-278.

Evans, J. S. B. T., and Stanovich K. E., 2013 Dual-process theories of higher cognition: advancing the debate. Perspectives on Psychological Science, Volume 8, Issue 3, pp. 223-241.

Farquhar, P.H., 1989. Managing brand equity. Marketing Research, Volume 1, Issue 3, pp. 24-33.

Frayling, C., 1993, Research in Art and Design. Royal Collage of Art Research Papers, volume1, Issue 1, pp. 1-5.

Fielden, G. B. R., 1963. Engineering Design H.M.S.O., London, UK.

Gartman, D., 1994. Harley Earl and the Art and Color Section: The Birth of Styling at General Motors. Design Issues, Volume 10, Issue 2, pp. 3-22.

Giannini, F., Monti, M., and Podhle, G., 2006. Aesthetic-driven tools for industrial design, Journal of Engineering Design, Vol. 17(3), pp.193-215.

Glaser, B. G., and Strauss, A., 1967. The discovery of grounded theory. Aldine de Gruyter, Hawthorne, NY, USA.

Goode, M.R., Dahl D.W., \& Moreau C.P., 2013. Innovation Aesthetics: The Relationship between Category Cues, Categorization Certainty, and Newness Perceptions. Journal of Product Innovation Management, Volume 30, Issue 2, pp. 192-208.

Göteborgs-Posten, 2021. Rimfrost ställer till det i spårvagnstrafiken. Olle Råde and Etezaz Yousuf, https://www.gp.se/nyheter/g\%C3\%B6teborg/ rimfrost-st\%C3\%A4ller-till-det-i-sp\%C3\%A5rvagnstrafiken-1.39776945 [Accessed Jan. 12, 2021]

Haidt, J., 2007. The new synthesis in moral philosophy. Science, Volume. 316, pp. 998-1002.

Haidt, J., and Kesebir, S., 2008. In the forest of values: why moral intuitions are different from other kinds, Intuition in judgment and decision making, pp. 209-229, New York, USA.

Hallberg, N. L., 2020, Teoretisk problematisering, tumreglerförsamhällsvetare och ekonomer. Studentlitteratur, Sweden. 
Hayashi, A. M., 2001. When to trust your gut. Harvard Business Review, Volume 79, Issue 2, pp. 59-65.

HDK-Valand - Academy of Art and Design, 2020. https://www.gu.se/en/hdkvaland [Accessed Nov. 26, 2020]

Hertenstein, J. H., Platt, M. B., and Veryzer, R. W. (2013). What is' good design'. An investigation of the complexity and structure of design. Design Management Journal, Volume 8, Issue 8.

Hestad, M., 2013. Branding and Product Design: An Integrated Perspective. Farnham, UK: Grower Publishing.

Heskett, J., 1991. Industrial Design. Thames and Hudson, Singapore.

Hilti, 2020. https://www.hilti.group/content/hilti/CP/XX/en/products/ product-overview/product-overview.html [Accessed 06 May 2020].

Hodgkinson, G. P., Langan-Fox, J., and Sadler-Smith, E., 2008. Intuition: A fundamental bringing construct in the behavioural sciences, British Journal of Psychology, Volume 99, pp. 1-27.

Hogarth, M. R., 2010. Intuition: A Challenge for Psychological Research on Decision Making, Psychological Inquiry, Volume 21, pp. 338-353.

Hollins B., and Pugh S., 1990. Successful Product Design. London: Butterworths.

Hounshell, D.A., 1984. From the American System to Mass production 18001932. The Hopkins University Press, Baltimore and London.

Hudson, J. M. and Viswanadha, K., 2009, Can "Wow" be a design goal?, Interaction, January and February, pp. 58-61.

Husqvarna, 2016. Consumer Brands. [online] Available at: <http://www. husqvarnagroup.com/sv/verksamheten/consumer-brands [Acce 21 Feb.].

Husqvarna, 2018. Chainsaws. [image online] Availableat: <http://www.husqvarna. com/se/products/chainsaws/136-li-batteri/> [Accessed 9 April 2018].

Jiao J. R., Simpson, T.W., and Siddique Z., 2007 Product family design and platform -based product development: a state-of-the-art review. Journal of Intelligent Manufacturing volume 18, pp. 5-29.

Johansson, U., and Holm-Svengren, L., 2008. Patterns of interaction, A study of relations between designers, engineers, marketers, and top management in four companies. Proceedings, Design Management Institute, education conference, Paris.

Jose, A., \& Tollenaere, M. 2005. Modular and platform methods for product family design: literature analysis. Journal of Intelligent manufacturing, volume 16, Issues 3, pp. 371-390. 
Kahneman, D., and Frederick, S., 2002. Representativeness revisited: Attribute substitution in intuitive judgment. In Gilovich, T., Griffin, D., and Kahneman, D., (Eds.), Heuristics of Intuitive Judgment: Extensions and Applications, p. 49-81, Cambridge Univ. Press, MA, USA.

Kahneman, D., 2011. Think Fast and Slow. Farrar, Straus and Giroux, NY, USA Kannengiesser, U., and Gero, J. S., 2019. Design Thinking, fast and slow: A framework for Kahneman's dual-system theory in design, Design Science, Volume 5, Issue 10, pp. 1-21.

Kapferer, J-N., 2014. The new strategic Brand Management: Advanced insights $\Xi$ strategic Thinking, 5ed. Croydon, United Kingdom.

Karjalainen M., 2004. Semantic Transformation in Design: Communicating Strategic Brand Identity through Product Design References. Helsinki: University of Art and Design.

Karjalainen M., and Snelders D., 2010. Design Visual Recognition for the Brand. Journal of Product Innovation Management, Volume 27, p.6-22.

Kellaris, J.J., and Kent, R.J., 1993. Exploring Responses Elicited by Music Varying in Tempo, Tonality, and Texture. Journal of Consumer Psychology, Volume 2, Issue 4, pp. 381-401.

Keller, K.L., Aperia, T., and Georgson, M., 2012. Strategic Brand Management: A European Perspective. 2ed.

Klimchuk, M.R., and Krasovec, S.A., 2012. Packaging Design: Successful Product Branding from Concept to Shelf. 2ed. John Wiley \& Sons, Inc., Hoboken, New Jersey.

Kippendorf, K., 1989. On the essential context of artefacts or on the proposition that "design is making sense (of things)". Design Issues, Vol. 5(2), pp. 9-39.

Kim W.C., and Mauborgne R, 2005. Value Innovation: A Leap into the Blue Ocean. Journal of Business Strategy, Volume 26, Issue 4, pp. 22-28.

Kitchenham B.A., and Chartes S., 2007. Guidelines for Performing Systematic Literature Reviews in Software Engineering. Version 2.3, EBSE Technical Report, EBSE 2007-1, Keele University.

Konstfack, 2020. University of Arts, Crafts and Design, https://www. konstfack.se/en/ [Accessed Nov. 26, 2020]

Kotler P.G., and Rath, A., 1984. Design: A Powerful but Neglected Strategic Tool. Journal of Business Strategy, Volume 5, Issue 2, pp. 16-21.

Kreuzbauer, R., and Malter, J.A., 2005. Embodied Cognition and new product Design: Changing product form to influence Brand Categorization. Journal of Product Innovation Management, Vol. 22, Issue 1, pp. 65-176. 
Kreuzbauer, R., and Malter, J.A., 2007. Product Design Perception and Brand Categorization. Advances in Consumer Research. Vol. 34, pp. 240-246.

Kusiak, A., and Huang, C. C. (1996). Development of modular products. IEEE Transactions on Components, Packaging, and Manufacturing Technology: Part A. Volume 19, Issue 4, pp. 523-538.

Lawson, B., \& Dorst, K., 2009. Design Expertise. Oxford: Architectural Press. Lewalski, ZM., 1988. Product Esthetics: An Interpretation for Designers. Design \& Development engineering Press. Carson City, NV.

Loewy, R., 1951, 2002. Never Leave Well Enough Alone. Baltimore: MD: Johns Hopkins University Press.

Martin, B., \& Hanning, B., 2012. Universal Methods of design. Rockport Publishers. Meyer, M.H. \& Lehnerd, A.P., 1997. The Power of Product Platforms: Building Value and Cost Leadership. New York, NY: The Free Press.

Meyer M.H., and Utterback J.M., 1992. The Product Family and the Dynamics of Core Capability. The international Center for research on the management of technology, Sloan WP\# 3490-92, Massachusetts Institute of Technology.

Micheli, P., Perks, H., and Beverland, M. B., 2018. Elevating design in the organization, Journal of Product Innovation Management, Volume 35, Issue 4, pp. 629-651.

Micheli, P., Wilner, S. J., Bhatti, S. H., Mura, M., and Beverland, M. B., 2019. Doing design thinking: Conceptual review, synthesis, and research agenda. Journal of Product Innovation Management, Vol. 36, Issue 2, pp. 124-148.

Michlewski, K., 2008. Uncovering Design Attitude: Inside the Culture of Design, Organization Studies, Volume 29, Issue 3, p.373-392.

Miles, M.B., Huberman, M.A., and Saldaña, J., 2014. Qualitative Data Analysis. 3ed. Sage, USA.

Miller, T. D., and Elgard, P., 1998. Defining modules, modularity and modularization. In Proceedings of the 13th IPS research seminar, Fuglsoe. Aalborg Universiy Fuglsoe.

Millard, N., 2006. Learning from the 'wow' factor - how to engage customers through the design of affective customer experiences, BT Technology Journal, Volume 24, Issue 1.

Mills, C.W., 1959. The social Imagination. Harmondsworth: Penguin.

Monö, R., 1997. Design for Product Understanding. Liber AB, Trelleborg.

Nelson, H. G. \& Stolterman, E. 2002. Design Judgment: Decision-making in the 'real' world. The Design Journal, Volume 6, Issue 1, pp. 23-31. 
Nelson, H. G. and Stolterman, E. 2014. The Design Way - Intentional Change in an Unpredictable World 2ed. The MIT Press, Cambridge, Massachusetts London, England.

Oliva, A., \& Torralba, A. (2006). Building the gist of a scene: The role of global image features in recognition. Progress in brain research, Vol. 155, p.23-36.

Pahl, G., Beitz, W., Feldhusen, J., and Grote, K. H., 2007. Engineering Design, A Systematic Approach, 3ed, Springer.

Palmer, S. E., Schloss, K. B., Sammartino, J., 2013. Visual Aesthetics and Human Preference, Annual Review of Psychology, Volume 64, pp. 77-107.

Pennycook, G., Fugelsang, J. A., and Koehler, D. J., 2015. What makes us think? A three-stage dual-process model of analytic engagement. Cognitive Psychology, Volume 80, pp. 34-72.

Pennycook, G., 2017. A perspective on the theoretical foundation of dual process models. In W. De Nyes (Ed.), Dual Process Theory 2.O. Routledge, Oxon, UK.

Person, O., Snelders, D., Karjalainen T-M., \& Schoormans, J., 2007a. Complementing intuition: insights on styling as a strategic tool. Journal of Marketing Management, Volume 23, Issue 9-10, pp. 901-916.

Person, O., Schoormans, J., Snelders, D., and Karjalainen T-M., 2007b. Should New Products Look Similar or Different? The Influence of the Market Environment on Strategic Product Styling. Designstudies, Vol.29(1), p.30-48.

Person, O., and Snelders, D., 2010. Brand Styles in Commercial Design. Design Issues, Volume 26, Issue 1, pp .82-94.

Persson, M., and Åström, P., 2006. Managerial issues in modularising complex products. Technovation, Volume 26, pp. 1201-1209.

Proctor, R.A., and Kitchen, P.J., 1990. Strategic planning: an overview of product portfolio models. Market Intelligence छ Planning, Vol. 8(7), p.4-10.

Ranscombe, C., Hicks, B., and Mullineux, G., 2012. A method for exploring similarities and visual references to brand in the appearance of mature mass-market products. Design studies, Vol.33(5), pp. 496-520.

Read, H., 1934;1966. Art छ Industry, Faber and Faber Limited, Shenval Press Ltd. London, UK.

Rodgers, P. A. And Yee, J., 2018. The Routledge Companion to Design Research. Routledge, Taylor \& Francis Group, London United Kingdom.

Roper, S., Micheli, P., Love, J. H., and Vahter, P. (2016). The roles and effectiveness of design in new product development: A study of Irish manufacturers. Research Policy, volume 45, Issue 1, pp. 319-329. 
Robertson, D., \& Ulrich, K. (1998). Planning for product platforms. Sloan management reviere, Volume 39, Issue 4, p. 19.

Salas, E., Rosen, M. A., DiazGranados, D., 2010. Expertise-based intuition and decision making in organizations, Journal of Management, Volume 36, Issue 4, pp. 941-973.

Sanches R. and Mahoney J.T., 1996. Modularity, flexibility, and knowledge management in product and organization design. Strategic Management Journal, Volume 17, pp.63-76.

Sanchez. R. and Collins R. P., 2001, Competing - and learning - in Modular Markets. Long Range Planning, Volume 34, p. 645-667.

Sanchez, R., 2002. Using modularity to manage the interactions of technical and industrial design. Design Management Journal, Vol. 2(1), pp. 8-19.

Sanchez, R., 2004. Creating Modular Platforms for Strategic Flexibility. Design Management Reviere, volume 15, Issue 1, pp. 58-67.

Sanderson, S., ad Uzmeri, M., 1995. Managing Product Families: The Case of the Sony Walkman. Research Policy, Volume 24, pp. 761-782.

Scania, 2015. Exterior Cabs. [image online] Available at: <http://www.scania. se/lastbilar/main-components/cabs/exterior/> [Accessed 20 October 2015]

Schön, D., 1987. Educating the reflective practitioner. John Wiley \& Sons, A Wiley Imprint.

Shusterman, R., 1997. The end of aesthetic experience, The Journal of Aesthetics and Art Criticism, Volume 44, Issue 1.

Schoormans, J., and Robben, H., 1997. The effect of new package design on product attention, categorization and evaluation. Journal of Economic Psychology, Volume 18, Issues 2-3, pp. 271-287.

Simpson, T.W., 2004. Product platform, design and customization: Status and promise. AIEDAM, Volume 18, Issue 1, pp. 3-20.

Simson, T.W., Siddique, Z., \& Jiao, J., 2006. Product Platform and Product Family Design: Methods and Applications, New York, NY: Springer Science and Business Media.

Sloman, S. A., 1996. The empirical case for two systems of reasoning. Psychological Bulletin, Volume 119, pp. 3-22.

Starr, M.K., 1965. Modular-production: a new concept. Harvard Business Reviere, Volume 43, Issue 6, pp. 131-142.

Stanovich, K. E., 1999. Who is rational? Studies of individual differences in reasoning. Mahwah, NJ: Lawrence Erlbaum. 
Stanovich, K. E., and West, R. F., 2000. Individual differences in reasoning: Implications for the rationality debate. Behavioural and Brain Sciences, Volume 23, pp. 645-726.

Stanovich, K. E., 2011. Rationality and the reflective mind. Oxford University Press, New York, USA.

Stompff, G., Smulder, F., 2013. The boundary spanning practice of (user centred) design. 20th International Product Development Management Conference, Paris, France, 23-25 June.

Sony 2021. Press image of Sony Walkman TPS-L2. [Accessed 12 January 2021] Sudjianto, A., \& Otto, K. (2001). Modularization to support multiple brand platforms. In International Design Engineering Technical Conferences and Computers and Information in Engineering Conference, Volume 80258, pp. 125-138.

Swan, A. B., Calvillo, D. P., and Revlin, R., 2018, To detect or not to detect: A replication and extension of the three-stage model, Acta Psychologica, Volume 187, pp. 54-65.

The Economist, 2011. A checkered story [online] Available at: <http://www. economist.com/node/17963363?story_id=17963363> [ 4 April 2016]

Tovey, M., 1992. Intuitive and objective processes in automotive design. Design Studies, Volume 13, Issue 1.

Tovey, M., 1997. Styling and design: intuition and analysis in industrial design, Design Studies, Volume 18, Issue 1, pp. 5-31.

Ulrich, K., 1995. The role of product architecture in the manufacturing firm. Research Policy, Volume 24, Issue 3, pp. 419-440.

Ulrich, K. T., Eppinger, S. D., and Yang M. C., 2020. Product Design and Development. 7ed. McGraw-Hill, New York, USA.

Unilever, 2020. Unilever all Brands. Available at: https://www.unilever.com/ brands/?page $=4$ [Accessed 28 May 2020].

Verganti R., 2009. Design driven innovation - changing the rules of competition by radically innovating what things mean. Harvard Business Press, USA.

Vihma, S., 2010. Design Semiotics in Use. Taik, Helsinki, Finland.

Villamil, C., \& Hallstedt, S., 2018. Sustainability Product Portfolio - a Review. European Journal of Sustainable Development, Vol.7(4), pp. 146-158.

Volvo Cars, 2015. Build your own Volvo. [image online] Available at: <http:// byggdinvolvo.volvocars.se/\#/series [Accessed 21 October 2015]. 
Warell, A., 2002. Design Syntactics: A functional Approach to Visual Product Form - Theory, Models, and Methods. PhD. Chalmers University of Technology, Gothenburg.

Warell, A., 2006. Identity Recognition in product Design: An Approach for Design Management, proceedings of the 13th International Product Development Management Conference. Milan: Politecnico di Milano.

Warell, A., 2008. Modelling Perceptual Product Experience: Towards a Cohesive Framework of Presentation and Representation in Design. Proceedings of the 6th Design and Emotion Conference. Hong Kong: The Hong Kong Polytechnic University.

Wason, P. C. And Evans J. ST. B. T. Evans 1974. Dual processes in reasoning?*, Cognition, Volume 3, Issue 2, pp. 141-154

Wohlin, C., 2014. Guidelines for Snowballing in Systematic Literature Studies and a Replication in Software Engineering. Proceedings of the 18th International Conference on Evaluation and Assessment in Software Engineering. London, UK.

Yin, R. K., 2014. Case study research: Design and methods. 5ed. Thousand Oaks, CA: Sage, USA. 



\section{APPENDIX A}

\section{Intervjuguide inhouse designers}

I en produktutvecklingsprocess på stora företag där flera olika intressenter är involverade måste beslut fattas för att kunna driva processen vidare. Denna intervju är en del i en case studie, där vi vill kartlägga hur beslut påverkat formgivningen på en av era färdigutvecklade produkter. Fokus kommer att ligga på designerns roll i er process men vi vill även intervjua de andra aktörer som påverkat besluten.

Företag:

datum:

studie nr:
man kvinna
Ålder:

Anställd som:

Utbildning:

\section{Organisation och process}

1. I stora drag hur är företaget organiserat?

2. Vem svarar ni (designavdelningen) mot i organisationen? - dvs vilka beslutar om att stylingen skall gå till produktion?

3. Hur är designavdelningen organiserat på företaget? - hur många och vilka ingår i designteamet, kompetenser?

4. Vilka andra avdelningar jobbar ni mest mot och hur? 
5. Hur ser din huvudsakliga arbetsuppgift ut?

6. När produkt $X$ designades, hur gick processen till och hur var du inblandad? - Använd ett A3 papper med en linje på och be dom beskriva sin process.

7. När ni hade styling-beslutsmöten hur gick diskussionerna då?

a. vilka underlag fanns det inför besluten? - skisser, modeller, renderingar, $P M$, agendor, design brief's.

b. På de beslut du närvarade hur fattades besluten? - Journal paper VI

c. Kan du exemplifiera hur ni gick igenom designaspekter på designmöten?

\section{Företagets Product Portfolio - Generellt}

8. Vilka designelement (styling) är karakteristiska för produkt X's kategori?

9. Vad är storyn bakom skapandet av varumärket och designen av Produkt X?

10. Hur har ni byggt upp företagets produktportfölj?

a. Designperspektiv

b. Produktionsperspektiv

11. Vilken produktplattform bygger produkt X på?

12. Vilka produktkategorier är det tänkt att ni skall sälja när portföljen är helt utvecklad?

13. Du har jobbat med flera generationer av samma produkt, hur ser processen ut vid starten av en ny generation?

14. Face-lifts, hur har ni planerat in detta i produkt X? 


\section{Företagets produkter i portföljen}

15. Vad tycker du är kännetecknade i formen på Produkt X? - bilder, rita med pennan på bilderna, dokumentation, vilka ord används för att beskriva formen?

16.Vilket Design DNA vill ni bygga in i produkt X?
a. Styling-element?
b. Brand story?

17. Är stylingen uppbyggd för att kunna gå att skala? - modularitet $i$ designen a. Vad tycker du är fördelar och nackdelar med modularitet i era produkter?

b. Hur gick det till när skalbarheten togs fram i designen?

c. Vad kunde ni påverka ifrån styling?

18. Har du fått redesigna din egen design någon gång? - be om ett exempel

a. Vad lärde du dig i processen?

b. Vad skulle du rekommendera att man skall tänka på när man designar en form som skall gå att uppdatera i tex face-lifts.

19. Har du någon gång designat flera produkter samtidigt för olika produktkategorier? - exempel

a. Vad är dina erfarenheter positive och negative?

b. Hur bestäms det vilka designade delar som förs över och vilka som inte förs över mellan produktkategorier? - ca i procent, tex så kan backspeglar, lister, lampor, kofängare, dörrar ibland återanvändas iflera produktkategorier

20. Hur bestämmer ni vad som skall vara särskiljande (unika) designelement mellan produkter i en portfölj?

\section{Uppföljningsfrågor}

21. kan jag höra av mig med följdfrågor på telefon eller mail? - Be om nummer 


\section{Papers}

The papers associated with this thesis have been removed for copyright reasons. For more details about these see:

http://urn.kb.se/resolve?urn=urn:nbn:se:liu:diva-173826 


\section{FACULTY OF SCIENCE AND TECHNOLOGY}

Linköping Studies in Science and Technology, Dissertations No. 2131, 2021 Department of Management and Engineering

Linköping University

SE-581 83 Linköping, Sweden

www. liu.se 